\title{
Climate Assessment for 1996
}

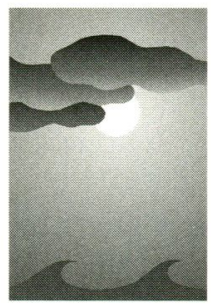

\author{
Michael S. Halpert and Gerald D. Bell \\ Climate Prediction Center, NCEP/NWS/NOAA, Washington, D.C.
}

\begin{abstract}
The climate of 1996 can be characterized by several phenomena that reflect substantial deviations from the mean state of the atmosphere persisting from months to seasons. First, mature cold-episode conditions persisted across the tropical Pacific from November 1995 through May 1996 and contributed to large-scale anomalies of atmospheric circulation, temperature, and precipitation across the Tropics, the North Pacific and North America. These anomalies were in many respects opposite to those that had prevailed during the past several years in association with a prolonged period of tropical Pacific warm-episode conditions (ENSO). Second, strong tropical intraseasonal (Madden-Julian oscillations) activity was observed during most of the year. The impact of these oscillations on extratropical circulation variability was most evident late in the year in association with strong variations in the eastward extent of the East Asian jet and in the attendant downstream circulation, temperature, and precipitation patterns over the eastern North Pacific and central North America. Third, a return to the strong negative phase of the atmospheric North Atlantic oscillation (NAO) during November 1995-February 1996, following a nearly continuous 15 -yr period of positive-phase NAO conditions, played a critical role in affecting temperature and precipitation patterns across the North Atlantic, Eurasia, and northern Africa. The NAO also contributed to a significant decrease in wintertime temperatures across large portions of Siberia and northern Russia from those that had prevailed during much of the 1980 s and early 1990 s.

Other regional aspects of the short-term climate during 1996 included severe drought across the southwestern United States and southern plains states during October 1995-May 1996, flooding in the Pacific Northwest region of the United States during the 1995/96 and 1996/97 winters, a cold and extremely snowy 1995/96 winter in the eastern United States, a second consecutive year of above-normal North Atlantic hurricane activity, near-normal rains in the African Sahel, abovenormal rainfall across southeastern Africa during October 1995-April 1996, above-normal precipitation for most of the year across eastern and southeastern Australia following severe drought in these areas during 1995, and generally nearnormal monsoonal rains in India with significantly below-normal rainfall in Bangladesh and western Burma.

The global annual mean surface temperature for land and marine areas during 1996 averaged $0.21^{\circ} \mathrm{C}$ above the $1961-$ 90 base period means. This is a decrease of $0.19^{\circ} \mathrm{C}$ from the record warm year of 1995 but was still among the 10 highest values observed since 1860 . The global land-only temperature for 1996 was $0.06^{\circ} \mathrm{C}$ above normal and was the lowest anomaly observed since $1985\left(-0.11^{\circ} \mathrm{C}\right)$. Much of this relative decrease in global temperatures occurred in the Northern Hemisphere extratropics, where land-only temperatures dropped from $0.42^{\circ} \mathrm{C}$ above normal in 1995 to $0.04^{\circ} \mathrm{C}$ below normal in 1996.

The year also witnessed a continuation of near-record low ozone amounts in the Southern Hemisphere stratosphere, along with an abnormally prolonged appearance of the "ozone hole" into early December. The areal extent of the ozone hole in November and early December exceeded that previously observed for any such period on record. However, its areal extent at peak amplitude during late September-early October was near that observed during the past several years.
\end{abstract}

Corresponding author address: Michael S. Halpert, Climate Prediction Center, NCEP/NOAA, W/NP52, NSC, Rm. 605, 5200

Auth Rd., Camp Springs, MD 20746 


\section{Table of Contents}

1. Introduction

2. Climate and global change issues

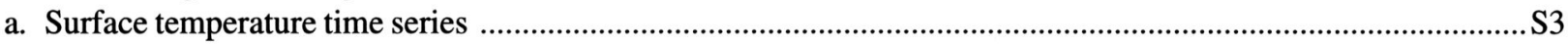

b. Annual-average temperature, precipitation, and circulation anomalies ….......................................................S4

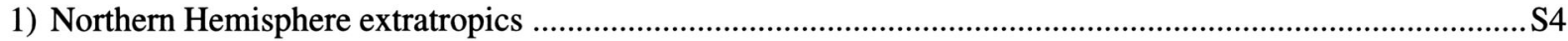

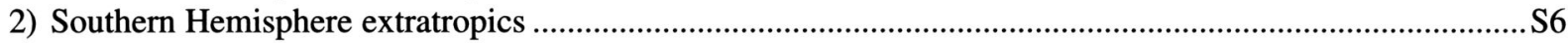

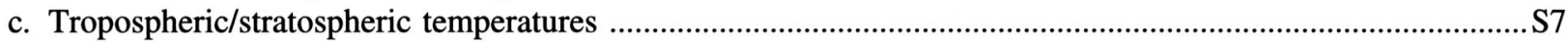

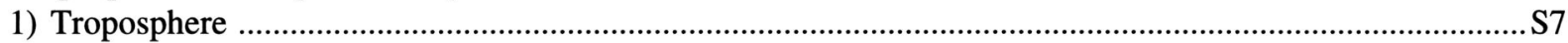

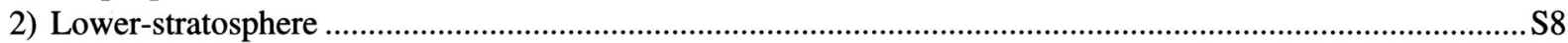

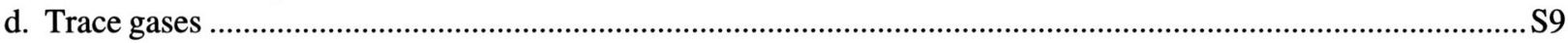

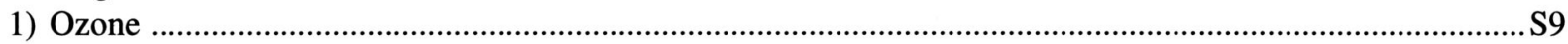

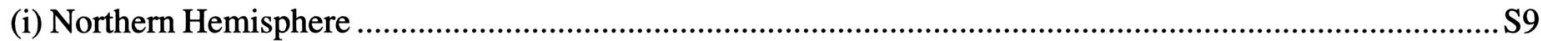

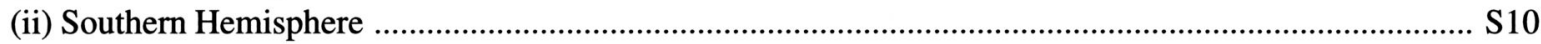

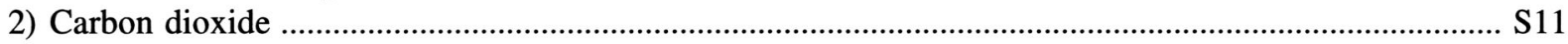

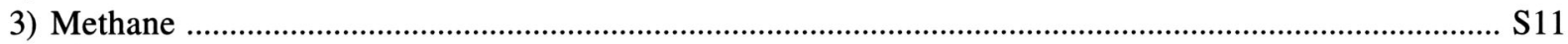

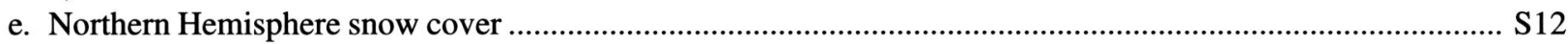

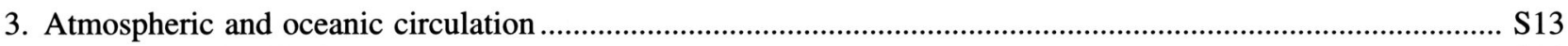

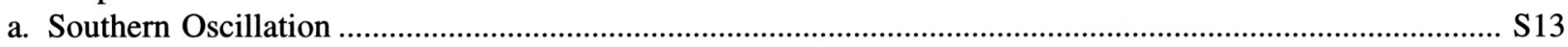

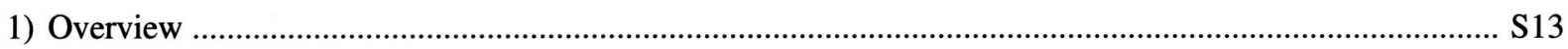

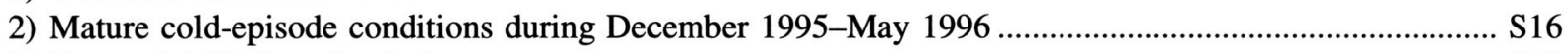

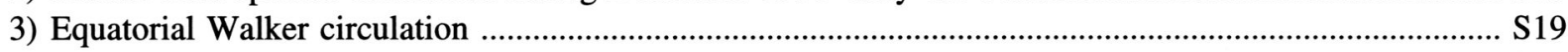

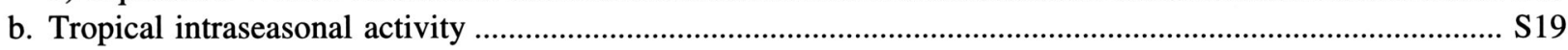

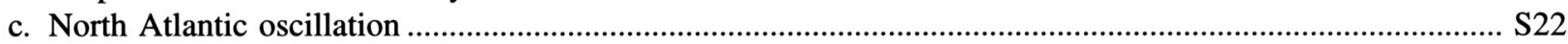

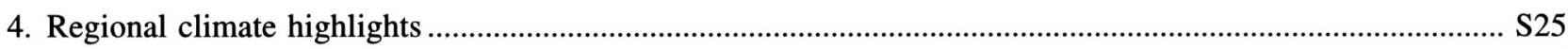

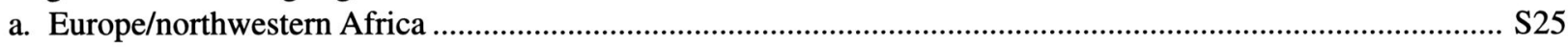

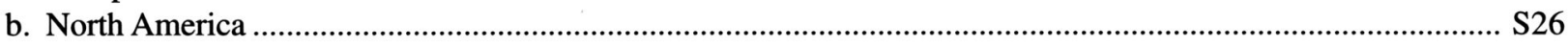

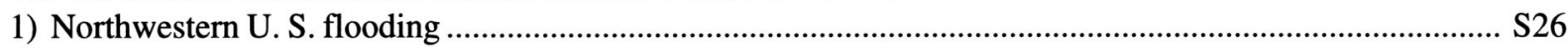

(i) 5-9 February 1996 flooding of the Willamette and Columbia Rivers ................................................ S27

(ii) Late-December 1996 flooding in the Northwest ........................................................................ S28

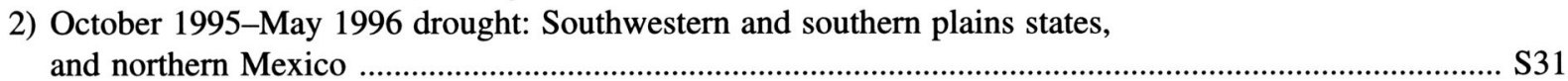

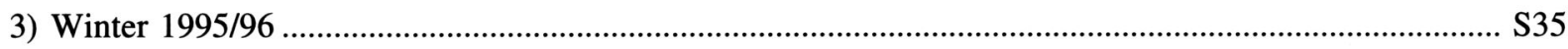

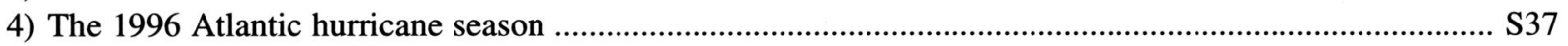

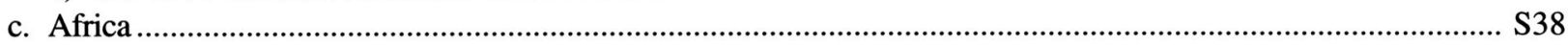

1) June-September 1996: Western Africa (Sahel) rainy season ........................................................... S38

2) October 1995-April 1996: Southern Africa rainy season .................................................................... S39

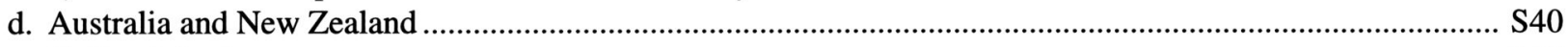

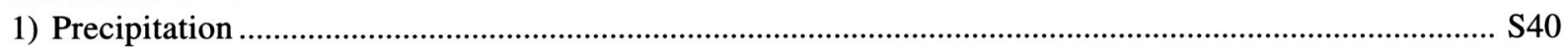

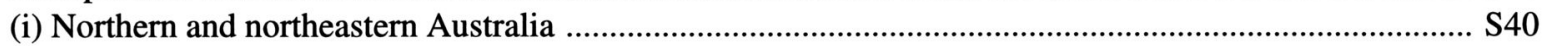

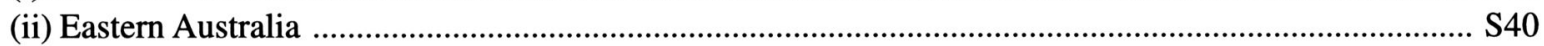

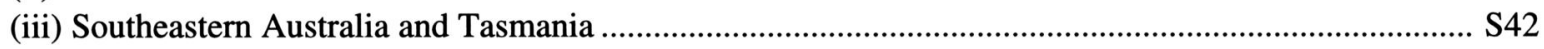

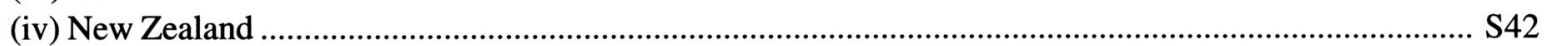

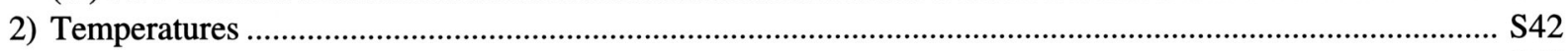

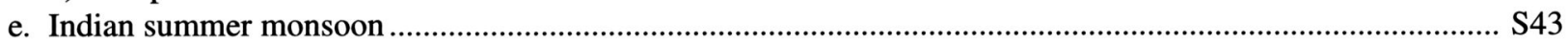

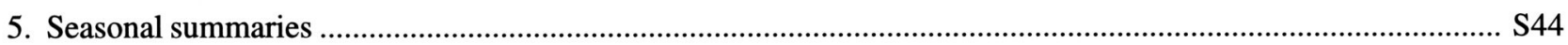

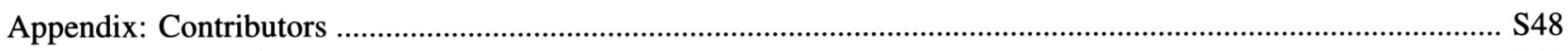

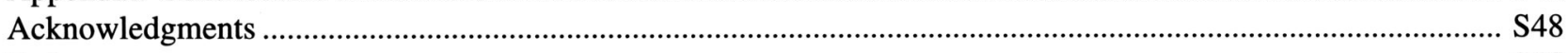

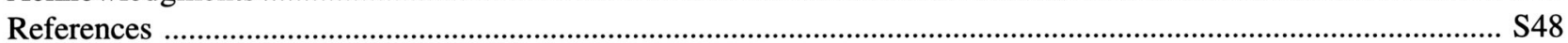




\section{Introduction}

This assessment is designed to provide a timely summary of the current state of the global climate system. It is the seventh in an ongoing series of annual climate assessments produced by the Climate Prediction Center. The assessment documents global climate variations, oceanic and atmospheric anomalies in the global Tropics and extratropics, and selected significant regional climate highlights.

Issues related to global and regional climate change are addressed in section 2 , including atmospheric temperatures and precipitation, ozone, methane, carbon dioxide, and snow cover. An analysis of several phenomena that exhibit substantial interannual variability and influence the shortterm climate on timescales of months to seasons is presented in section 3. The analysis includes 1) the Southern Oscillation (section 3a), with a focus on cold episode conditions in the tropical Pacific during 1996; 2) tropical intraseasonal (Madden-Julian oscillation) activity (section $3 b$ ), which played an important role in the tropical and extratropical circulation features during the year; and 3) the North Atlantic oscillation (section $3 \mathrm{c}$ ), which exhibited a strong negative phase during the year. Section 4 documents regional climate highlights and provides a summary of the major monsoon systems during the past year. Topics include flooding (drought) in the northwestern (southwestern) United States, a cold and snowy 1995/96 winter in the eastern United States, a summary of the African rainy seasons, major rainfall and temperature anomalies over Australia, and the Indian monsoon. Finally, section 5 shows seasonal maps for temperature anomalies, precipitation percentiles, and $500-\mathrm{hPa}$ heights and anomalies. These maps are included for reference and to continue the set of maps that have appeared in the previous six Annual Climate Assessments.

A variety of data sources were used in the compilation of this assessment, including 1) gridded analyses from the National Centers for Environmental Prediction/National Center for Atmospheric Research (NCEP/NCAR) Climate Data Assimilation System/Reanalysis Project (Kalnay et al. 1996), 2) surface data obtained over the operational Global Telecommunications System (GTS), 3) satellites, 4) radiosondes, and 5) ship reports. Selected analyses were also obtained from international climate data centers. It should be noted that due to the variety of different data sources used through- out the assessment, it is not possible to maintain a consistent base period among all fields when computing anomalies.

\section{Climate and global change issues}

\section{a. Surface temperature time series}

Estimated global (land area only) mean temperatures during 1996 (determined from station data received over the GTS and computed relative to the 1961-90 base period means) were the coolest in the past $11 \mathrm{yr}$, and only the 19th warmest out of 46 years dating back to 1951 (Fig. 1a). The anomaly for $1996\left(0.06^{\circ} \mathrm{C}\right.$ above the $1961-90$ mean of $\left.11.5^{\circ} \mathrm{C}\right)$ was the lowest since $1985\left(-0.11^{\circ} \mathrm{C}\right)$. The decrease from 1995 to 1996 is the largest since that observed between 1981 and 1982.

There was relatively little intermonthly variability in the global land-only surface temperatures during 1996 (not shown), with all months averaging within $0.30^{\circ} \mathrm{C}$ of the long-term mean. Each of the four seasons [December-February (DJF), MarchMay (MAM), June-August (JJA), and SeptemberNovember (SON)] during 1996 were cooler than the corresponding 1995 season. MAM $\left(-0.03^{\circ} \mathrm{C}\right)$ and SON $\left(-0.08^{\circ} \mathrm{C}\right)$ averaged below the 1961-90 base period mean, while DJF $\left(0.12^{\circ} \mathrm{C}\right)$ and JJA $\left(0.19^{\circ} \mathrm{C}\right)$ averaged above the mean. Only May and December were warmer than their 1995 counterparts. June 1996 (although cooler than June 1995) was still the sixth warmest June dating back to 1951 (June 1995 was fourth).

Much of the relative decrease in global temperature during 1996 occurred in the Northern Hemisphere extratropics, where mean land temperature anomalies decreased from $0.42^{\circ} \mathrm{C}$ in 1995 to $-0.04^{\circ} \mathrm{C}$ in 1996 (Fig. 1c). This was the first time that mean Northern Hemisphere land temperatures averaged below normal since 1985 .

In contrast, mean temperature anomalies in the Southern Hemisphere extratropics increased from $0.08^{\circ} \mathrm{C}$ in 1995 to $0.13^{\circ} \mathrm{C}$ in 1996 (Fig. 1d), while anomalies decreased slightly in the tropical belt from $0.41^{\circ} \mathrm{C}$ in 1995 to $0.38^{\circ} \mathrm{C}$ above normal in 1996 (Fig. 1b). Mean land temperatures in the global Tropics have been above normal since the beginning of the decade, coincident with the beginning of a long period of warm [El Niño-Southern Oscillation (ENSO)] episode conditions in the tropical Pacific. Despite the weak cold episode condi- 

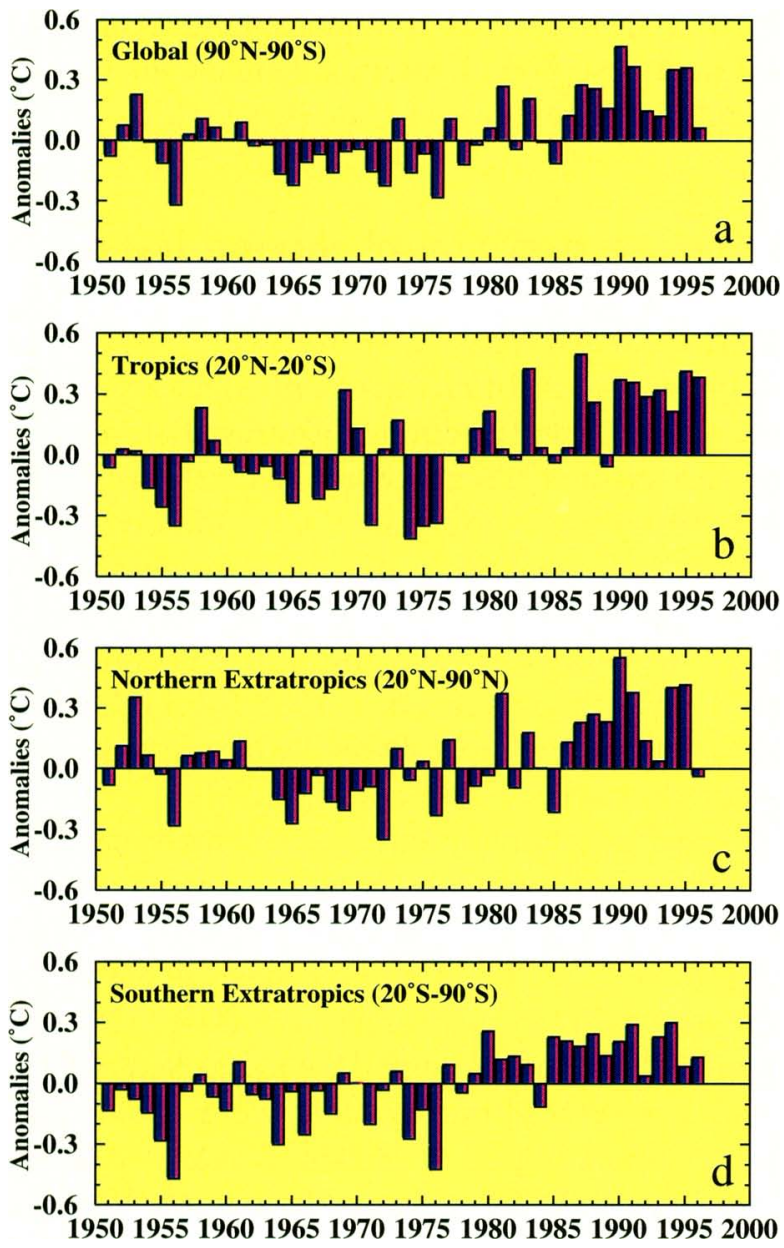

FIG. 1. Annual temperature anomalies (land only, ${ }^{\circ} \mathrm{C}$ ): (a) global, (b) Tropics, (c) Northern Hemisphere extratropics, and (d) Southern Hemisphere extratropics. Anomalies are departures from the 196190 base period means.

tions that prevailed during much of 1996 in the tropical Pacific, land surface temperatures in the Tropics continued to be much above normal, with the 1996 value surpassed only in 1983, 1987, and 1995. During previous cold episodes (e.g., 1975$76,1988-89$ ) land temperatures throughout the global Tropics were often colder than the long-term mean.

The estimated global mean surface temperature for land and marine areas combined (Fig. 2a) is derived from observations at over 1000 land stations and from sea surface temperatures (SSTs) measured by ships and buoys. The time series also indicates a cooling during 1996 relative to the record warm year of 1995 previously measured by the land and marine data. However, the anomaly for $1996\left(0.21^{\circ} \mathrm{C}\right)$ is still among the 10 highest since
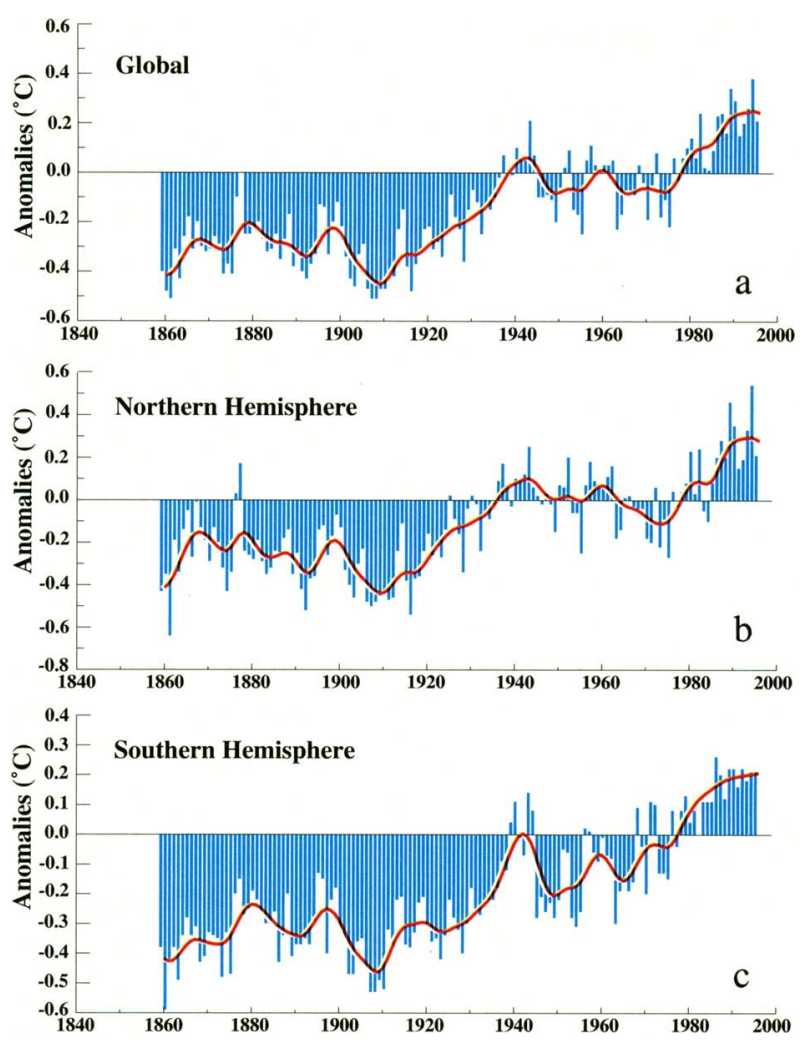

FIG. 2. Annual averages of combined land-air and SST anomalies (blue bars, ${ }^{\circ} \mathrm{C}$ ): (a) global, (b) Northern Hemisphere, and (c) Southern Hemisphere. Anomalies are departures from the 196190 base period means. Smoothed values (red curve) were obtained using a 13-term Gaussian filter designed to suppress variations on timescales less than 10 yr. (Source: Hadley Centre for Climate Prediction and Research, United Kingdom, and Climatic Research Unit, University of East Anglia, United Kingdom.)

1860. The 1996 annual anomaly in both the Northern and Southern Hemispheres was also $0.21^{\circ} \mathrm{C}$. In the Northern Hemisphere this value represents a significant decrease from the record value of $0.54^{\circ} \mathrm{C}$ observed in 1995 (Fig. 2b). In the Southern Hemisphere, mean temperatures have averaged near $0.2^{\circ} \mathrm{C}$ above normal for the past decade (Fig. 2c).

\section{b. Annual-average temperature, precipitation, and circulation anomalies}

1) Northern Hemisphere EXTRATropics

The overall pattern of annual-average temperature anomalies during 1996 shows below-normal temperatures across the middle latitudes of the Northern Hemisphere and above-normal temperatures over large parts of the high latitudes (Fig. 3). In the middle latitudes, three primary areas of sub- 
stantially below-normal surface temperatures prevailed during the year. The first region extended southeastward from eastern Alaska to the Gulf of Mexico. This area included all of western and central Canada, where annual temperatures averaged $1.0^{\circ}-3.0^{\circ} \mathrm{C}$ below normal. It also included the contiguous United States east of the Rocky Mountains, where temperatures in many regions averaged $0.5^{\circ}-$ $1.5^{\circ} \mathrm{C}$ below normal for the year. Another area of below-normal temperatures extended from the eastern North Atlantic eastward across northern and central Europe to south-central Russia. The largest negative anomalies in this area were observed across northern Europe and south-central Russia and averaged $1.0^{\circ}-1.5^{\circ} \mathrm{C}$ below normal for the year. The final region of negative anomalies extended from Japan eastward to the central North Pacific between $30^{\circ}$ and $40^{\circ} \mathrm{N}$, with temperatures averaging $0.5^{\circ}-1.5^{\circ} \mathrm{C}$ below normal during 1996 .

Above-normal surface temperatures covered the subtropical eastern North Pacific and the southwestern United States during the year, with much of the latter region recording annual mean temperatures more than $1^{\circ} \mathrm{C}$ above normal. Temperatures also averaged more than $0.5^{\circ} \mathrm{C}$ above normal across northern Africa, southwestern Europe, and much of the Middle East. Farther north, temperatures averaged $1.0^{\circ}-2.5^{\circ} \mathrm{C}$ above normal across large portions of Siberia, the high latitudes of the North Pacific from eastern Siberia to the Aleutian Islands, and across much of eastern and extreme northern Canada.

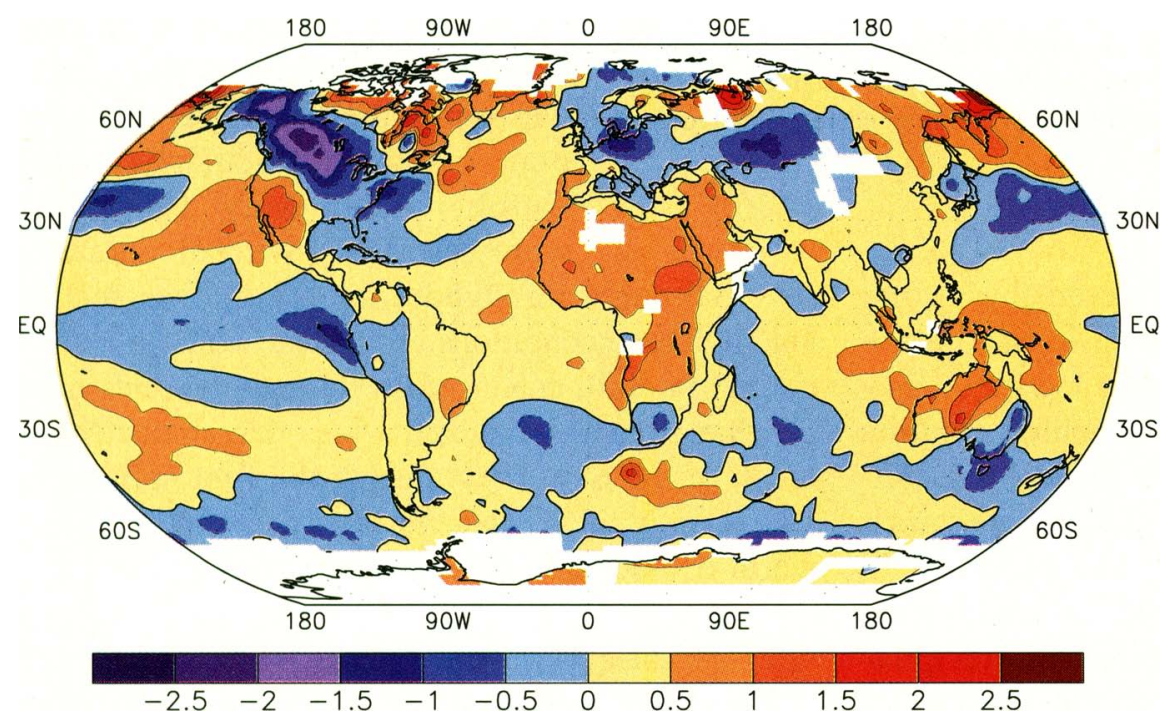

FIG. 3. Annual surface temperature anomalies $\left({ }^{\circ} \mathrm{C}\right)$ for 1996 . Analysis is based on station data over land and on SST data over the oceans. Anomalies are departures from the 1961-90 base period means. White areas are regions with insufficient data for analysis.
Precipitation anomalies and percentiles for the 1995-96 "water year," defined as the period from October 1995-September 1996 and chosen because this 12-month calendar period minimizes interruptions in the rainy seasons for most regions around the globe, are shown in Figs. 4a,b. In the Northern Hemisphere the primary regions of substantially above-normal precipitation included the northwestern and northeastern United States, southern Europe, and northern Africa. Substantially below-normal precipitation was observed across the high latitudes of the North Pacific and Alaska, eastern Canada, the central and southwestern United States, the central and subtropical North Atlantic, northern Europe, extreme eastern China, and southern Japan. Also evident is a well-defined pattern of anomalous rainfall across the Tropics, featuring above-normal precipitation from South America eastward to Indonesia and below-normal precipitation across the central and eastern equatorial $\mathrm{Pa}-$ cific (Fig. 4). This pattern reflects the positive phase of the Southern Oscillation (SO) during the year (see section 3a).

The pattern of annual average height anomalies during 1996 over the Northern Hemisphere was generally dominated by above-normal heights across the high latitudes and below-normal heights across the middle latitudes (Fig. 5a). However, there was also considerable zonal variability in this pattern. The largest positive height anomalies were observed over the North Pacific and North Atlantic Ocean basins, and over the southwestern United States, and the largest negative anomalies were observed across the western and central North Pacific between $30^{\circ}$ and $40^{\circ} \mathrm{N}$, across the southeastern South Atlantic and southern Europe, and over central Russia. These anomalies were generally consistent with the annual temperature and precipitation anomaly patterns and, in many instances, reflected extremely persistent circulation features that lasted for several consecutive months.

Regionally, the pattern of height anomalies over the 

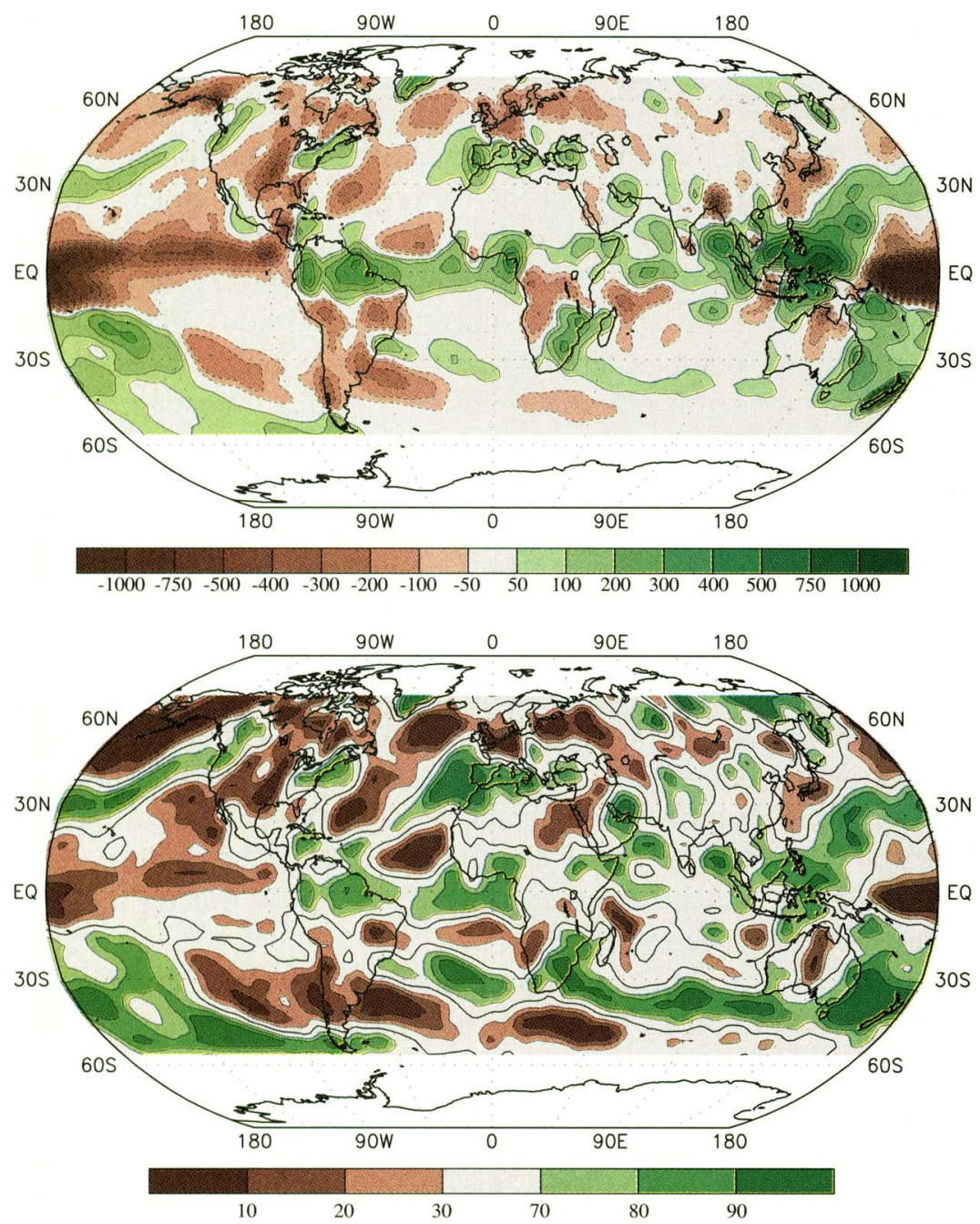

FIG. 4. October 1995-September 1996: (a) anomalous precipitation (mm) and (b) precipitation percentiles based on a gamma distribution fit to the 1979-95 base period October-September means. Data are obtained from a merge of rain gauge observations and satellite-derived precipitation estimates. The satellite estimates are generated by the outgoing longwave radiation precipitation index (OPI) technique (Xie and Arkin 1997, manuscript submitted to $J$. Climate) which are merged with rain gauge data via the method adopted from Xie and Arkin (1996).

North Atlantic and Europe reflected the strong negative phase of the North Atlantic oscillation (NAO), which is a primary mode of low-frequency variability in the extratropics and which exhibits considerable interannual and interdecadal variability (see section 3c). The NAO pattern was most prominent during DJF 1995/96 and MAM 1996 and again during December 1996, and was associated with large-scale temperature and precipitation anomalies throughout Eurasia and northwestern Africa (see section 4a).

Over the high latitudes of the North Pacific, the pattern of above-normal temperatures and below- normal precipitation reflected a recurring pattern of above-normal heights and substantial blocking activity in all seasons. Across the middle latitudes of the western and central North Pacific, the pattern of below-normal temperatures and above-normal precipitation was associated with below-normal heights and an overall strengthening of the East Asian jet in all seasons. Collectively, these conditions were consistent with Pacific coldepisode conditions and the positive phase of the Southern Oscillation during the year.

The southwestern United States was dominated by above-normal heights in all seasons, while western Canada was characterized by below-normal heights in all seasons. This anomaly pattern reflected enhanced westerly flow, storm activity, and moisture transport into the northwestern United States throughout the year. These conditions contributed to abnormally cool conditions across western Canada and to significantly above-normal precipitation and periodic flooding in the Pacific Northwest [see section $4 b(1)$ ]. They also resulted in abnormally warm and dry conditions across the southwestern United States and central plains states, particularly during October 1995-May 1996, and were associated with moderate to severe drought throughout the region [see section $4 b(2)]$. These conditions contrasted with the abovenormal rainfall, enhanced storm activity, and stronger than normal jet stream winds that characterized much of the Southwest during the first half of the 1990 s, in association with recurring mature-phase warm-episode conditions in the tropical Pacific.

\section{2) SOUTHERN HEMISPHERE EXTRATROPICS}

The 1996 annual surface temperature anomalies in the Southern Hemisphere extratropics (Fig. 3) showed above-normal temperatures over western and central Australia, Indonesia, the central lati- 


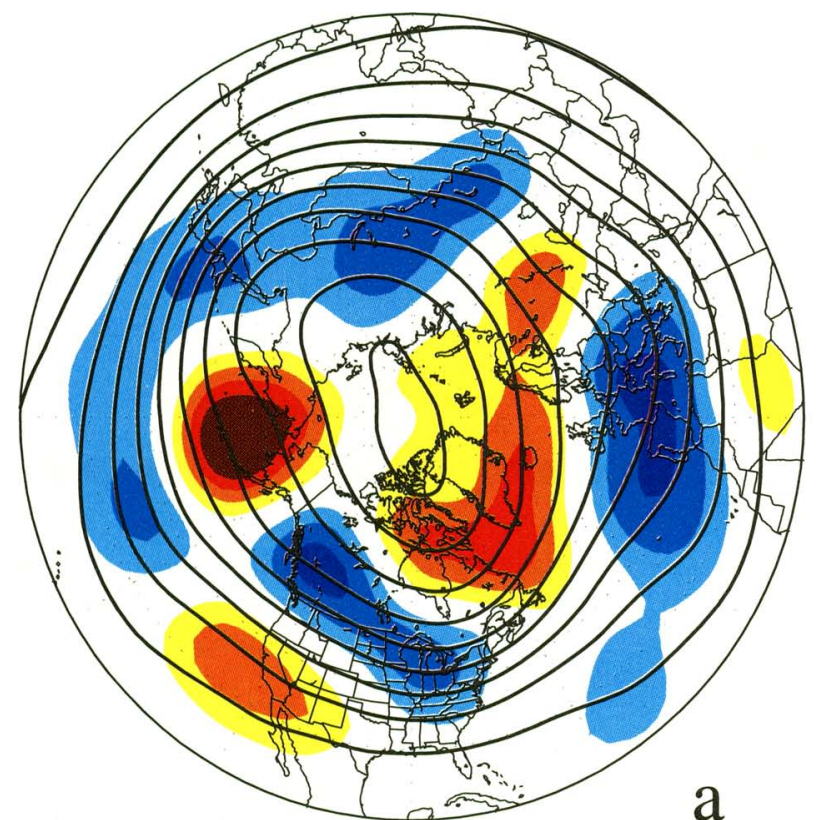

a

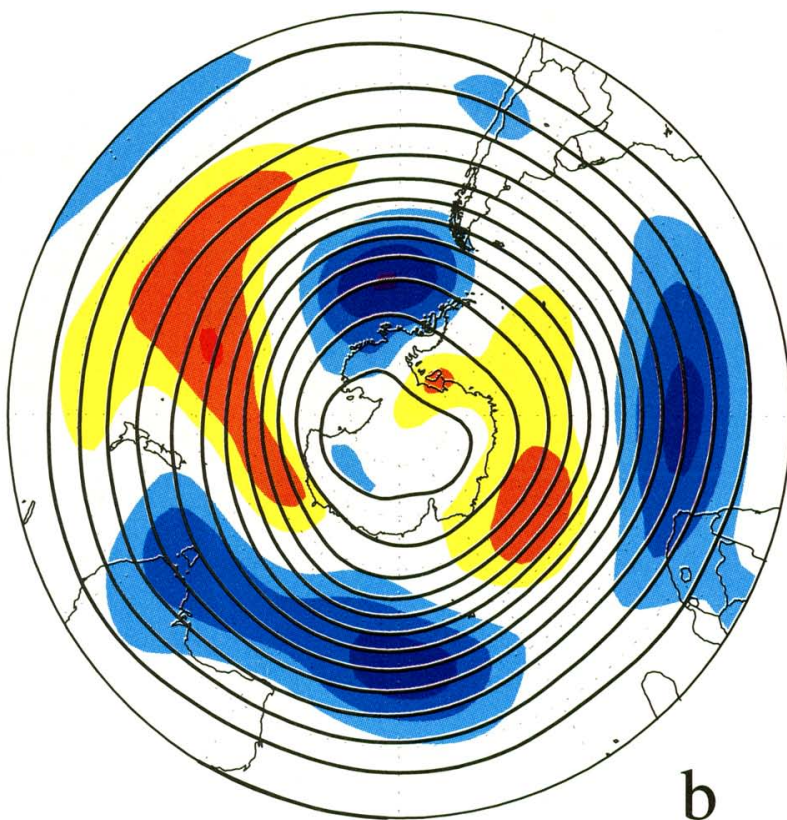

$\mathrm{b}$

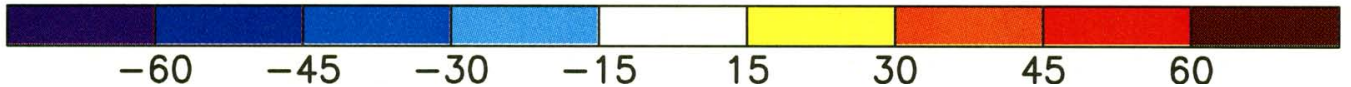

FIG. 5. Mean annual 250-hPa height (contours, m) and anomalies (shaded, m) for 1996: (a) Northern Hemisphere; and (b) Southern Hemisphere. Contour interval for heights is $120 \mathrm{~m}$. Anomalies are departures from the 1979-95 base period means.

tudes of the South Pacific, and much of the region south of Africa. Below-normal temperatures were observed over the high latitudes between $50^{\circ}$ and $70^{\circ} \mathrm{S}$, across southern Africa, and over southeastern Australia.

The regions of significantly below-normal precipitation during the 1995-96 water year (Figs. $4 a, b)$ included the east-central South Pacific, most of extratropical South America, the region between South America and the area immediately south of the African continent, and central Australia. In contrast, precipitation totals were above-normal during the water year across the central latitudes of the western and central South Pacific, and from southeastern Africa eastward to the Tasman Sea.

In southern Africa, the cooler and wetter than normal conditions during 1996 were observed mainly in the climatologically high precipitation areas of northeastern South Africa, southern Mozambique, and much of central Madagascar [see section $4 c(2)$ ]. This above-normal rainfall is consistent with Pacific cold episode conditions during the year (Ropelewski and Halpert 1989) and contrasts with the suppressed rainfall observed during the 1994/95 rainy season in association with $\mathrm{Pa}$ cific warm episode conditions. Above-normal rain- fall also occurred in association with an elongated band of abnormally heavy precipitation that extended in all seasons from the central South Atlantic eastward to southeastern Australia and the Tasman Sea. This precipitation was associated with below-normal heights and stronger than normal westerlies at upper levels (Fig. 5b) and with enhanced storm activity across the region.

\section{c. Tropospheric/stratospheric temperatures}

\section{1) TROPOSPHERE}

The global-mean tropospheric temperature is monitored by two independent observing systems: radiosondes and polar-orbiting satellites. The global radiosonde record began in 1958 and has the advantage of a relatively long time series (39 yr) of directly measured temperatures. The satellite record [derived from measurements taken by the Microwave Sounding Unit (MSU) channel 2R flown aboard the polar-orbiting satellites] began in 1979 and has the advantages of 1) sampling the atmosphere with one type of instrument at any given time and 2) global sampling, with most of the earth sampled twice daily from each of two instruments flying concurrently on different satellites (Spencer et al. 1990). However, potential problems 


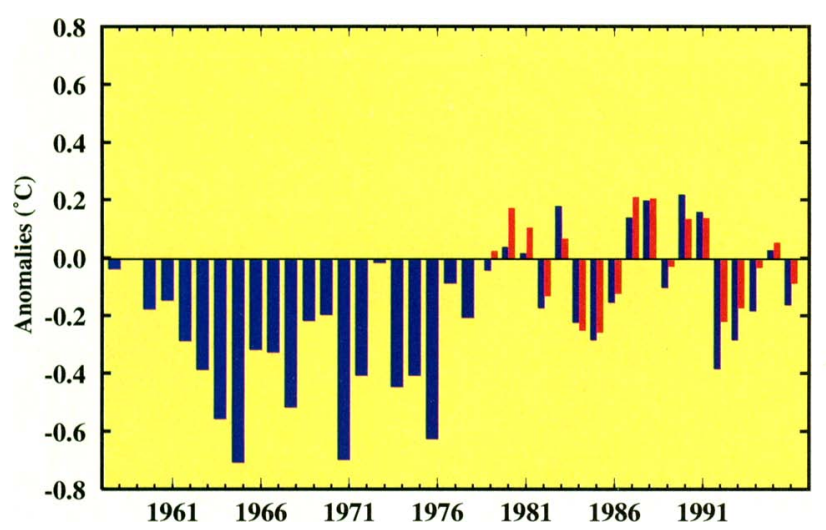

FIG. 6. Annual global-tropospheric temperature anomalies $\left({ }^{\circ} \mathrm{C}\right.$, blue bars) derived from radiosonde data based on a 63-station network (850-300 $\mathrm{hPa}$ ) and annual global-tropospheric temperature anomalies derived from the MSU channel 2R (red bars). Anomalies are departures from the 1982-91 base period means. (Radiosonde analysis provided by the Air Resources Laboratory; MSU data provided by the University of Alabama in Huntsville.)

with the satellite data include calibration, diurnal sampling aliasing, orbital drift, etc. (Hurrell and Trenberth 1997).

The overall time series of the satellite-derived and radiosonde-derived tropospheric temperature anomalies are similar during the period from 1979 through 1996 (Fig. 6). The radiosonde observations (blue bars) indicate a mean tropospheric temperature $0.16^{\circ} \mathrm{C}$ below normal for 1996 , while the satellite-based temperature anomalies (red bars) show an annual global-mean anomaly of $-0.09^{\circ} \mathrm{C}$, with both anomalies computed with respect to the 1982-91 base period. This is the fourth time in 5 yr that temperatures in the global troposphere have averaged below the $10-y r$ means. However when the last $5 \mathrm{yr}$ of radiosonde data are compared to the entire 39-yr period, it is evident that global tropospheric temperatures remain above the cooler 1960-78 period, but below the 1987-91 warm period.

The spatial pattern of annual mean tropospheric temperature anomalies during 1996 shows the largest negative anomalies across North America, Europe, and western Asia (Fig. 7). This pattern is similar to the surface temperature anomaly pattern during 1996 (Fig. 3) and is opposite to that observed during 1995 (see Halpert et al. 1996, their Fig. 9). Colder than normal tropospheric temperatures were also observed throughout most of the global Tropics and over the land masses of the Southern Hemisphere during 1996, while positive anomalies were

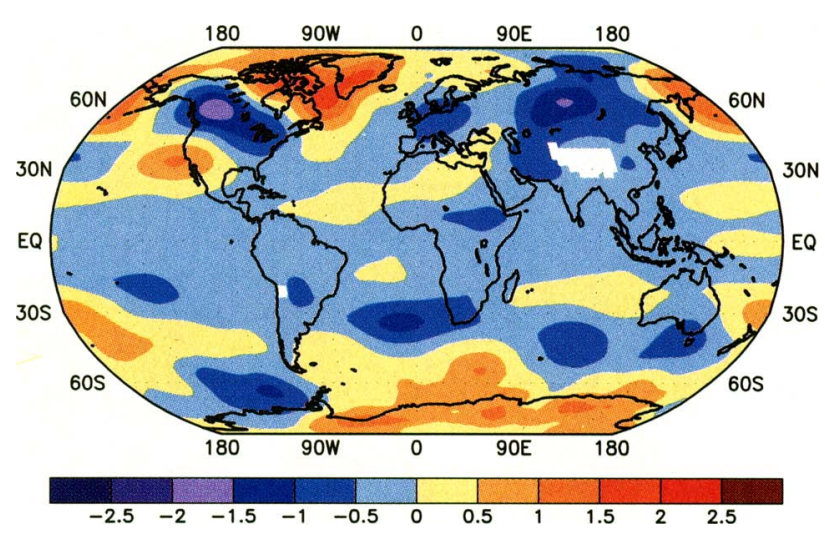

FIG. 7. Mean annual tropospheric temperature anomalies for 1996 derived from the MSU channel 2R. Anomalies are departures from the 1982-91 base period means. (MSU data provided by the University of Alabama in Huntsville.)

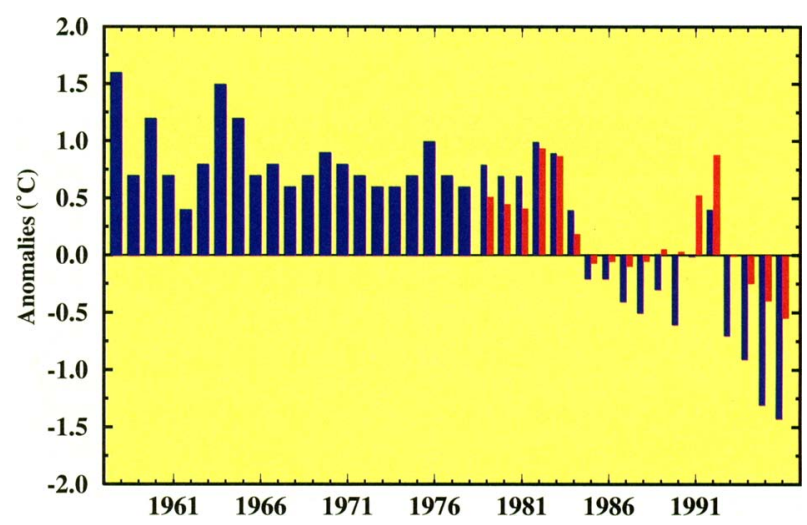

FIG. 8. Annual global-stratospheric temperature anomalies $\left({ }^{\circ} \mathrm{C}\right.$, blue bars) derived from radiosonde data based on a 63-station network (100-50 hPa) and annual global-tropospheric temperature anomalies derived from the MSU channel 4 (red bars). Anomalies are departures from 1982-91 base period means. (Radiosonde analysis provided by the Air Resources Laboratory; MSU data provided by the University of Alabama in Huntsville.)

observed over Greenland, extreme eastern and northern Canada, the southwestern United States, and extreme eastern Siberia.

\section{2) LOWER STRATOSPHERE}

Estimates of global lower-stratospheric temperatures (Fig. 8) from both radiosonde observations (blue bars) and satellite observations (red bars) show 1996 to be the coldest year on record. However, the magnitude of the anomalies is substantially larger in the radiosonde network $\left(-1.4^{\circ} \mathrm{C}\right)$ than in the satellite record $\left(-0.52^{\circ} \mathrm{C}\right)$. At least some of this difference can be related to changes in the radiosonde sensors throughout the period (IPCC 


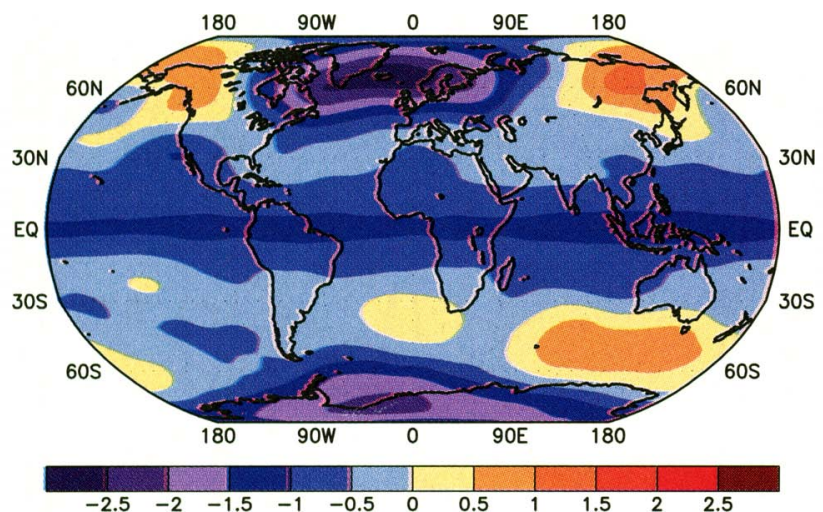

FIG. 9. Mean annual stratospheric temperature anomalies for 1996 derived from the MSU channel 4. Anomalies are departures from the 1982-91 base period means. (MSU data provided by the University of Alabama in Huntsville.)

1995). For the radiosonde network, 1996 is the 11th year out of the past 12 with negative temperature anomalies relative to the 1982-91 base period mean. In contrast, annual stratospheric temperatures averaged above the 1982-91 mean in all years prior to 1979 .

The spatial pattern of annual stratospheric temperature anomalies was dominated by negative anomalies over much of the globe (Fig. 9). The only exceptions were over eastern Siberia, Alaska, and northwestern Canada in the Northern Hemisphere, and in a band extending from south of Australia and New Zealand to near $60^{\circ} \mathrm{E}$ in the Southern Hemisphere. At high Northern Hemisphere latitudes, a strong wavenumber-1 pattern showed below-normal temperatures (more than $1.5^{\circ}-2.5^{\circ} \mathrm{C}$ below normal) extending across the North Atlantic from eastern Canada to Scandinavia. This feature coincided with below-normal heights throughout the middle stratosphere across the high latitudes of the North Atlantic, overlaying a vertically deep pattern of above-normal heights and temperatures in the troposphere (Fig. 10). These conditions were consistent with a strong negative phase of the North Atlantic oscillation (see section 3c) and with recurrent blocking episodes across the high latitudes of the North Atlantic. Negative anomalies in tropical and subtropical regions were related to the quasibiennial oscillation of stratospheric temperatures. In the Southern Hemisphere, the largest negative temperatures anomalies $\left(1.5^{\circ}-2.5^{\circ} \mathrm{C}\right.$ below normal) were observed over Antarctica, consistent with the enhanced ozone depletion during September-

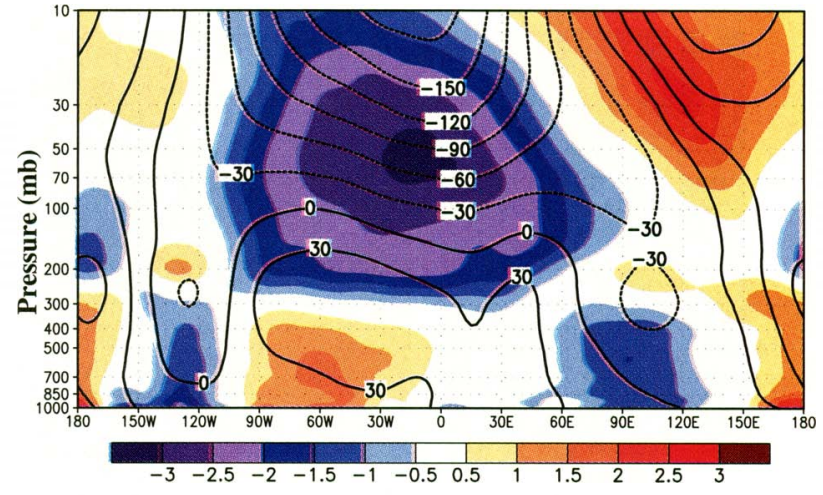

FIG. 10. Height-longitude cross section at $62.5^{\circ} \mathrm{N}$ of annual temperature (shaded, ${ }^{\circ} \mathrm{C}$ ) and height (contours, m) anomalies for 1996. Contour interval for height (temperature) anomalies is $30 \mathrm{~m}$ $\left(0.5^{\circ} \mathrm{C}\right)$. Anomalies are departures from the $1979-95$ base period means.

December throughout the polar region [see section $2 d(1)]$.

\section{d. Trace gases}

1) Ozone

Total column ozone data were obtained from the NASA Nimbus-7 SBUV instrument from 1979 through 1988, from the NOAA-11 SBUV/2 instrument from January 1989 through August 1994, and from the NOAA-9 SBUV/2 instrument beginning in September 1994. Data from the SBUV instruments are only available during daylight viewing conditions; therefore no data are available over polar latitudes during winter.

\section{(i) Northern Hemisphere}

Total column ozone in the Northern Hemisphere is generally lowest during December-March (DJFM). Overall, total ozone in the middle latitudes has decreased at a rate of $2 \%-4 \%$ per decade since 1979 (Stolarski et al. 1992). However, during DJFM $1995 / 96$ total ozone at these latitudes was slightly above normal, in contrast to the large negative anomalies observed last year (Fig. 11). In the Arctic, total ozone values during DJFM 1995/96 were more than $12 \%$ below the $1979-96$ base period means and more than $24 \%$ below values observed in the early 1980s. In the Tropics, a weak negative anomaly seen during late 1996 is part of the wellknown quasi-biennial oscillation in ozone. No long-term ozone trend is evident in the Tropics.

Temperatures in the lower stratosphere are closely coupled to ozone through dynamics and 


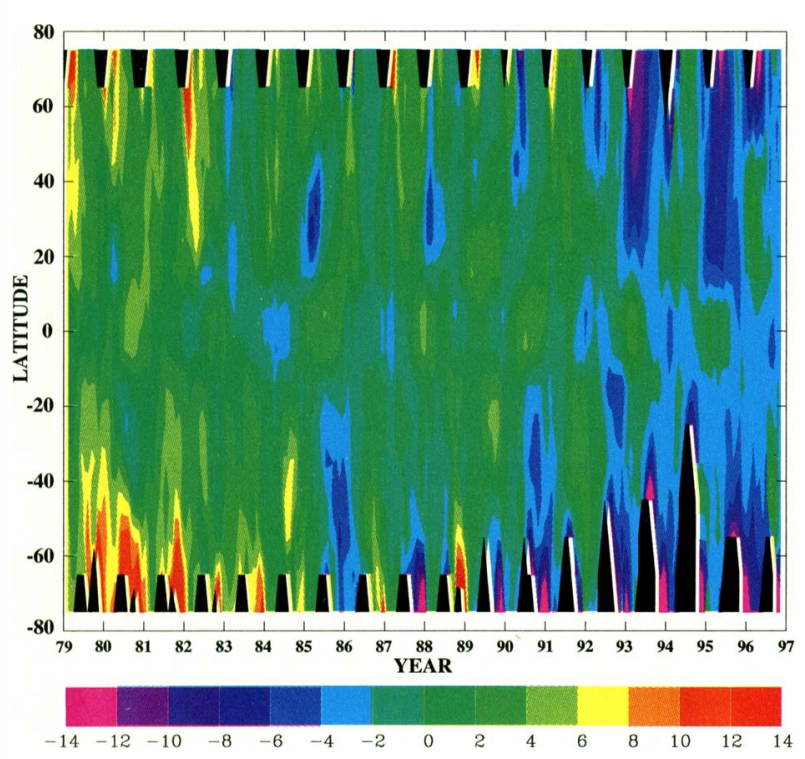

FIG. 11. Time-latitude section of monthly average anomalies (percent) of zonal mean total ozone. Percentages are departures from the 1979-96 base period means. The region of no SBUV and $\mathrm{SBUV} / 2$ data during the winter polar night is shown in black.

photochemistry, with extremely low temperatures (less than $-78^{\circ} \mathrm{C}$ ) believed to lead to ozone depletion. These low temperatures contribute to the formation of polar stratospheric clouds (PSCs), which enhance the production and lifetime of reactive chlorine, leading to ozone depletion (WMO/UNEP 1994). During DJFM 1995/96 daily minimum temperatures at $50 \mathrm{hPa}$ over the Northern Hemisphere polar region $\left(65^{\circ}-90^{\circ} \mathrm{N}\right)$ were below the long-term mean for the entire period (Fig. 12), with record low temperatures observed in February and March. These values were sufficiently low to favor PSC formation and enhanced ozone depletion during the period.

\section{(ii) Southern Hemisphere}

Total column ozone also exhibits a well-defined annual cycle in the Southern Hemisphere, with lowest values typically observed over Antarctica during SON. During 1996 total ozone values approached 100 Dobson units (DUs) over the polar region during late September-early October (Fig. 13). This value is only slightly higher than the record low values observed in 1993 and is more than $12 \%$ below the 1979-96 base period mean (Fig. 11).

The "ozone hole," denoted by total ozone concentrations less than $220 \mathrm{DU}$, is most pronounced over the polar region and typically reaches maximum areal extent during late September-early Oc-

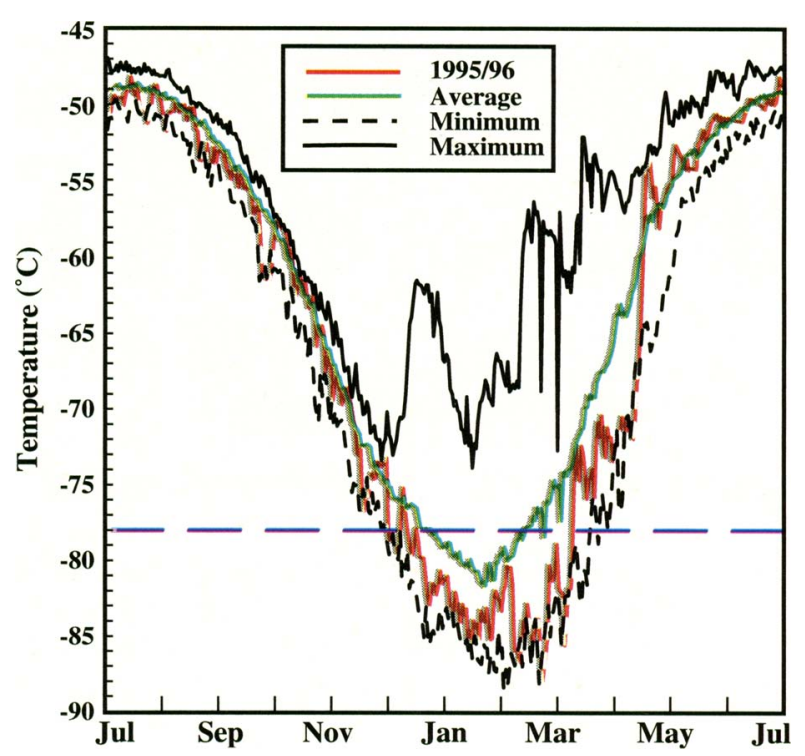

FIG. 12. Daily minimum temperatures at $50-\mathrm{hPa}(19 \mathrm{~km})$ in the region $65^{\circ}-90^{\circ} \mathrm{N}$ for July $1995-J u n e ~ 1996$ (red line). Mean daily values for the period 1979-95 are shown in green. Daily extreme maxima (solid) and minima (dashed) for any year are also shown.

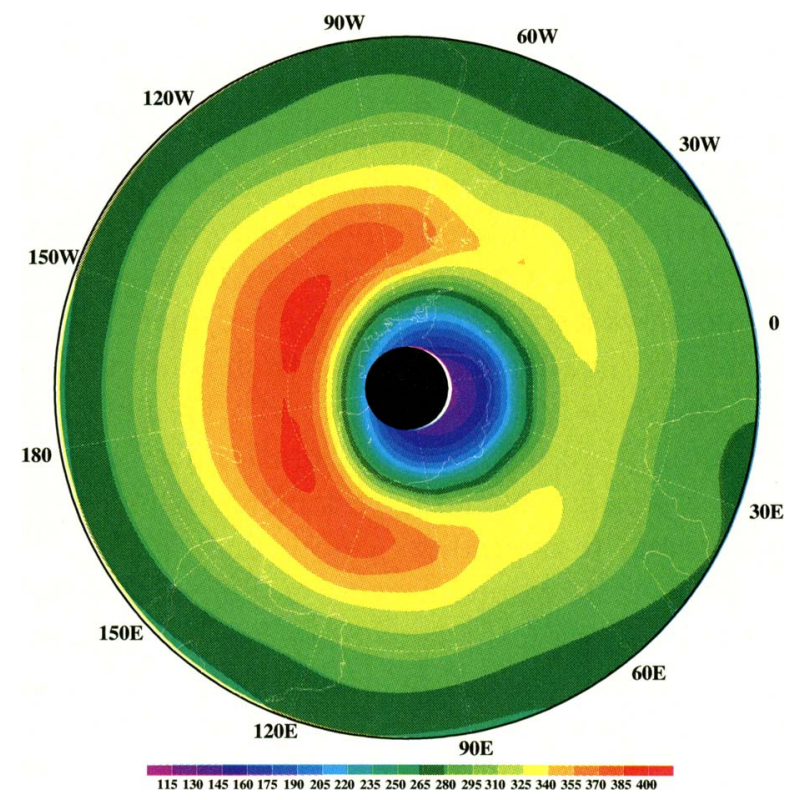

FIG. 13. Monthly mean total ozone for October 1996. Areas of total ozone less than $220 \mathrm{DU}$ (indicating the ozone hole) are shown in blue. Regions of no data are shown in black.

tober. Additionally, the ozone hole typically disappears by the beginning of December. During September and October 1996, the area of the ozone hole was similar to the recent record-setting year of 1995 (Fig. 14). However, during November, the areal extent exceeded any previous November on 


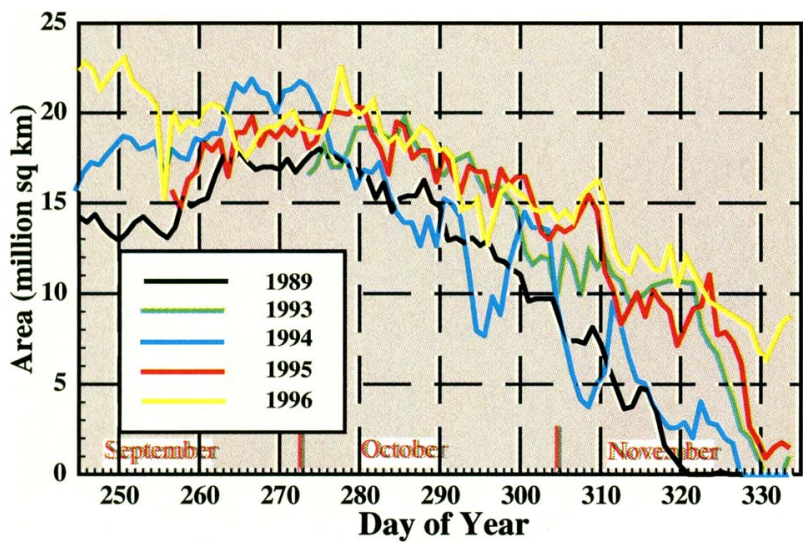

FIG. 14. Daily areal coverage $\left(10^{6} \mathrm{~km}^{2}\right)$ of the ozone hole, denoted by values less than $220 \mathrm{DU}$, as measured by the SBUV/2 sensor.

record. The large areal coverage (exceeding $5 \times 10^{6} \mathrm{~km}^{2}$ ) persisted into early December, in association with a continuation of anomalously cold stratospheric temperatures (Fig. 15). In fact, these daily minimum temperatures in the lower stratosphere averaged lower than average across the polar region during most of September-November 1996 and often approached record low values.

\section{2) Carbon dioxide}

The atmospheric carbon dioxide $\left(\mathrm{CO}_{2}\right)$ measurements made at Mauna Loa Observatory, Hawaii, since 1958 provide strong evidence for human alteration of the environment (Fig. 16). The data through 1973 are from Keeling et al. (1982), while data since 1973 are from the National Oceanic and Atmospheric Administration (NOAA) program (Thoning et al. 1989).

Mauna Loa Observatory, located at an elevation of $3350 \mathrm{~m}$ on the flank of Mauna Loa volcano, is an ideal site for carbon dioxide measurements. There is no nearby vegetation, and the prevailing nighttime downslope winds give a representative sampling of midtropospheric air from the central North Pacific Ocean. Thus, this record is taken as a reliable index of long-term carbon dioxide growth.

The average $\mathrm{CO}_{2}$ concentration increase at Mauna Loa during the 1980s and 1990s has been about $1.4 \mathrm{ppm} \mathrm{yr}^{-1}$ but with significant year-to-year variability in this growth rate. The growth rate de-

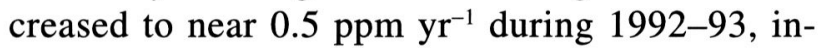
creased to more than $2 \mathrm{ppm} \mathrm{yr}^{-1}$ during 1995, but then dropped in 1996 to near the average of the last

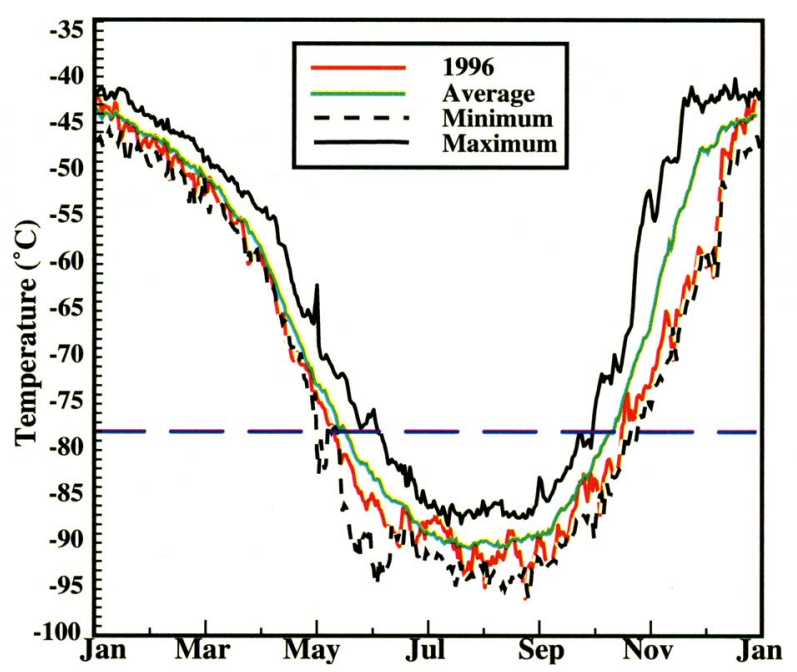

FIG. 15 . Daily minimum temperatures at $50 \mathrm{hPa}(19 \mathrm{~km})$ in the region $65^{\circ}-90^{\circ} \mathrm{S}$ for 1996 (red line). Mean daily values for the period 1979-95 are shown in green. Daily extreme maxima (solid) and minima (dashed) for any year are also shown.

decade in 1996. Contributing factors to these variations in growth rate include ENSO and the natural exchange of carbon dioxide between the oceans, the terrestrial biosphere, and the atmosphere.

\section{3) Methane}

Globally averaged methane mixing ratios are collected approximately weekly from various sites in the NOAA/CMDL cooperative air sampling network (Dlugokencky et al. 1994). Air sampling sites are distributed between $90^{\circ} \mathrm{S}$ and $82^{\circ} \mathrm{N}$ and provide air samples representative of the well-mixed boundary layer. The average growth rate during the measurement period is 9.6 parts per billion ( $\mathrm{ppb}$ ) per year; the growth rate is largest near the beginning of the record and has been decreasing at 0.8 (ppb $\mathrm{yr}^{-1}$ ) per year (Dlugokencky et al. 1994). Significant interannual variations in the methane growth rate are also evident (Fig. 17). For example, a significant increase in methane growth was observed in the Tropics and the high latitudes of the Southern Hemisphere during 1991-92 following the eruption of Mt. Pinatubo. The $\mathrm{SO}_{2}$ emitted into the stratosphere during the eruption resulted in a decrease in the UV flux in the wavelength region 290 $330 \mathrm{~nm}$ (Dlugokencky et al. 1994). It has been suggested (Dlugokencky et al. 1994) that this decrease in the UV flux decreased the steady-state [OH], thus leading to the observed increase in the methane growth rate. 


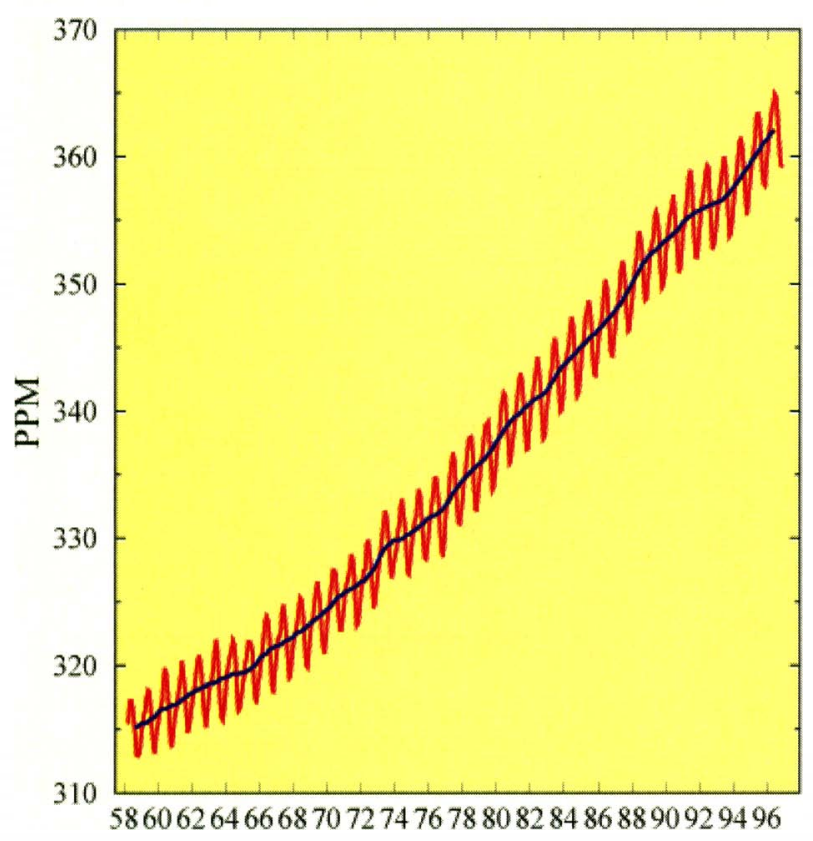

FIG. 16. Monthly mean carbon dioxide concentrations (red curve, ppm) measured at Mauna Loa, Hawaii. Blue line is the 12-month running mean. The data through 1973 are from C. D. Keeling at Scripps Institute of Oceanography. [Analysis provided by the Climate Monitoring and Diagnostics Laboratory (CMDL).]

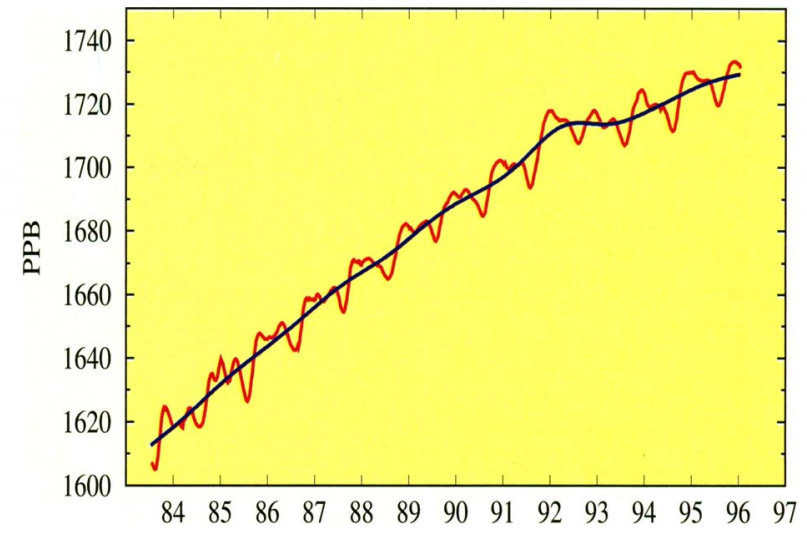

FIG. 17. Globally averaged, biweekly methane mixing ratios (red curve, ppb) determined from the NOAA/CMDL Carbon Cycle Group cooperative air sampling network. Solid blue line shows the growth with the seasonal cycle removed. (Analysis provided by the Climate Monitoring and Diagnostics Laboratory.)

Increased methane affects the earth's radiation balance and the chemistry of the atmosphere. While the major sources of methane have been identified, their absolute contributions to the global methane budget remain poorly quantified. The exact causes of the observed increase will remain uncertain until a better understanding of the methane budget is realized.

\section{e. Northern Hemisphere snow cover}

The 1996 annual average snow cover in the Northern Hemisphere was $25.3 \times 10^{6}$ $\mathrm{km}^{2}$, and was above the median for the first time since 1985 (Fig. 18). Overall, 1996 was the fifth snowiest year in the 24 years of satellite record considered here, with above-normal snow cover observed primarily during the following eight months: January, March-June, and September-November (Fig. 18). In comparison, above-normal hemispheric snow cover was observed for 8-10 months of the year during the four snowiest years $(1978,1985,1977$, and 1972).
Fig. 18. Anomalies of monthly snow cover extent over the Northern Hemisphere between January 1976 and December 1996. Smoothed curve is a 12-month running mean. Anomalies are departures from the 1972-96 base period means. (Analysis provided by Rutgers University.) 
During DJF 1995/96, North American snow cover averaged near normal $\left(16.6 \times 10^{6} \mathrm{~km}^{2}\right)$, despite the fact that locally anomalous conditions were experienced over much of the United States. For example, the frequency of snow cover was above normal in the eastern United States, the Ohio valley, and the northern plains states, and below normal throughout the intermountain region of the western United States (Fig. 19a). This pattern of anomalous snow cover reflected enhanced ridging, reduced precipitation, and above-normal surface temperatures in the West, and enhanced troughing, above-normal precipitation, and cooler than normal surface temperatures in the East (see section 5, Figs. 59, 60). In Eurasia, above-normal snow cover extended across eastern Europe and southwestern Russia during DJF 1995/96, while belownormal snow cover frequency was observed over large portions of northwestern Europe.

During MAM 1996, the above-normal hemispheric snow cover reflected a late retreat of the winter snow pack across central Canada, the northcentral United States, and across northeastern Europe and western Russia (Fig. 19b). These conditions were consistent with vast areas of below-normal temperatures throughout the season across central North America and much of western Eurasia (see section 5, Fig. 61). In contrast, below-normal snow cover was again observed over the western United States during the season, in association with a continuation of abnormally warm surface temperatures.

During SON 1996, the above-normal hemispheric snow cover frequency reflected an early buildup to, and an abnormally large southward extent of, the snow pack across much of Canada, Alaska, and the eastern half of Siberia (Fig.19c). Interestingly, 1996 was the first year since 1982 that above-normal hemispheric snow cover was observed during all three fall months (Fig. 18). Again, this above-normal snow cover was associated with vast areas of below-normal temperatures across much of North America and eastern Siberia (see section 5, Fig. 65).

\section{Atmospheric and oceanic circulation}

\section{a. Southern Oscillation}

\section{1) OVERVIEW}

The Southern Oscillation refers to large-scale pressure anomalies that develop at irregular inter-

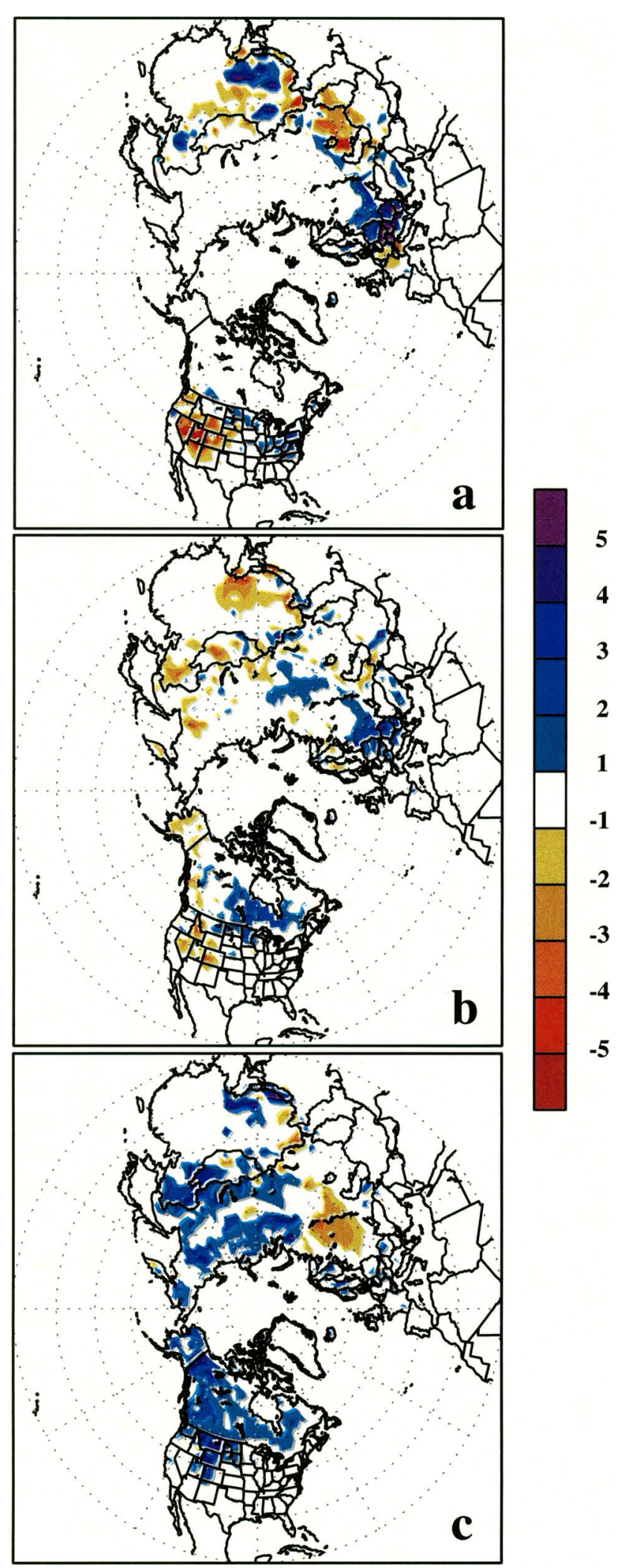

FIG. 19. Snow cover duration anomaly in weeks derived from operational analysis of visual imagery by NOAA/NESDIS: (a) December 1995-February 1996, (b) March-May 1996, and (c) September-November 1996. 
vals between the Indian Ocean-western tropical Pacific and the east-central tropical Pacific (Berlage 1957; Bjerknes 1969). Extreme phases of the SO are accompanied by large-scale patterns of anomalous sea level pressure (SLP), wind, tropical convection, SST, and subsurface ocean temperature that generally span the entire equatorial Pacific. Collectively, these anomaly patterns represent a strongly coupled ocean-atmosphere interaction and comprise the dominant mode of interannual variability in the global Tropics.

From SON 1995 through SON 1996, the positive phase of the SO (Fig. 20a) and abnormally cold sea surface temperatures were observed across the central and east-central equatorial Pacific (Figs. 20b, 21a). These conditions are in marked contrast to the negative phase of the SO and abnormally warm ocean temperatures that dominated these regions from 1991 to early 1995 (Halpert et al. 1996). During this time, three periods of maturephase ENSO conditions were evident: November 1991-May 1992, December 1992-May 1993, and November 1994-February 1995.

These periods of mature ENSO conditions were associated with enhanced atmospheric convection [negative anomalies of outgoing longwave radiation (OLR)] over the central and east-central equatorial Pacific, and with generally suppressed convective activity (positive OLR anomalies) over the western equatorial Pacific and Indonesia (Fig. 21b). This distribution of anomalous convection reflects several features typical of ENSO (Rasmusson and Carpenter 1982; Janowiak and Arkin 1991), including an eastward extension of the climatological mean region of deep tropospheric heating well east of the date line, a strengthening and equatorward shift of the intertropical convergence zone (ITCZ) over the central and eastern Pacific, and a northeastward shift of the South Pacific convergence zone (SPCZ). Other ENSO-related features during these periods included 1) above-normal SLP over the western equatorial Pacific and below-normal SLP over the eastern equatorial Pacific (Fig. 21c), 2) westerly wind anomalies at 850 $\mathrm{hPa}$ across the equatorial Pacific (Fig. 21d), and 3) abnormally warm (cold) subsurface ocean temperatures east (west) of the date line down to thermocline depth, that is indicated by the depth of the $20^{\circ} \mathrm{C}$ isotherm (Fig. 22a). These subsurface anomalies reflect a reduced (increased) depth of the oceanic thermocline over the western (eastern) equa-
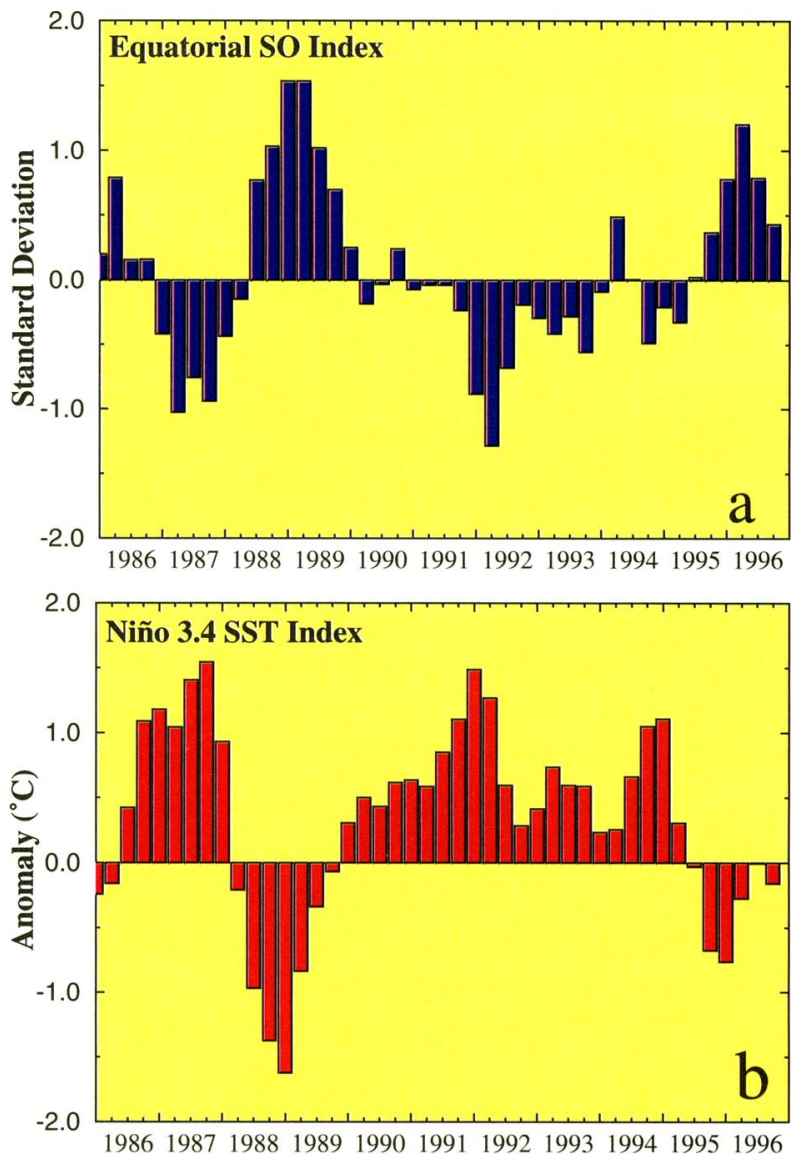

FIG. 20. (a) Seasonal equatorial index of the Southern Oscillation and (b) seasonal Niño 3.4 SST index. SST anomalies are departures from the adjusted OI climatology (Reynolds and Smith 1995) and are averaged over the region $5^{\circ} \mathrm{N}-5^{\circ} \mathrm{S}$ and $170^{\circ} \mathrm{W}-120^{\circ} \mathrm{W}$. The equatorial index of the $\mathrm{SO}$ is calculated as the standardized difference between the standardized anomalies at $140^{\circ} \mathrm{W}$ and $120^{\circ} \mathrm{E}$.

torial Pacific and a reduction in the overall slope of the thermocline.

The development of cold episode conditions during 1995 was accompanied in the Tropics by enhanced convection over Indonesia and suppressed convection over the central equatorial Pacific in the vicinity of the date line (Fig. 21b) and by enhanced low-level easterly winds across the equatorial $\mathrm{Pa}$ cific (Fig. 21d). It was also accompanied by a transition to an increased slope of the oceanic thermocline across the equatorial Pacific, resulting in abnormally warm (cold) subsurface ocean temperatures down to thermocline depth in the western (eastern) Pacific (Fig. 22b).

These cold-episode conditions contributed to pronounced large-scale changes in the anomaly patterns from those that had prevailed during much 


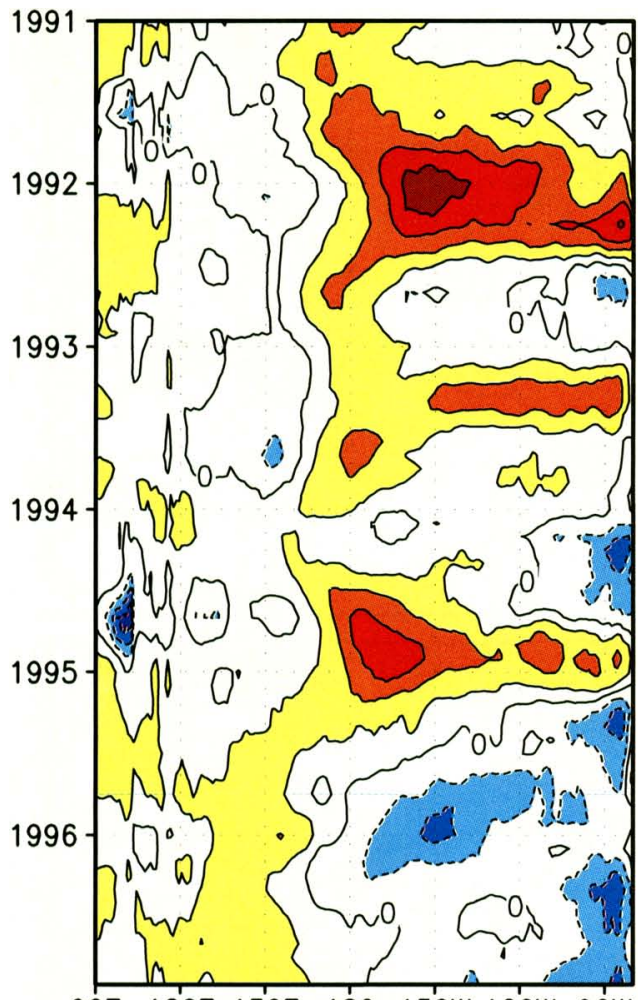

90E 120E 150E 180 150W 120W 90W

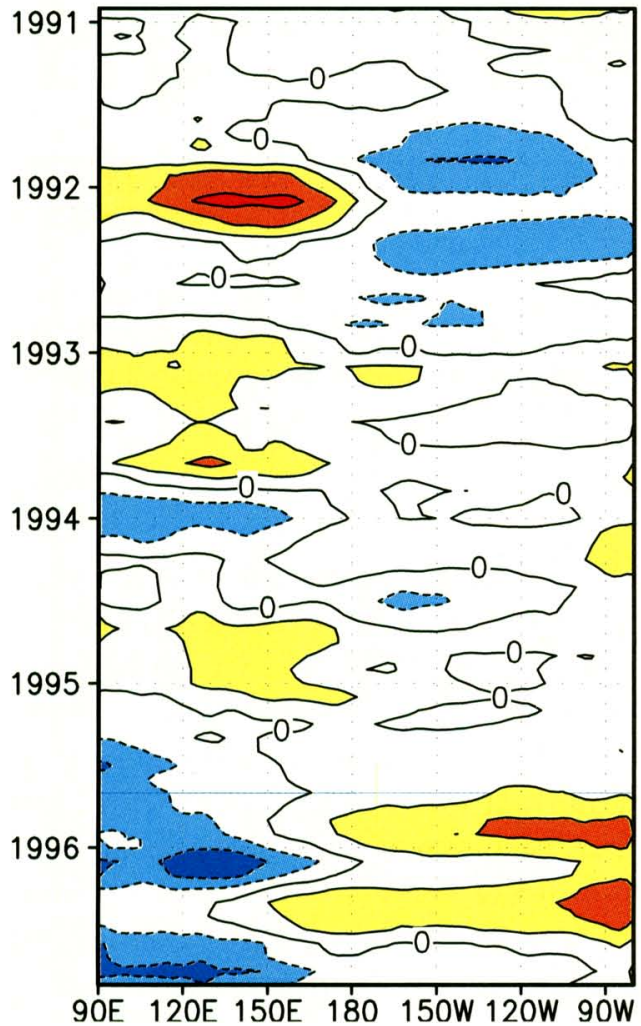

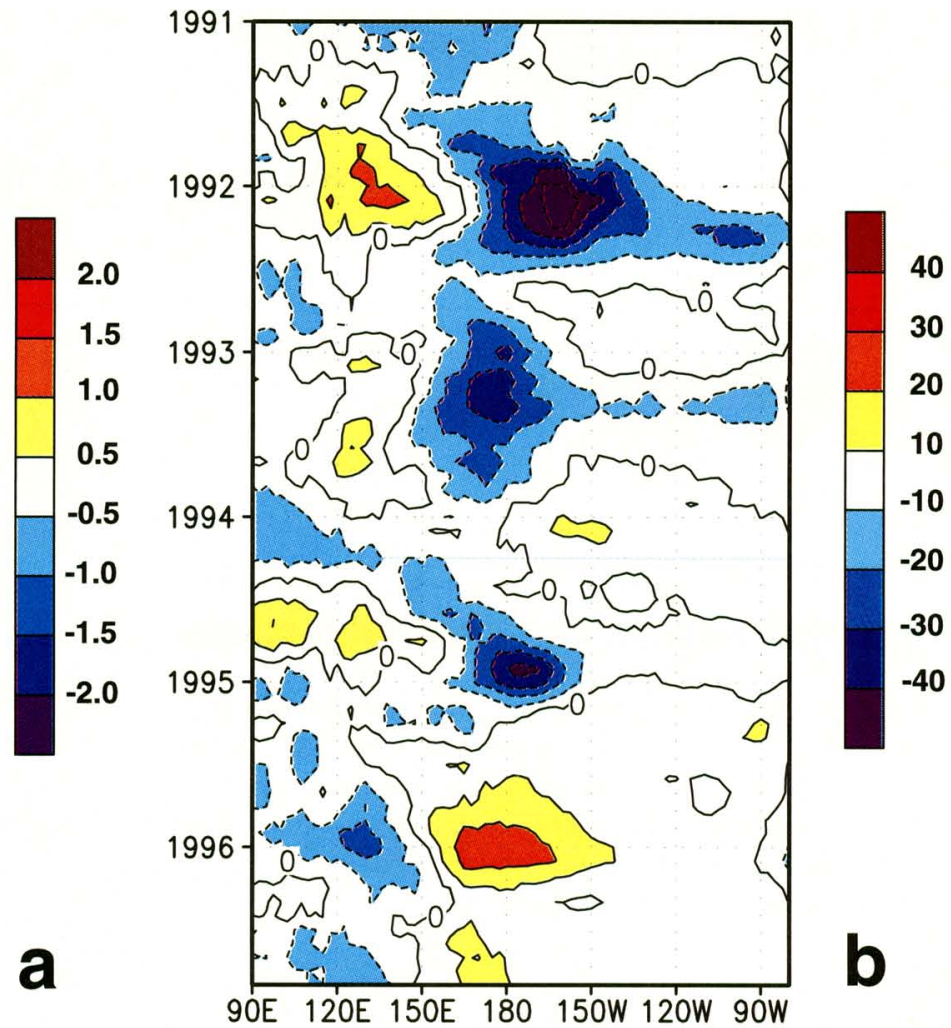

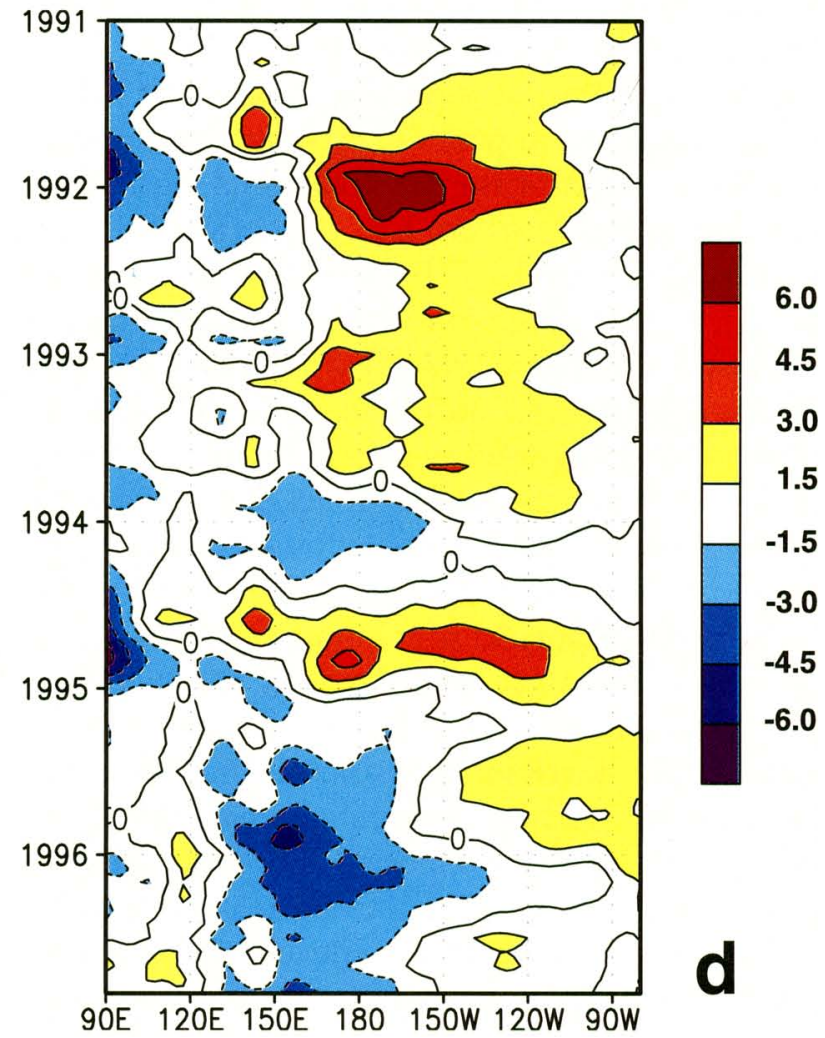

Fig. 21. Time-longitude section averaged $5^{\circ} \mathrm{N}-5^{\circ} \mathrm{S}$ of anomalous (a) SST $\left({ }^{\circ} \mathrm{C}\right)$, (b) OLR (W m $\left.{ }^{-2}\right)$, (c) SLP (hPa), and (d) $850-\mathrm{hPa}$ zonal wind $\left(\mathrm{m} \mathrm{s}^{-1}\right.$ ). SST anomalies are departures from the 1950-79 adjusted OI climatology (Reynolds and Smith 1995); OLR anomalies, SLP anomalies, and 850-hPa zonal wind anomalies are departures from the 1979-95 base period means. 

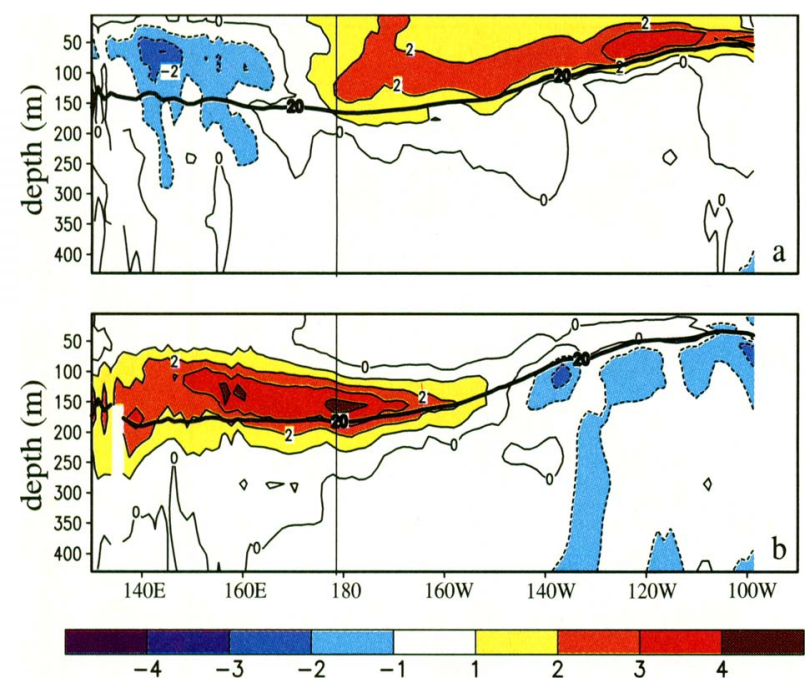

FIG. 22. Equatorial depth-longitude section of ocean temperature anomalies for (a) December 1994 and (b) December 1995. Data are derived from an analysis system that assimilates oceanic observations into an oceanic GCM (Ji et al. 1995). Contour interval is $1^{\circ} \mathrm{C}$. Anomalies are departures from the 1983-92 base period means. The dark line is the $20^{\circ} \mathrm{C}$ isotherm.

of the early 1990s. For example, above-normal rainfall returned to Indonesia, northern Australia [see section $4 \mathrm{~d}(1)$ ], and southern Africa [see section $4 \mathrm{c}(2)$ ], following a prolonged period of belownormal rainfall and periodic drought. Additionally, a poleward shift of the jet stream and storm track position over the eastern half of the North Pacific was evident during DJF 1995/96 [see section $4 \mathrm{~b}(1)$ ], following several winter seasons (three in the last four) characterized by a marked strengthening, equatorward shift, and eastward extension of these features toward the southwestern United States. In the southwestern United States, there was a transition to significantly below-normal precipitation and severe drought [see section $4 b(2)$ ], following above-normal precipitation in this region during the previous several winter seasons. Over the North Atlantic, there was a dramatic return to very active hurricane seasons during 1995 and 1996, following four consecutive years (1991-94) of significantly below-normal hurricane activity [see section $4 \mathrm{~b}(4)$ ]. This strong relationship between the phase of the SO and intense hurricane activity over the North Atlantic has been previously documented by Gray et al. (1992).

\section{2) Mature cold-episode conditions during \\ December 1995-May 1996}

The period December 1995-May 1996 featured
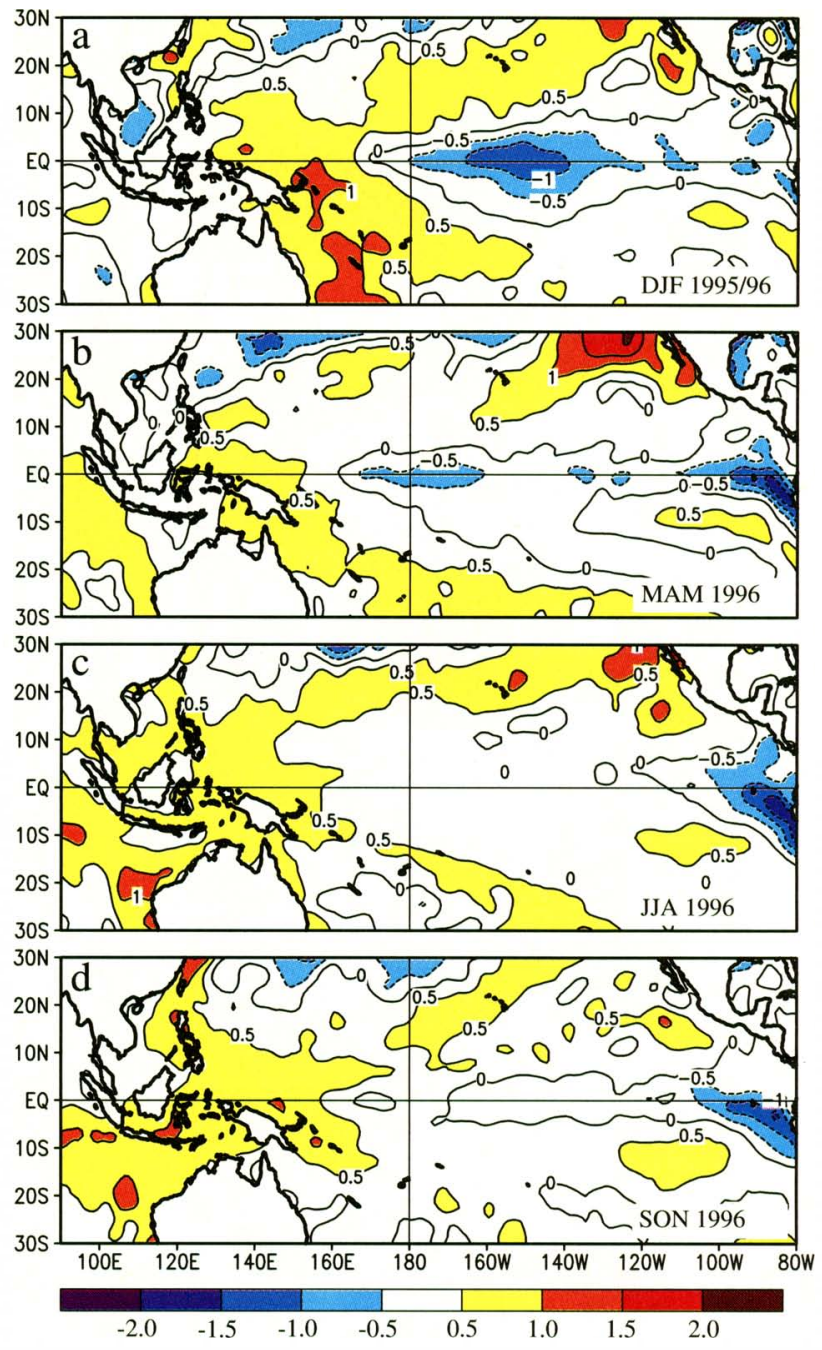

FIG. 23. SST anomalies for (a) DJF 1995/96, (b) MAM 1996, (c) JJA 1996, and (d) SON 1996. Contour interval is $0.5^{\circ} \mathrm{C}$. Anomalies are departures from the 1950-79 adjusted OI climatology (Reynolds and Smith 1995).

the development of mature-phase cold-episode conditions for the first time since the 1988-89 cold episode (Fig. 20b). During DJF 1995/96, below-normal SSTs covered the equatorial Pacific east of the date line (Fig. 23a), with temperatures more than $1.0^{\circ} \mathrm{C}$ below normal observed between $170^{\circ}$ and $145^{\circ} \mathrm{W}$. Farther west, abnormally warm ocean temperatures averaging $0.5^{\circ}-1.0^{\circ} \mathrm{C}$ above normal dominated the western equatorial Pacific during the season. Accompanying this anomalous SST pattern, enhanced convection was observed throughout Indonesia and northern Australia, while suppressed convection covered the central equatorial Pacific (Fig. 24a). This pattern reflected three important changes in the normal distribution of tropi- 
cal convection: 1) a westward retraction of the mean region of deep tropical convection toward Indonesia and a nearly complete dissipation of the normal pattern of tropical convection over the central equatorial Pacific, 2) an overall weakening of the Northern Hemisphere ITCZ over the central and eastern Pacific, and 3) a strengthening of the western flank of the SPCZ.

The $200-\mathrm{hPa}$ wind field during the season featured a large-scale anticyclonic circulation anomaly centered over the western subtropical North Pacific (Fig. 24a), which represents an amplification of the mean subtropical ridge along the equatorward (or anticyclonic) flank of the East Asian jet entrance region. [The mean axis of the East Asian jet crosses central China and southern Japan near $32^{\circ} \mathrm{N}$.] This anticyclonic anomaly comprises several important changes in the atmospheric circulation over the western Pacific and is also a well known feature linking enhanced convection over Indonesia with changes in extratropical circulation farther north (Mo and Kousky 1993). For example, the enhanced westerly flow along its northern flank is coupled to an amplification of the East Asian jet stream, while the enhanced poleward geostrophic flow along its western flank is linked to enhanced confluence (not shown) along the southern half of the East Asian jet entrance region.

We suggest that additional aspects of the link between the enhanced convection over Indonesia and the intensified East Asian jet are revealed by the ageostrophic (both rotational and divergent contributions) component of the flow. For example, a coherent pattern of southerly ageostrophic flow at upper levels normally extends from the deep subtropics to the cyclonic-shear (poleward) side of the East Asian jet entrance region (Fig. 25a). Accompanying this flow is ascending motion at low latitudes and descending motion at higher latitudes, primarily on the cyclonic-shear side of the East Asian jet. This overall circulation represents a strong coupling of two prominent features: 1) the subtropical Hadley cell, with its associated outflow from deep tropical convection over the western tropical Pacific; and 2) the thermodynamically direct, transverse ageostrophic circulation that characterizes the entrance region of the East Asian jet. This transverse ageostrophic circulation is a required feature of any jet stream of finite length (Hoskins et al. 1978) and, among its many properties, produces the westerly momentum and kinetic energy in- creases that air parcels experience as they approach the jet (Fig. 25a), via cross-contour flow toward lower geopotential height (Keyser and Shapiro 1986; Palmén and Newton 1969, sections 1.5 and 8.3; and Holton 1979, section 10.7).

The anomalous ageostrophic flow over the western North Pacific during DJF 1995/96, along with the accompanying patterns of anomalous Lagrangian kinetic energy tendency, are shown in Figs. $25 \mathrm{~b}-\mathrm{d}$. Enhanced southerly ageostrophic flow was
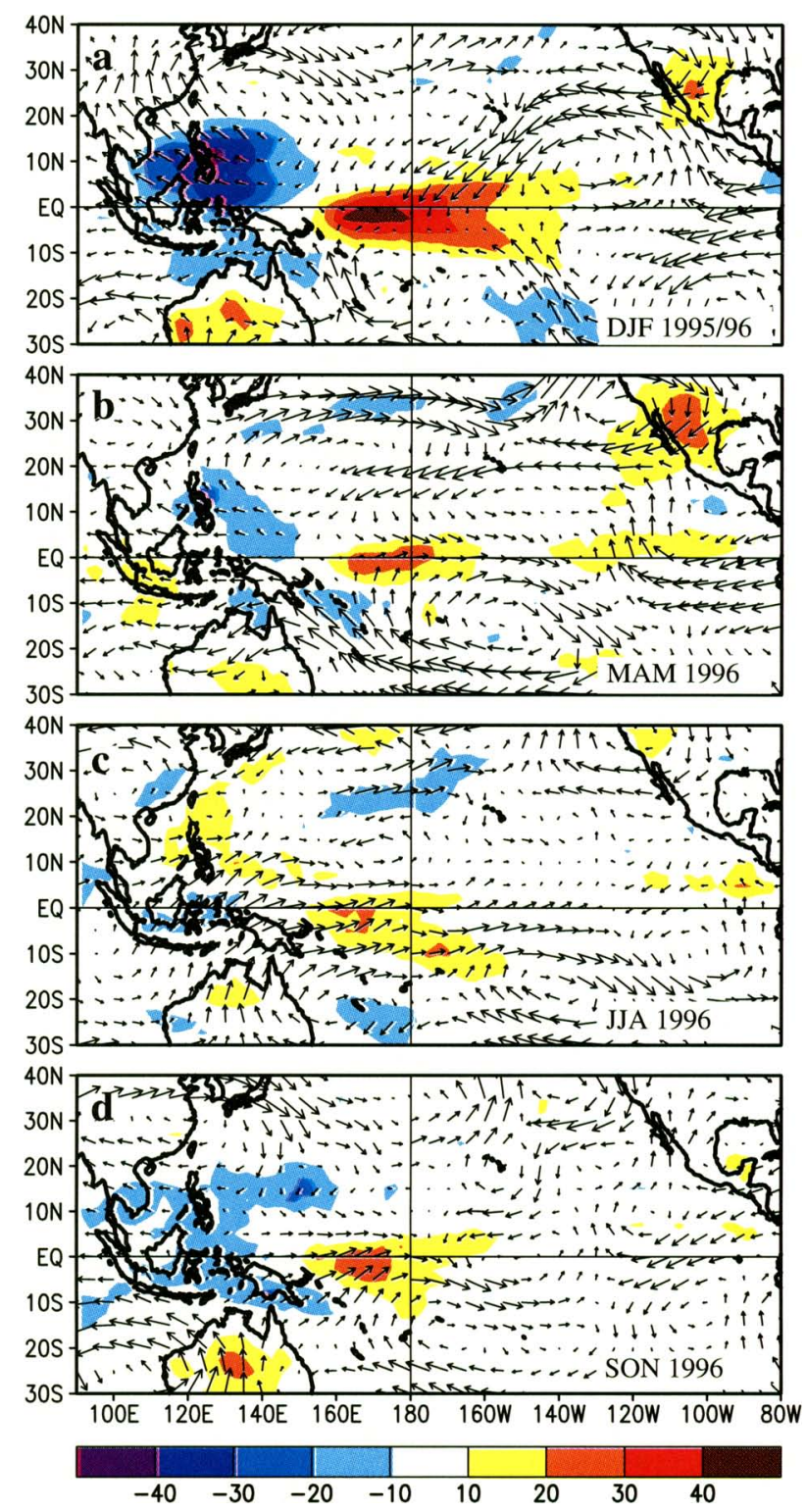

FIG. 24. OLR anomalies (shaded) and 200-hPa vector wind anomalies for (a) DJF 1995/96, (b) MAM 1996, (c) JJA 1996, and (d) SON 1996. Contour interval for OLR anomalies is $10 \mathrm{~W} \mathrm{~m}^{-2}$. Anomalies are departures from the 1979-95 base period monthly means. 
evident at upper levels during the season, extending poleward from the area of enhanced convection well into the axis of the amplified East Asian jet (Fig. 25b). This flow was associated with an enhanced subtropical Hadley circulation. Additionally, it was directed toward lower geopotential height throughout the anticyclonic flank of the jet entrance region, resulting in anomalously strong Lagrangian increases in kinetic energy in that region. The rotational and divergent components of the ageostrophic flow (Figs. 25c and 25d, respectively) each accounted for approximately one-half of these total ageostrophic flow and kinetic energy tendency anomalies.

\section{DJF Climatology}
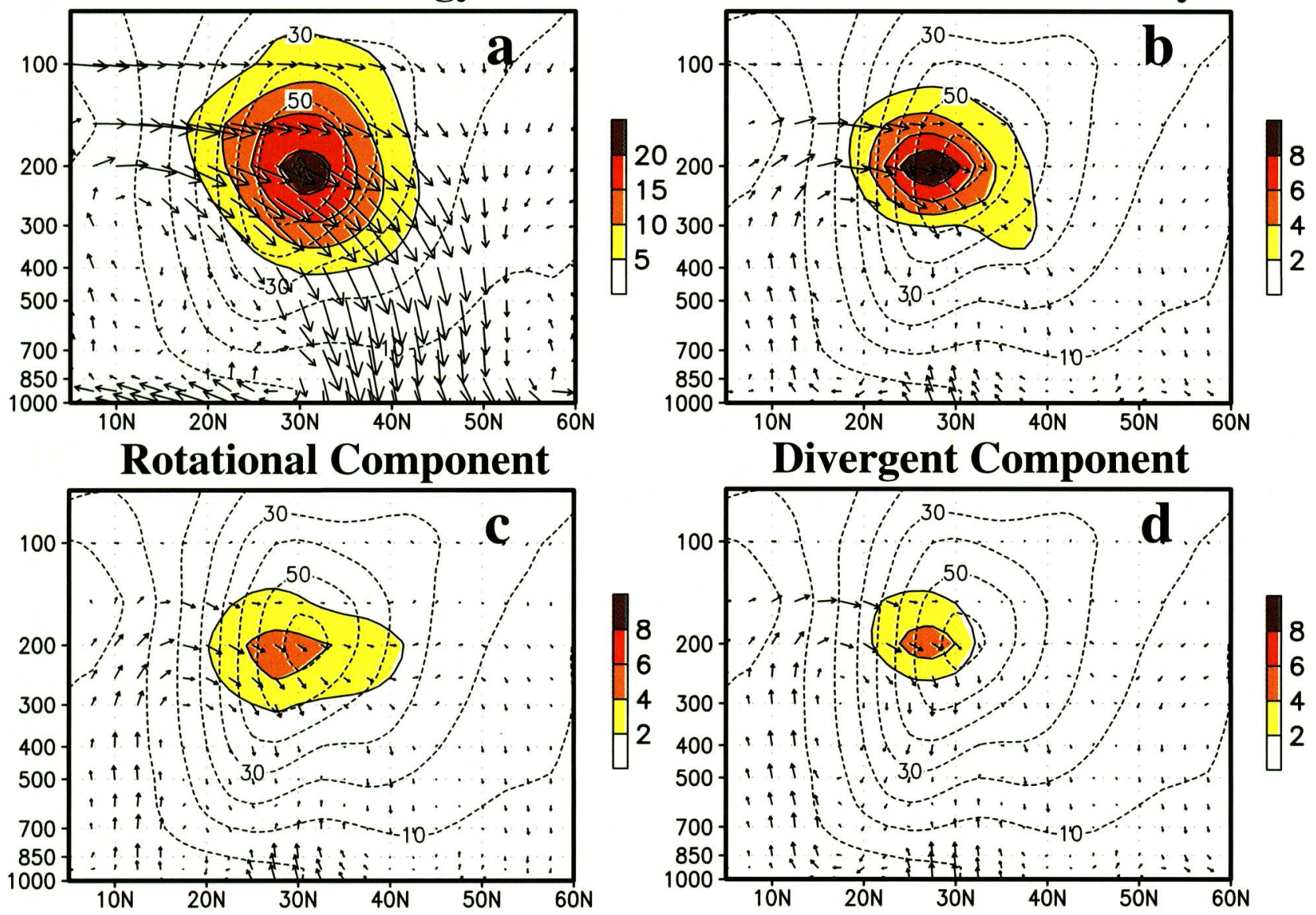

These results suggest that the ageostrophic component (both rotational and divergent contributions) of the flow along the western flank of the subtropical anticyclonic circulation (Fig. 24a) reflected a coupling of both an enhanced subtropical Hadley circulation and an amplified transverse ageostrophic circulation in the East Asian jet entrance region. Collectively, these conditions are consistent with both the increase in deep tropical convection and enhanced deep tropospheric heating over Indonesia during the season, and with the stronger westerly momentum and kinetic energy increases experienced by air parcels migrating through the amplified East Asian jet.

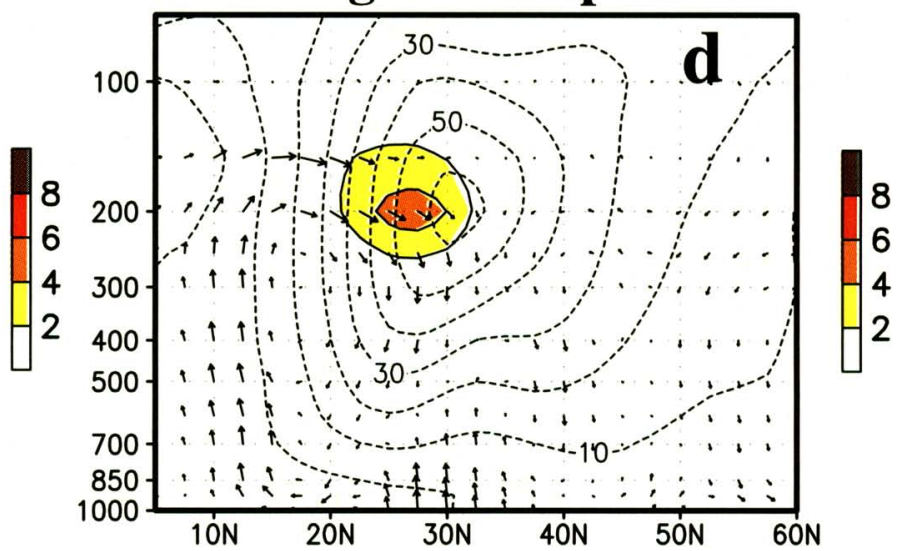

FIG. 25. Pressure-latitude cross sections showing the Lagrangian tendency of kinetic energy (shading, units are $1 \times 10^{-3} \mathrm{~m}^{2} \mathrm{~s}^{-3}$ ) calculated from the ageostrophic flow directed across the geopotential height contours and averaged over the longitude band $95^{\circ}-130^{\circ} \mathrm{E}$ for DJF: (a) 1979-95 climatological mean; (b) 1995/96 seasonal anomaly; (c) 1995/96 seasonal anomaly, contributed by the rotational component of the ageostrophic flow; (d) 1995/96 seasonal anomaly, contributed by the divergent component of the ageostrophic flow. Vertical vector component shows pressure vertical velocity for (a) climatological mean and (b)-(d) 1995/96 anomaly. Horizontal vector component in (a) shows the meridional component of the ageostrophic wind, in (b) the anomalous meridional component of the ageostrophic wind, in (c) the anomalous meridional component of the rotational ageostrophic wind, and in (d) the anomalous meridional component of the divergent ageostrophic wind. Isotachs of zonal geostrophic wind are overlayed in all panels using thin-dashed contours (interval is $10 \mathrm{~m} \mathrm{~s}^{-1}$ ). 
By MAM 1996, the region of largest negative SST anomalies had shifted westward to near $175^{\circ} \mathrm{W}$ and had diminished considerably (Fig. 23b). Despite this evolution, the pattern of tropical convection remained suppressed (Fig. 24b). Additionally, well-developed cyclonic circulation anomalies were observed in both hemispheres at upper levels flanking the region of suppressed tropical convection, while farther west the anomalous anticyclonic circulation over the western subtropical North Pacific persisted but had shifted $30^{\circ}$ to the east (Fig. 24b).

By the end of May, mature-phase cold-episode conditions had ended, with only near-normal to slightly below-normal SSTs observed during the next two seasons across the tropical Pacific east of the date line (Figs. 23c,d). Nonetheless, abnormally warm SSTs (averaging $0.5^{\circ}-1.0^{\circ} \mathrm{C}$ ) persisted over much of the tropical and subtropical western $\mathrm{Pa}$ cific during June-August and September-November, along with a continuation of enhanced (suppressed) convection over Indonesia (near the date line) (Figs. 24c,d). This large-scale pattern of anomalous tropical convection is consistent with a continued positive phase of the Southern Oscillation during these seasons.

\section{3) Equatorial WaLKer CiRCULATION}

The equatorial Walker circulation is an important component of the atmospheric general circulation over the tropical Pacific and is also an integral part of the still larger Southern Oscillation (Bjerknes 1969). During DJF, the mean Walker circulation consists of a maximum in ascending motion over Indonesia, a maximum in descending motion over the east-central equatorial Pacific, and upper-level westerly (lower-level easterly) flow completing the direct circulation cell.

Mature-phase warm- (cold-) episode conditions are accompanied by a reduced (enhanced) strength of the equatorial Walker circulation. These circulation anomalies can be illustrated in equatorial height-longitude plots of vector anomalies (Fig. 26 ), where the horizontal component is the divergent zonal wind (referred to as $u^{*}$ ) and the vertical component is the anomalous vertical velocity. The accompanying relative humidity anomalies are also shown shaded in Fig. 26.

During DJF 1994/95 the strength of the Walker circulation was weaker than normal with the $u^{*}$ and vertical motion anomalies confined to the eastern portion of the Walker circulation. During this period the region of enhanced ascending motion and above-normal relative humidity covered the area between $175^{\circ} \mathrm{E}$ and $150^{\circ} \mathrm{W}$ (Fig. 26a). These conditions then disappeared during March-May 1995 (Fig. 26b) as SSTs returned to near normal throughout the region (Fig. 21a).

By June-August 1995 enhanced descending motion and dryness developed throughout the troposphere across the central equatorial Pacific, and enhanced ascending motion and increased relative humidity became established over the western equatorial Pacific (Fig. 26c). Additionally, a welldefined pattern of anomalous easterly $u^{*}$ in the lower and middle troposphere (up to near the 500-hPa level) and anomalous westerly $u^{*}$ at upper levels was evident. This enhanced Walker circulation became increasingly well defined during September-November 1995 (Fig. 26d) and reached peak amplitude during DJF 1995/96 (Fig. 26e) as mature cold-episode conditions became established.

The strength of the equatorial Walker circulation weakened during MAM 1996, with the area of anomalous descending motion restricted to the vicinity of the date line (Fig. 26f). This evolution is consistent with the decrease in magnitude of both the negative SST anomalies (Fig. 23b) and suppressed convection over the central equatorial $\mathrm{Pa}$ cific during the season (Fig. 24b).

An enhanced Walker circulation persisted during the next two seasons (Figs. 26g,h), consistent with the continued positive phase of the Southern Oscillation and with the continuation of abnormally warm SSTs throughout the western equatorial Pacific (Figs. 23c,d). Thus, by late 1996 the tropical atmosphere still retained its positive phase SO characteristics, despite the return to near-normal SSTs over the central and east-central equatorial Pacific.

\section{b. Tropical intraseasonal activity}

Low-frequency variability in the Tropics is dominated by two phenomena: 1) the Southern Oscillation (e.g., Rasmusson and Arkin 1985), characterized by nearly stationary features persisting for more than one season with a typical periodicity of four to five years; and 2) the Madden-Julian oscillation (e.g., Madden and Julian 1971, 1972, 1994), characterized by a strong eastward propagation of atmospheric features with a typical periodicity of 30-60 days. There is also strong year-to-year vari- 

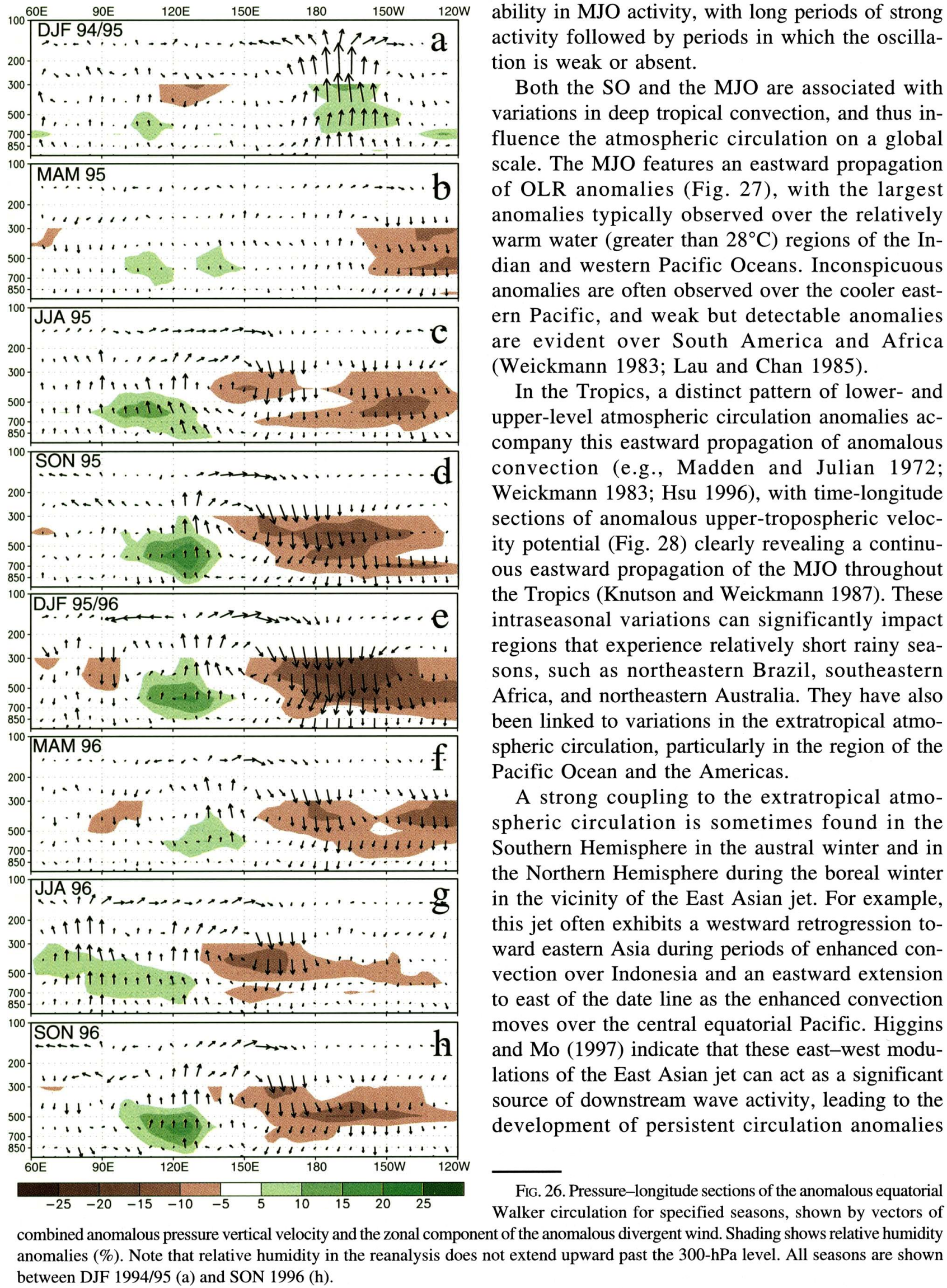
combined anomalous pressure vertical velocity and the zonal component of the anomalous divergent wind. Shading shows relative humidity anomalies (\%). Note that relative humidity in the reanalysis does not extend upward past the $300-\mathrm{hPa}$ level. All seasons are shown between DJF 1994/95 (a) and SON 1996 (h).

ability in MJO activity, with long periods of strong activity followed by periods in which the oscillation is weak or absent.

Both the SO and the MJO are associated with variations in deep tropical convection, and thus influence the atmospheric circulation on a global scale. The MJO features an eastward propagation of OLR anomalies (Fig. 27), with the largest anomalies typically observed over the relatively warm water (greater than $28^{\circ} \mathrm{C}$ ) regions of the Indian and western Pacific Oceans. Inconspicuous anomalies are often observed over the cooler eastern Pacific, and weak but detectable anomalies are evident over South America and Africa (Weickmann 1983; Lau and Chan 1985).

In the Tropics, a distinct pattern of lower- and upper-level atmospheric circulation anomalies accompany this eastward propagation of anomalous convection (e.g., Madden and Julian 1972; Weickmann 1983; Hsu 1996), with time-longitude sections of anomalous upper-tropospheric velocity potential (Fig. 28) clearly revealing a continuous eastward propagation of the MJO throughout the Tropics (Knutson and Weickmann 1987). These intraseasonal variations can significantly impact regions that experience relatively short rainy seasons, such as northeastern Brazil, southeastern Africa, and northeastern Australia. They have also been linked to variations in the extratropical atmospheric circulation, particularly in the region of the Pacific Ocean and the Americas.

A strong coupling to the extratropical atmospheric circulation is sometimes found in the Southern Hemisphere in the austral winter and in the Northern Hemisphere during the boreal winter in the vicinity of the East Asian jet. For example, this jet often exhibits a westward retrogression toward eastern Asia during periods of enhanced convection over Indonesia and an eastward extension to east of the date line as the enhanced convection moves over the central equatorial Pacific. Higgins and Mo (1997) indicate that these east-west modulations of the East Asian jet can act as a significant source of downstream wave activity, leading to the development of persistent circulation anomalies

FIG. 26. Pressure-longitude sections of the anomalous equatorial Walker circulation for specified seasons, shown by vectors of 
over the North Pacific. They note that one typical manifestation of this downstream wave pattern is the development of high-latitude blocking over the central North Pacific approximately 5-10 days after the onset of enhanced convection over Indonesia.

Beginning in early 1996 there was a marked increase in intraseasonal variability in the global Tropics, as shown in time-longitude sections of outgoing longwave radiation (Fig. 27) and $200-\mathrm{hPa}$ velocity potential (Fig. 28). However, the intraseasonal character of the tropical convection was modulated by persistent cold-episode conditions over the central equatorial Pacific. Thus, regions of enhanced convection (negative OLR anomalies) were most prominent over the Indian Ocean and Indonesia, and tended to diminish over the abnormally cold waters of the central equatorial Pacific. Nonetheless, the MJO signature in the upper-level velocity potential field remained intact over the global Tropics, indicating a strong eastward progression of these features throughout the period.

During March-June 1996, the MJO featured a period of approximately 40 days. The period of the

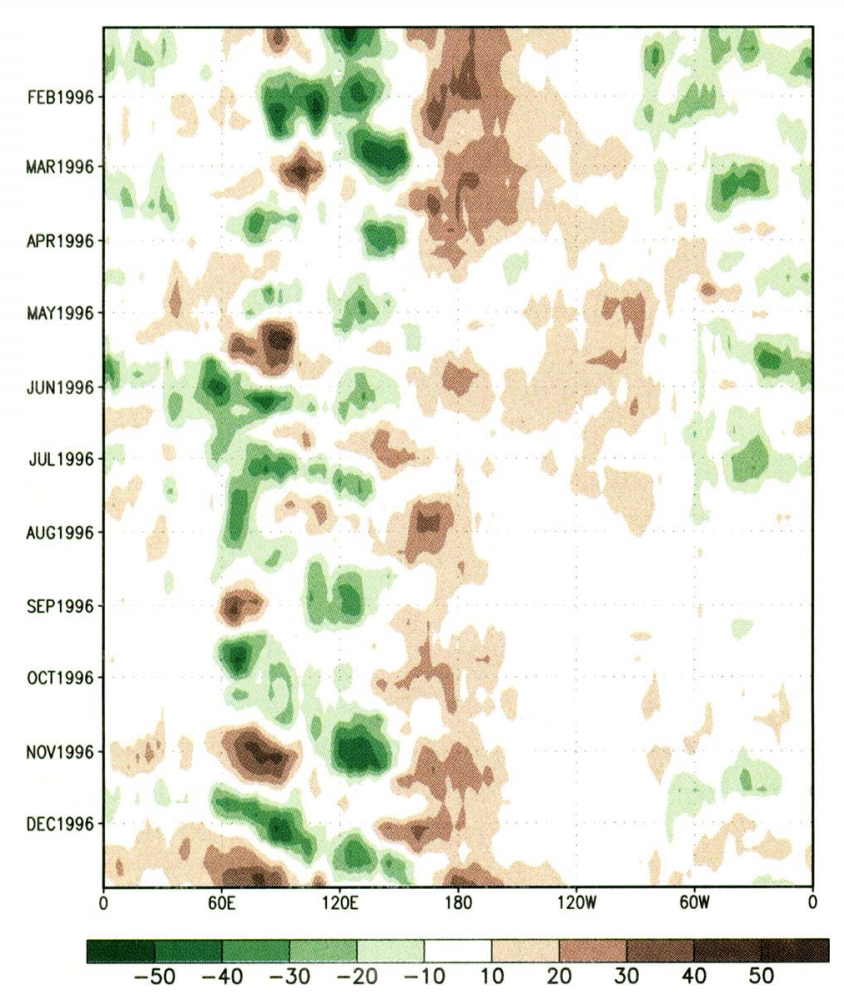

FIG. 27. Time-longitude section $\left(5^{\circ} \mathrm{N}-5^{\circ} \mathrm{S}\right)$ of OLR anomalies $\left(\mathrm{W} \mathrm{m}^{-2}\right)$. Anomalies are departures from the 1979-95 base period pentad means. oscillation then lengthened during July and August to about 60 days, where it remained until the end of the year. The MJO was particularly strong during September-December 1996. During this period, there was considerable variability in the midand high-latitude atmospheric circulation patterns over the North Pacific, with pronounced periods of both high-latitude blocking and strong modulations in the eastward extent of the East Asian jet (Fig. 29). This variability is indicated by the time series of the $500-\mathrm{hPa}$ height anomalies for the region of Alaska (Fig. 30a) which, with a lag of 5-10 days, is similar in character to the time series of tropical OLR anomalies near Indonesia (Fig. 30b).

Thus, it is likely that some aspects of midlatitude variability during September-December 1996 were linked to the strong intraseasonal activity in the Tropics. One aspect was strong blocking in the vicinity of the Bering Sea and Alaska during early November and again in late December (Figs. $29 \mathrm{~b}, \mathrm{~d})$. These periods coincided with times in which tropical convective activity was weaker than normal over the central Indian Ocean and stronger than normal over Indonesia. Interspersed with the

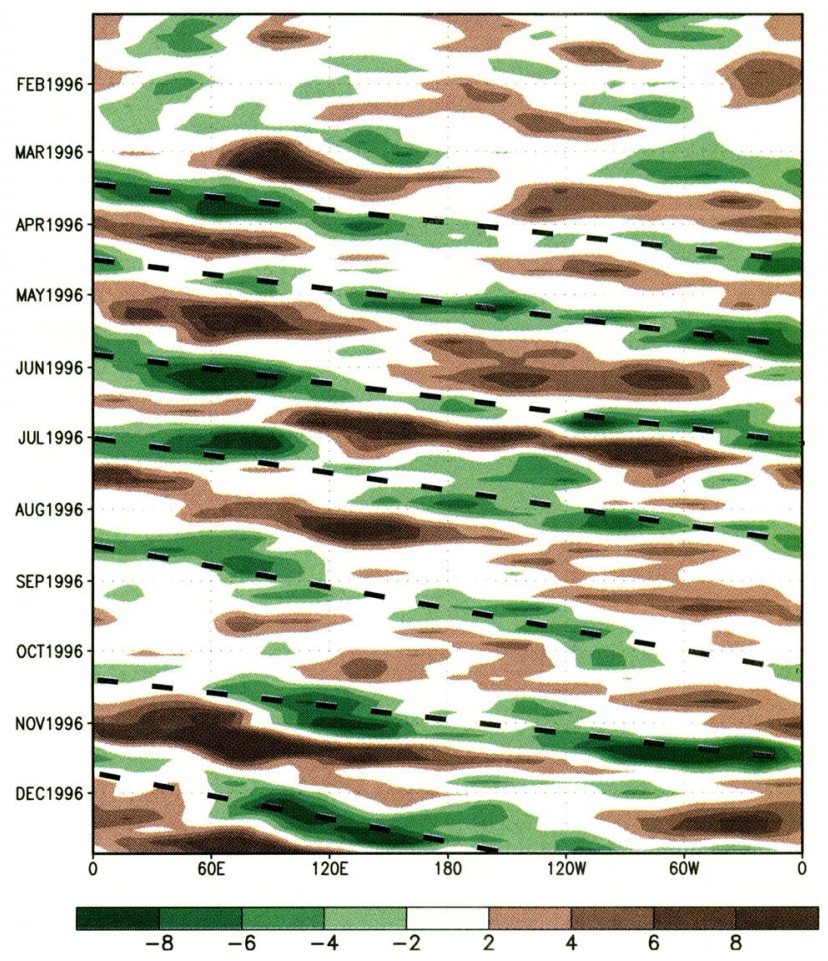

FIG. 28. Time-longitude section $\left(5^{\circ} \mathrm{N}-5^{\circ} \mathrm{S}\right)$ of 200 -hPa velocity potential anomalies $\left(10^{6} \mathrm{~m}^{2} \mathrm{~s}^{-1}\right)$. The period mean anomalies have been removed at each longitude. Dashed lines illustrate the eastward propagation associated with the MJOs. 

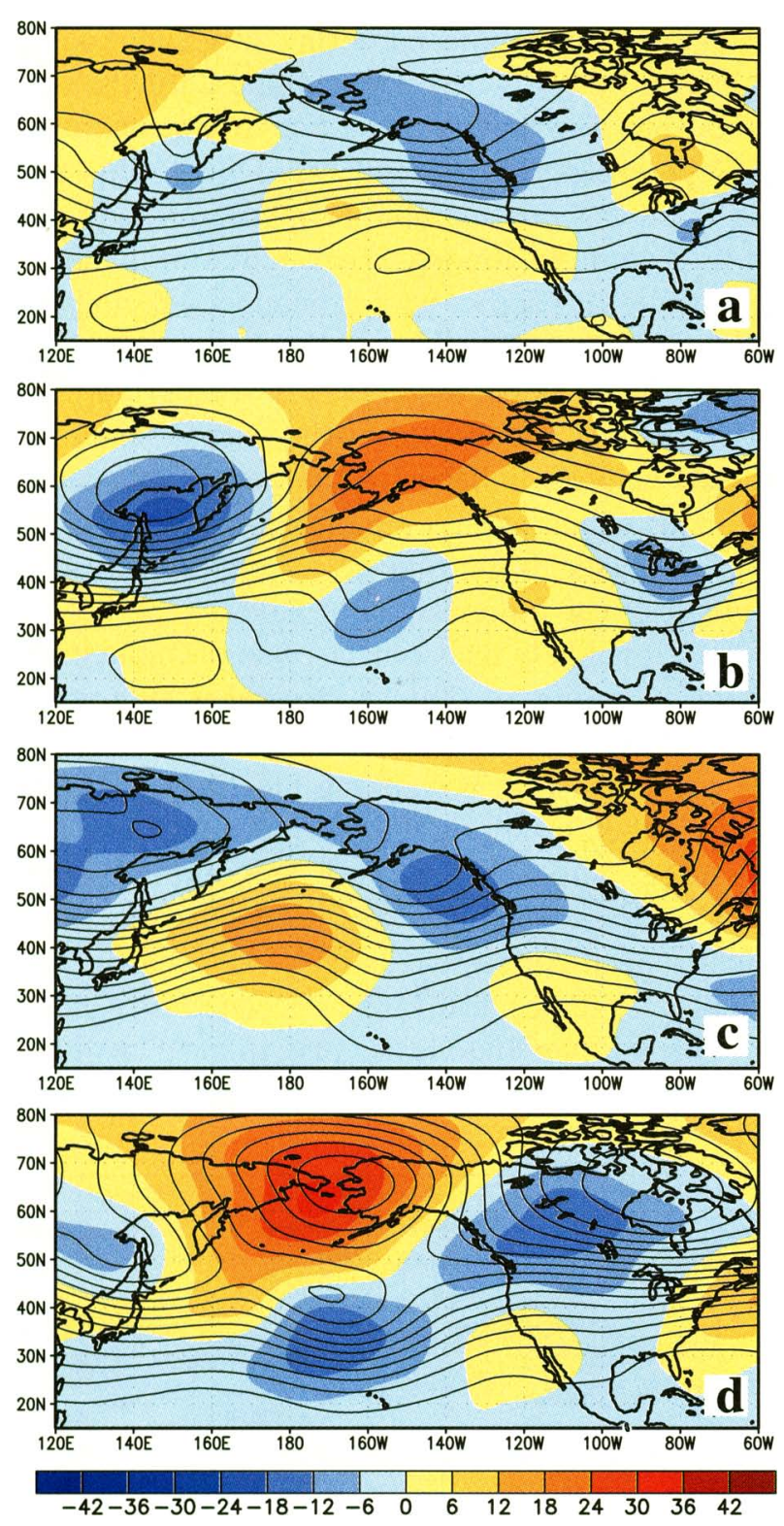

FIG. 29.500-hPa heights (interval is 6 dam) and anomalies (dam) for (a) 8-22 October 1996, (b) 2-16 November 1996, (c) 2-16 December 1996, and (d) 17-31 December 1996.

periods of blocking were periods of below-normal heights in this region (Figs. 29a,c).

Another manifestation of the intraseasonal variability was strong variations in the eastward extent of the East Asian jet, which affected precipitation along the West Coast of the United States. Satellite imagery suggested that late December 1996 heavy precipitation and flooding along the west coast of the United States was directly related to an abnormally strong southwesterly flow of warm, moist air extending from the western tropical Pacific to the
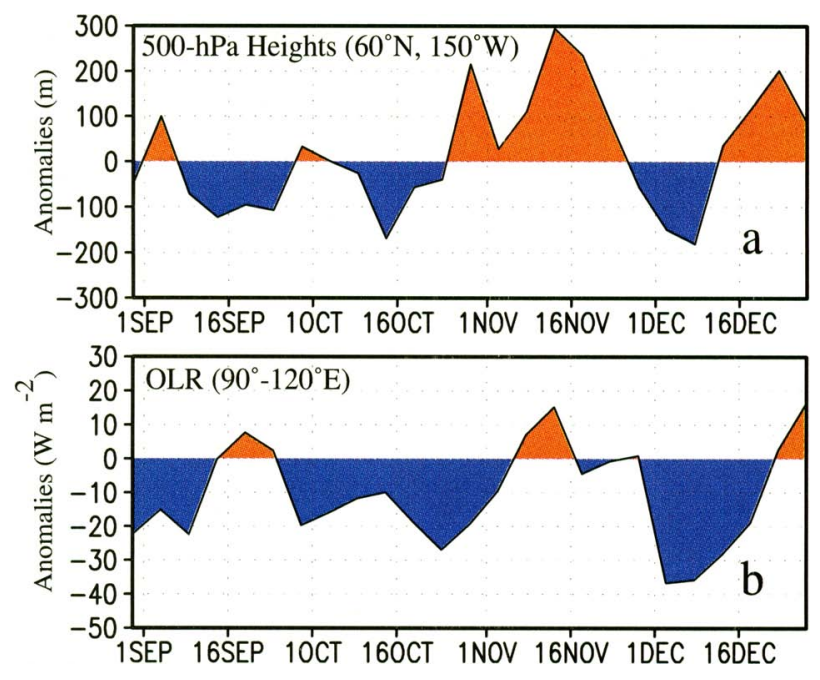

FIG. 30. Time series of (a) pentad 500-hPa height anomalies (m) for $60^{\circ} \mathrm{N}, 150^{\circ} \mathrm{W}$ and $(\mathrm{b})$ pentad OLR anomalies $\left(\mathrm{W} \mathrm{m}^{-2}\right)$ averaged over the latitude band from $10^{\circ} \mathrm{S}$ to $10^{\circ} \mathrm{N}$ for the eastern Indian Ocean $\left(90^{\circ}-120^{\circ} \mathrm{E}\right)$. Anomalies are departures from the $1979-95$ base period means.

west coast of North America (Fig. 29d). These conditions reflected a pronounced eastward extension of the East Asian jet to well east of the date line and also appeared to be strongly connected to the eastward progression of enhanced tropical convection associated with the MJO to the central equatorial Pacific.

\section{c. North Atlantic oscillation}

There are several prominent, recurring modes of low-frequency variability over the extratropical North Atlantic and Europe. Perhaps the most well known of these patterns is the North Atlantic oscillation. The NAO exhibits little variation in its climatological mean structure from month to month and consists of a north-south dipole of anomalies of opposite sign, with one center located over Greenland and the other spanning the central latitudes of the North Atlantic between $35^{\circ}$ and $40^{\circ} \mathrm{N}$. The positive phase of the NAO reflects below-normal heights and pressure across the high latitudes of the North Atlantic and above-normal heights and pressure over the central North Atlantic, the eastern United States, and western Europe (Fig. 31a). The negative phase reflects an opposite pattern of height and pressure anomalies. Both phases of the NAO are associated with basin-wide changes in the intensity and location of the North Atlantic jet stream and storm track, and in large-scale modu- 
lations of the normal patterns of zonal and meridional heat and moisture transport (Hurrell 1995), which in turn result in changes in temperature and precipitation patterns often extending from eastern North America to western and central Europe (Walker and Bliss 1932; van Loon and Rogers 1978; Rogers and van Loon 1979).

Strong positive phases of the NAO are often associated with above-normal temperatures in the eastern United States and across northern Europe and below-normal temperatures in Greenland and across southern Europe and the Middle East (Walker and Bliss 1932; Wallace and Gutzler 1981; van Loon and Rogers 1978). The positive NAO phase is also associated with above-normal precipitation over northern Europe and Scandinavia and below-normal precipitation over southern and central Europe. Opposite patterns of temperature and precipitation anomalies are typically observed during strong negative phases of the NAO. During prolonged periods dominated by one phase of the NAO, abnormal height and temperature patterns are also often seen extending well into central Russia and north-central Siberia.

The wintertime NAO exhibits significant interannual and interdecadal variability (Fig. 31b; Hurrell 1995). For example, the negative phase of the NAO dominated the circulation from the mid1950 s through the $1978 / 79$ winter. An abrupt transition to recurring positive phases of the NAO then occurred during the 1979/80 winter, with the atmosphere remaining in this mode through the 1994/ 95 winter season. During this $15-y r$ interval, a substantial negative phase of the pattern appeared only twice, in the winters of 1984/85 and 1985/86.

November 1995-February 1996 (NDJF 1995/ 96) was characterized by a return to a strong negative phase of the NAO. During this period, the circulation was marked by above-normal heights and substantial blocking activity across the high latitudes of the North Atlantic, and by below-normal heights over the eastern United States, the central latitudes of the North Atlantic, central Europe, and southwestern Russia (Fig. 32a). This pattern was associated with a westward retraction of the jet core toward the western North Atlantic (Fig. 32b) and with a strong split in the flow over the central and eastern North Atlantic. This "split" is identified by a strong low-latitude flow extending from the southeastern United States to northern Africa. A poleward shift of the northern branch of wester-

\section{North Atlantic Oscillation}
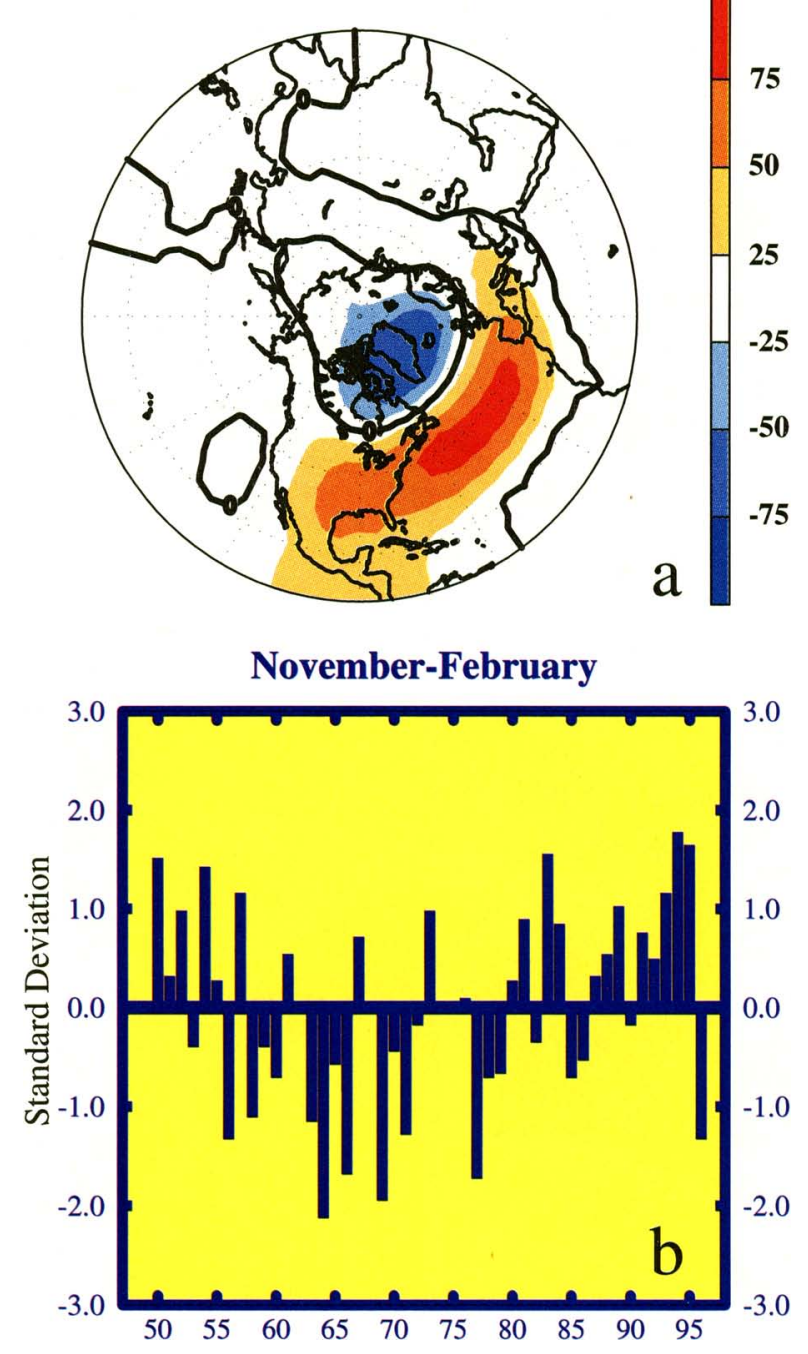

FIG. 31. Rotated Principal Component Analysis (RPCA) of the North Atlantic oscillation teleconnection pattern (NAO) during NDJF: (a) pattern showing the positive phase and (b) normalized amplitude time series. Labeling convention for years is such that 1995 indicates the NDJF 1994/95 season. Pattern is calculated from the 1964-93 base period seasonal means. See Bell and Halpert (1995) for details.

lies to central Greenland and northern Scandinavia, and a marked reduction in the normal northwesterly flow across northern Europe (Fig. 32a). During NDJF 1995/96, significant low-level (925 hPa) moisture transport (Fig. 33a) and heat flux (Fig. 34a) was confined to latitudes south of $45^{\circ} \mathrm{N}$ in the southern branch of westerlies, with the axis of largest transport extending from the southwestern North Atlantic eastward to Portugal and extreme northwestern Africa. Farther north, there was abnormally low moisture transport and heat flux 

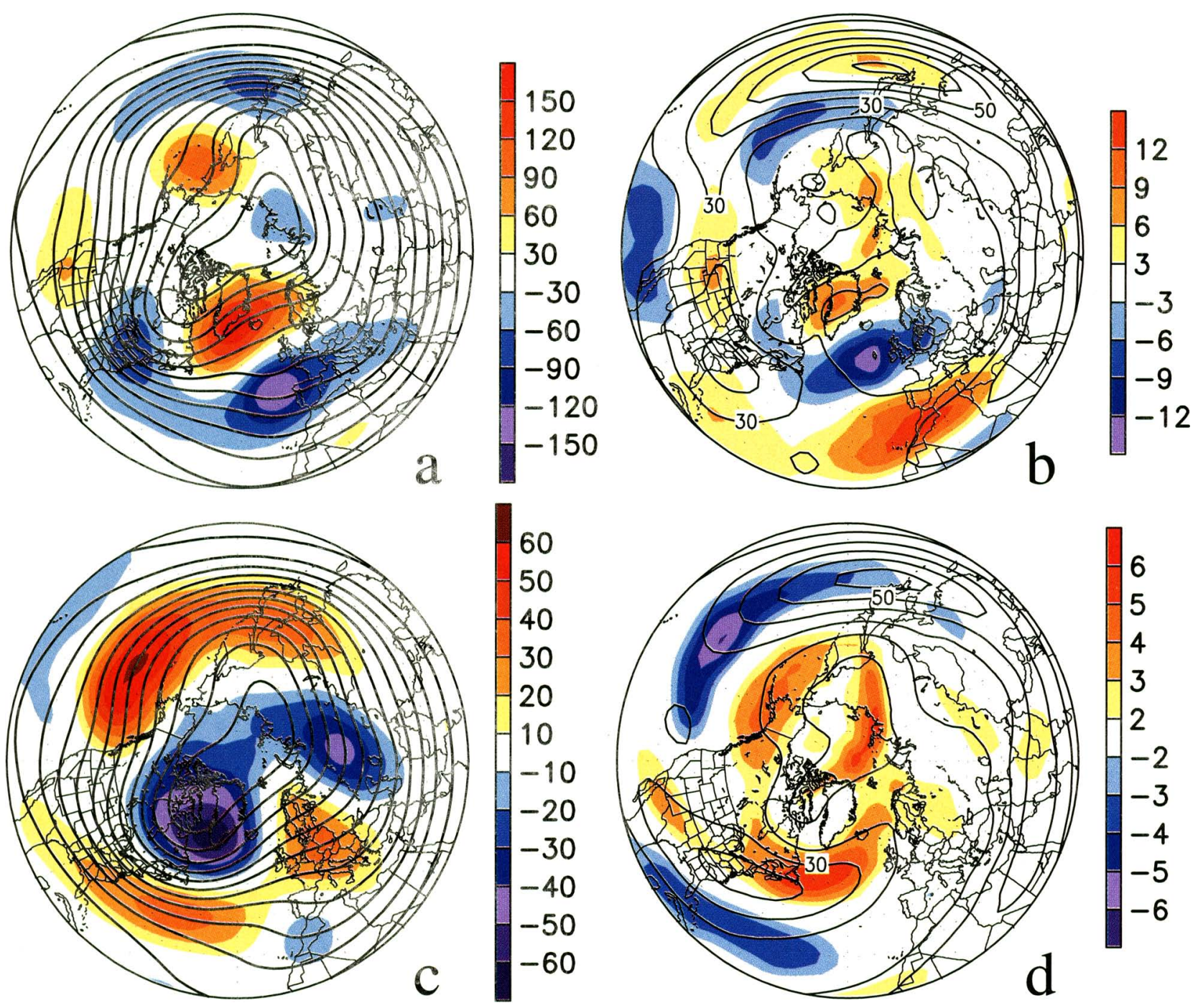

FIG. 32. 250-hPa height and anomaly (left) and 250-hPa zonal wind and anomaly (right) for (a), (b) NDJF 1995/96 and (c), (d) NDJF mean (1988/89-1994/95). Contour interval is $120 \mathrm{~m}$ for heights and $10 \mathrm{~m} \mathrm{~s}^{-1}$ for winds. Anomalies are departures from the $1979-95$ base period means.

across northern Europe and southern Scandinavia during the period.

This stands in strong contrast to the period from NDJF 1988/89 through NDJF 1994/95 (Figs. $32 \mathrm{c}, \mathrm{d}$ ), which was characterized by a prolonged positive phase of the NAO. During this 7-yr period the mean upper-level height field was dominated by below-normal heights throughout the high latitudes of the North Atlantic and by above-normal heights extending across the central latitudes of the North Atlantic from eastern North America to Europe (Fig. 32c). This anomaly pattern reflected an eastward shift toward the Labrador Sea of the mean Hudson Bay trough and a flattening of the mean ridge over the high latitudes of the central North
Atlantic. It also reflected a notable absence of blocking activity across the high latitudes of the North Atlantic. Accompanying these conditions was an enhanced North Atlantic jet stream, with a single jet core extending northeastward from the eastern United States to northern Europe and southern Scandinavia (Fig. 32d). During this period, significant poleward moisture transport (Fig. 33b) and heat flux (Fig. 34b) was evident, with the axis of maximum transport extending from the southwestern North Atlantic to Great Britain. The maximum values of heat transport over the North Atlantic averaged nearly double those observed during NDJF 1995/96. Farther south, transports were substantially reduced across the southeastern North Atlantic and 

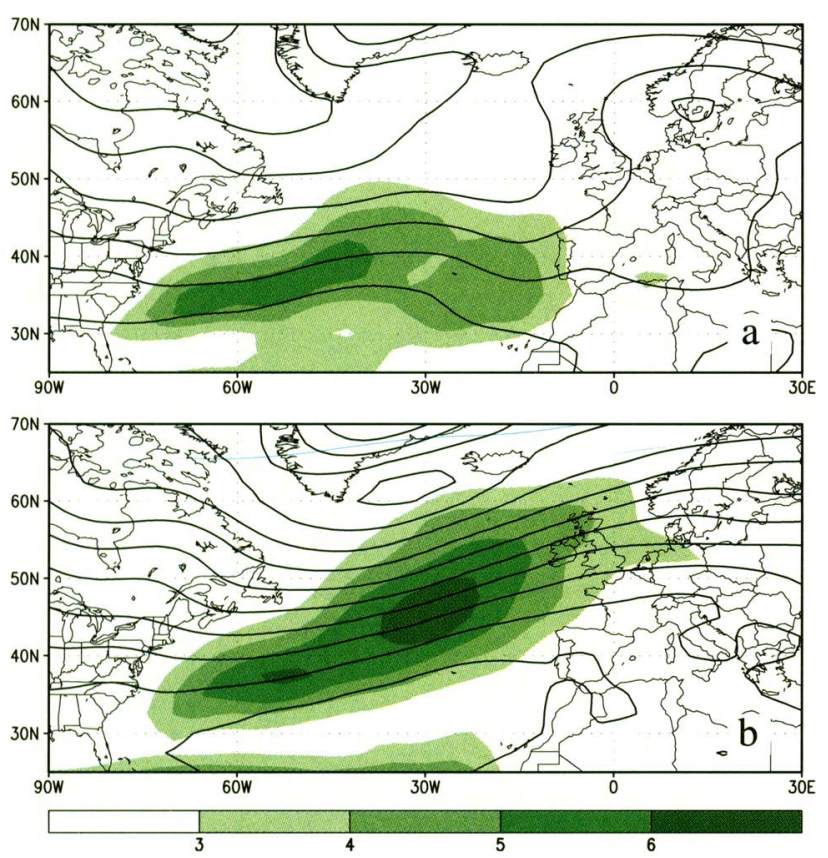

FIG. 33. 925-hPa mean moisture transport (shading, $\times 10^{-2} \mathrm{~m} \mathrm{~s}^{-1}$ ) and heights (contours, interval is $30 \mathrm{~m}$ ) for (a) NDJF 1995/96 and (b) NDJF mean (1988/89-1994/95).

southern Europe when compared to NDJF 1995/96.

These contrasting conditions contributed to substantial differences in the large-scale precipitation and surface temperature patterns across eastern North America, Europe, and western Russia between the two periods. Overall, northern Europe and Scandinavia were abnormally dry and cold during NDJF 1995/96 and abnormally wet and warm during NDJF 1988/89-1994/95 (Figs. 35, 36). In contrast, southern Europe and northwestern Africa were abnormally wet and warm during NDJF 1995/ 96 and abnormally dry during NDJF 1988/891994/95. These anomalous temperature and precipitation patterns are typical of the opposite phases of the NAO (van Loon and Rogers 1978).

Over North America, the anomalous height and wind patterns during NDJF 1995/96 reflected an intensification and southward extension of the climatological mean Hudson Bay trough, resulting in enhanced northwesterly geostrophic flow and an increased number of cold-air outbreaks into the northeastern and north-central United States and large parts of central Canada. Overall, below-normal surface temperatures were observed throughout the northeastern and north-central United States and large portions of central Canada during the period [see section $4 b(3)$ ].
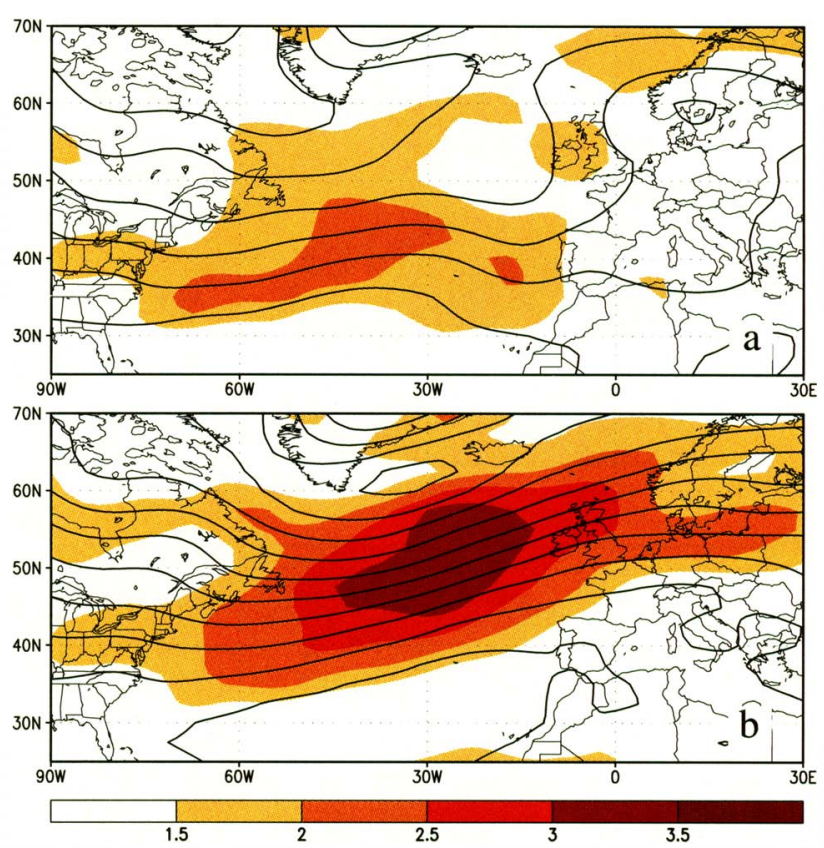

FIG. 34. 925-hPa mean temperature flux (shading, $\times 10^{3} \mathrm{~K} \mathrm{~m} \mathrm{~s}^{-1}$ ) and heights (contours, interval is $30 \mathrm{~m}$ ) for (a) NDJF 1995/96 and (b) NDJF mean (1988/89-1994/95).

\section{Regional climate highlights}

\section{a. Europe/northwestern Africa}

During NDJF 1995/96 the strong southern branch of the Atlantic jet stream brought enhanced storm activity and an enhanced flow of marine air into southern Europe and contributed to abnormally wet and warm conditions from Portugal and northern Morocco eastward to Turkey (Figs. 35b and 36a, respectively). Precipitation totals exceeded 250 $\mathrm{mm}$ above average in Portugal and extreme northwestern Morocco and ranged from 50-150 mm above average across Spain, southern France, and southern Italy (Fig. 35b). In Spain, this precipitation alleviated severe drought conditions that had plagued the region for the past several years. Locally, record annual totals were recorded in Gibraltar (1771 mm compared to a mean of 775 $\mathrm{mm}$ ), Malaga (1155 $\mathrm{mm}$ compared to a mean of $500 \mathrm{~mm})$, Casablanca (1168 mm compared to a mean of $523 \mathrm{~mm})$, and Essuaria $(830 \mathrm{~mm}$ compared to a mean of $297 \mathrm{~mm}$ ).

Temperatures during NDJF 1995/96 averaged $1^{\circ}-2^{\circ} \mathrm{C}$ above normal across southern Europe and northern Africa (Fig. 36a). Farther north, reduced storm activity and a reduced flow of marine air into northern Europe and southern Scandinavia contrib- 

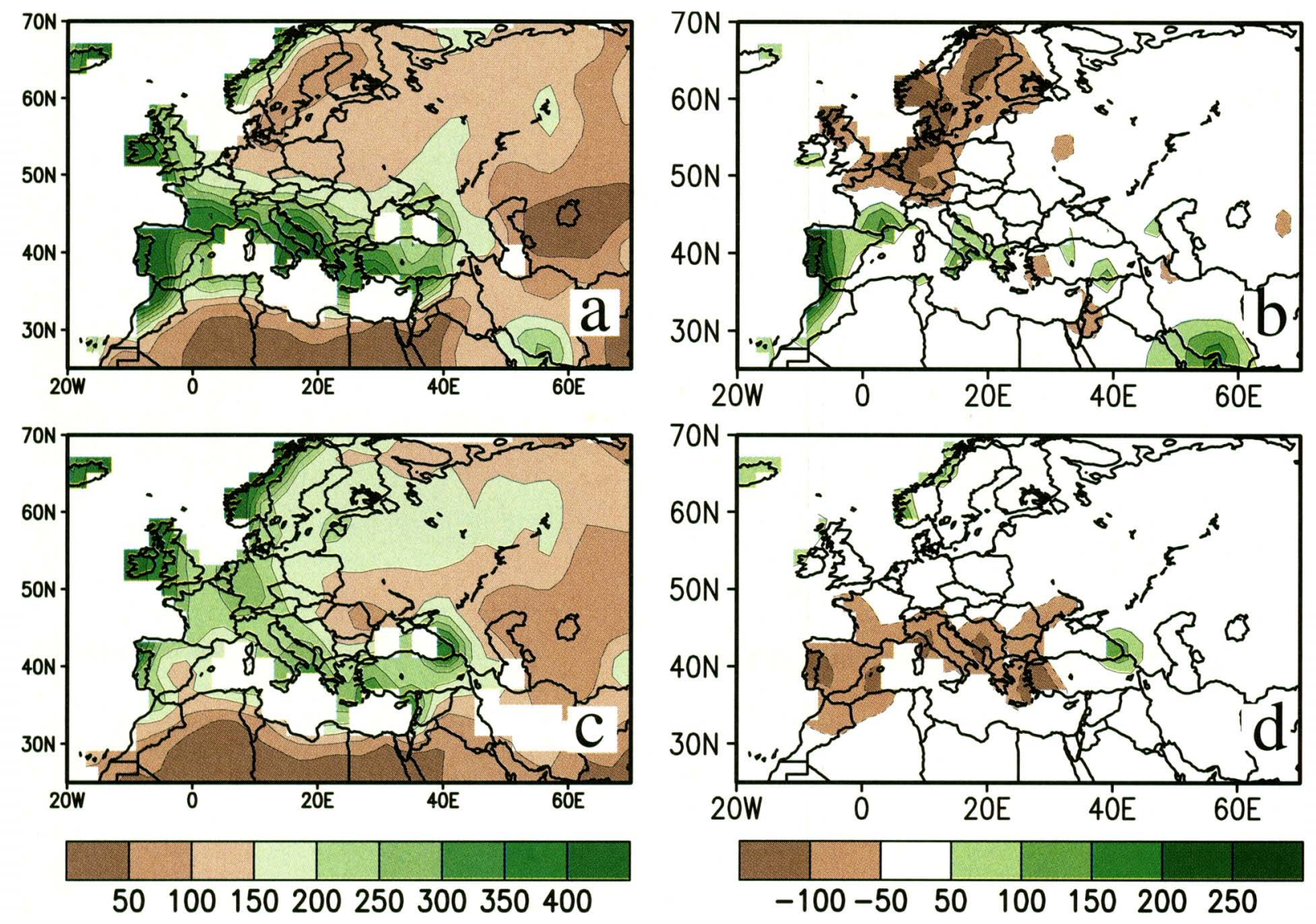

FIG. 35. (a),(b) Total precipitation and anomaly for NDJF 1995/96; (c),(d) average seasonal precipitation total and anomaly for NDJF 1988/89-1994/95. Anomalies are departures from the $1961-90$ base period means.

uted to the abnormally dry and colder than normal conditions. For the period as a whole, precipitation totals averaged $50-200 \mathrm{~mm}$ below average throughout northern Europe, northern Great Britain, and Scandinavia, while temperatures averaged $1^{\circ}-3^{\circ} \mathrm{C}$ below normal throughout northern Europe and western Russia. In Belgium, this dryness contributed to the lowest July 1995-July 1996 precipitation totals since regular observations started in 1833. For England and Wales, 1996 was the third driest year since records began in 1766 .

\section{b. North America}

1) NORTHWESTERN U.S. FLOODING

In general, the classic ingredients for wintertime flooding are a heavy snowpack over nearly saturated or frozen ground, followed by a rapid rise in temperature and heavy rain. The wet and warm weather contributes to significant snow melt, resulting in very large runoff that often leads to flood-

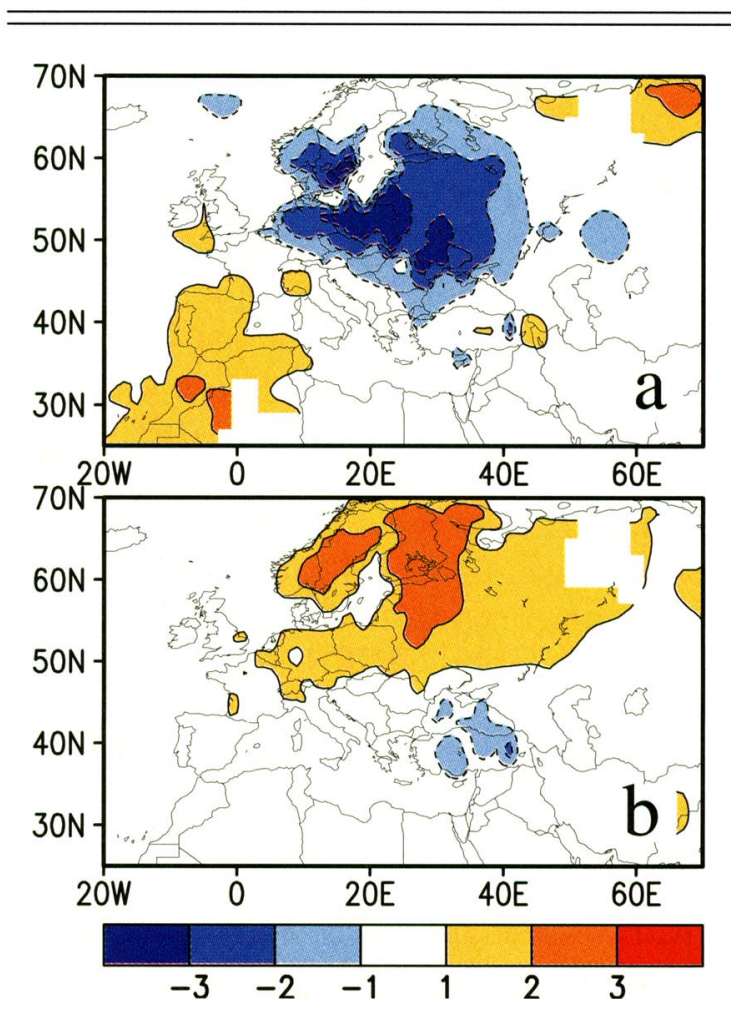

FIG. 36. Surface temperature anomaly for (a) NDJF 1995/96 and (b) NDJF mean (1988/89-1994/95). Anomalies are departures from the 1961-90 base period means. 
ing. Such conditions resulted in flooding of the Willamette and Columbia Rivers in the Northwest during February 1996 and also in large-scale flooding throughout the Pacific Northwest during December 1996. They also resulted in river flooding in the Northeast and mid-Atlantic states during midJanuary 1996 [section 4b(3)].

These first two flooding events occurred in association with a persistent and much larger pattern of above-normal precipitation in the Northwest and below-normal precipitation in the Southwest and central plains (Figs. 37a,b). This large-scale anomaly pattern is opposite to that which persisted during the first half of the 1990s. This interannual variability in precipitation can be linked to largescale changes in the atmospheric circulation resulting partly from the demise of warm-episode conditions in early 1995 and from the subsequent transition to cold-episode conditions by mid-1995 (see section 3a). This transition was accompanied by a pronounced poleward shift of the jet stream, storm track and abnormally heavy rainfall to the northwestern United States, approximately $18^{\circ}$ north of their mean position over the southwestern United States during the previous several winters (see Halpert et al. 1996, their Fig. 34).

\section{(i) 5-9 February 1996 flooding of the Willamette and Columbia Rivers}

Exceptionally heavy seasonal precipitation (125\%-175\% of the mean) dominated Washington, Oregon, Idaho, and northern California during DJF $1995 / 96$, with seasonal totals exceeding the gamma-based 80th percentile in the area of significant flooding in northwestern Oregon and southeastern Washington (Fig. 37a). The most significant flooding event of this rainy period occurred during 5-9 February 1996 when significant rain fell at all but the highest elevations. During this 5-day period rainfall totals exceeded $100 \mathrm{~mm}$ throughout the region and averaged $250-400 \mathrm{~mm}$ at many locations (Fig. 38a).
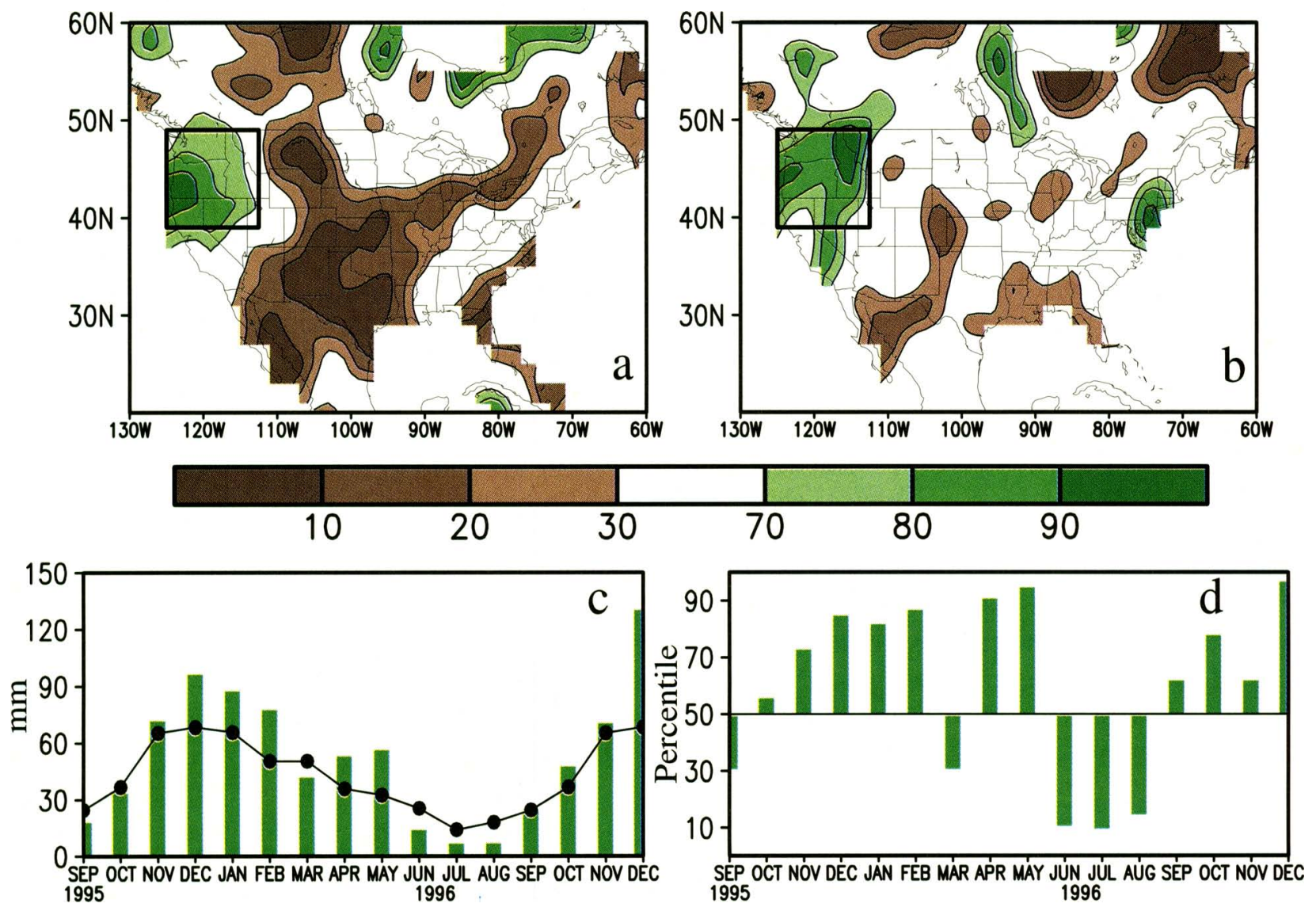

FIG. 37. Precipitation percentiles based on a gamma distribution fit to the 1961-90 base period for (a) December 1995-February 1996 and (b) October-December 1996. In (c) monthly total precipitation (mm, bars) and the 1961-90 monthly mean (mm, line) is shown, averaged over the boxed region depicted in $(a, b)$. Precipitation percentiles for the same months and region are shown in $(d)$. 

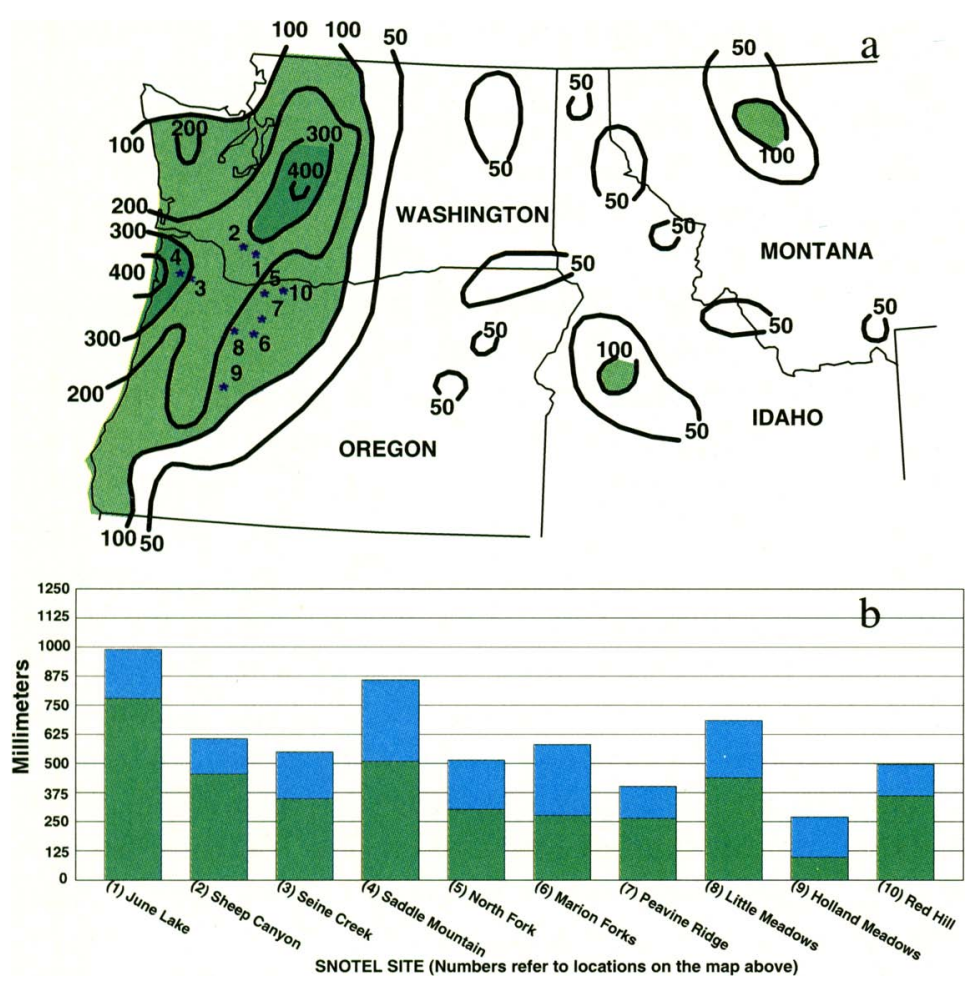

FIG. 38. (a) Total precipitation (mm) for 5-9 February 1996 and (b) total precipitation ( $\mathrm{mm}$, green bars) + snow water equivalent melt ( $\mathrm{mm}$, blue bars) for 5-9 February 1996 for selected SNOTEL sites. (SNOTEL data were obtained from the Western Regional Climate Center, Reno, NV, and the Water and Climate Center of the Natural Resources Conservation Service, Portland, Oregon.)

During these floods, most locations along the Willamette River reported river levels 3.3-5.7 $\mathrm{m}$ above flood stage (the highest since 1964 at most locations), with the largest departure from flood stage occurring near Oregon City. In addition, the Columbia River crested approximately $2.5-4.7 \mathrm{~m}$ above flood stage between Longview and Vancouver, Washington. As a result of these floods, approximately 60 counties in Oregon, Washington, Idaho, and Montana were declared federal disaster areas.

\section{(ii) Late-December 1996 flooding in the Northwest}

Primary contributors to the northwestern U. S. flooding in late-1996 were saturated soils and well above normal snowpack and snowpack water content throughout the region, which resulted from above-normal precipitation during October-December (Figs. 37b-d). Precipitation for the period exceeded $150 \%$ of the mean throughout the Northwest, with the heaviest monthly mean precipitation occurring in December when areaaveraged totals reached twice the mean

The atmospheric circulation during 5-9 February was characterized by a large-amplitude trough extending southward from western Alaska and a large-amplitude ridge centered over the intermountain region of the western United States (Fig. 39a). This pattern was accompanied by very strong southwesterly flow extending from the region north of Hawaii to the Pacific Northwest throughout the depth of the troposphere (Figs. 39b,c). This strong subtropical connection brought abundant moisture (Fig. 39c), excessive rainfall, and a very rapid temperature rise to the Northwest. These conditions also caused a rapid snowmelt (in excess of $1250 \mathrm{~mm}$ over a few days), resulting in a liquid water (rainfall plus snow melt) runoff of more than $500 \mathrm{~mm}$ in many areas, more than $975 \mathrm{~mm}$ at June Lake in southern Washington, and more than $850 \mathrm{~mm}$ at Saddle Mountain in northwestern Oregon (Fig. 38b). Runoff, combined with nearly saturated soil conditions from more than 3 months of above-normal precipitation, resulted in severe flooding west of the Cascade Mountains, particularly along the Willamette and Columbia Rivers. and exceeded the gamma-based 95th percentile throughout the region (Fig. 37d). Overall, many areas in the Pacific Northwest, northern California, and the Sierra Nevada received more than $1000 \mathrm{~mm}$ of precipitation during October-December (Fig. 40), with some orographically favored areas recording in excess of $1500 \mathrm{~mm}$. In addition, large portions of coastal central California received more than $750 \mathrm{~mm}$ of rain during the period, while large portions of Idaho, eastern Washington, and eastern Oregon received 300-600 mm of precipitation.

Most of the precipitation fell during two distinct periods in November and December. The first period lasted from 16 November to 13 December (Fig. 40a), which culminated in localized flooding in mid-December. During this period, much of western Oregon and large portions of the Sierra Nevada received precipitation exceeding $600 \mathrm{~mm}$, while more than $200 \mathrm{~mm}$ were recorded throughout the rest of western Oregon, western Washington, and coastal northern and central California. By 13 December, 6-week precipitation totals were 125-400 $\mathrm{mm}$ above the mean in parts of the northern Sierra 

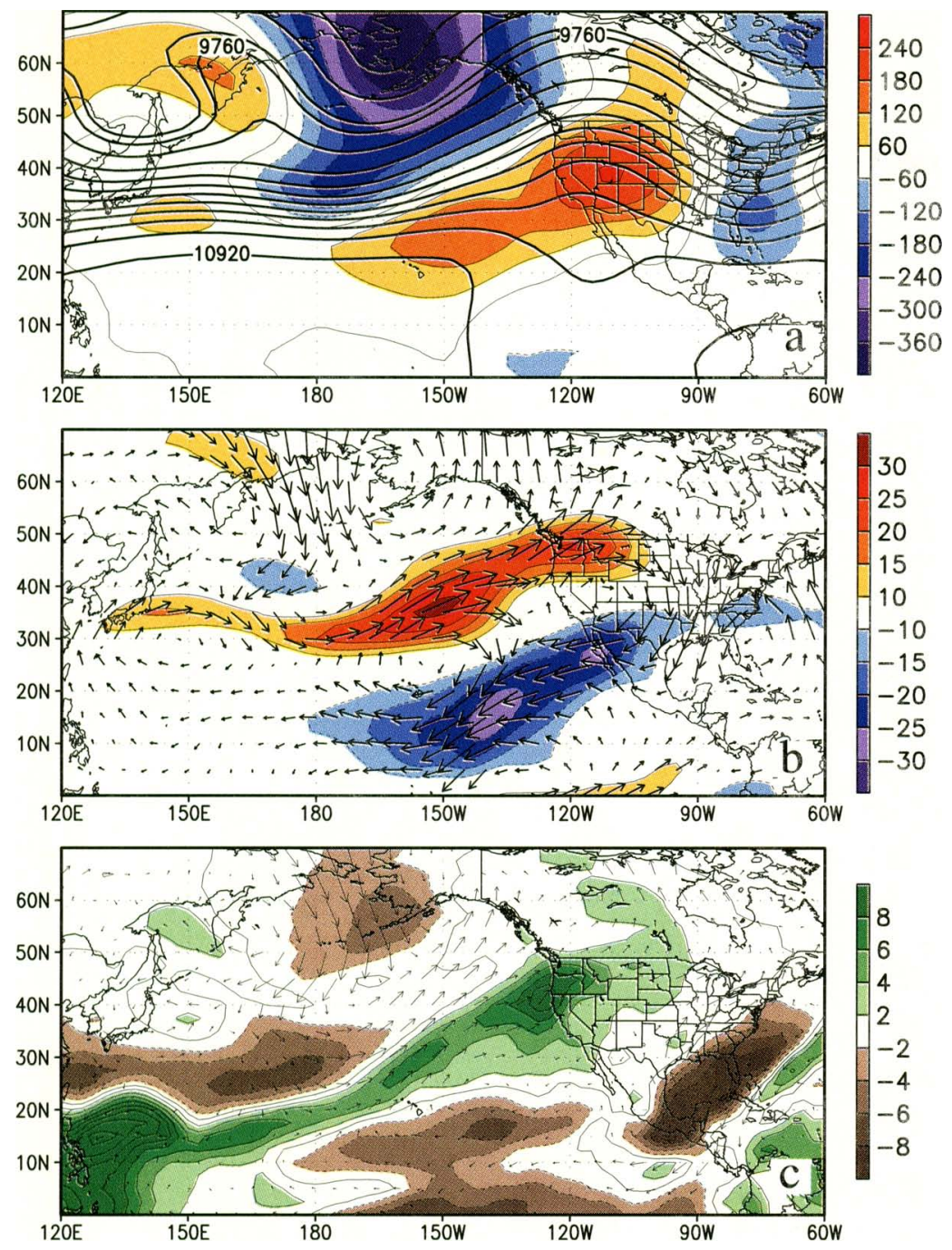

FIG. 39. Analyses for 5-9 February 1996: (a) 250-hPa heights (solid contours, interval is $120 \mathrm{~m}$ ) and anomalies (shading); (b) 250-hPa zonal wind anomalies (shading, $\mathrm{m} \mathrm{s}^{-1}$ ) and vector wind anomalies; and (c) precipitable water anomalies (shading, $\mathrm{mm}$ ) and $925-\mathrm{hPa}$ vector wind anomalies. Anomalies are departures from the 1979-95 base period means.

Nevada, western Oregon, and portions of northwestern Washington.

Over the next 10 days (14-23 December), cooler and drier conditions dominated the Northwest, with the heaviest precipitation $(50-100 \mathrm{~mm})$ falling primarily as snow across western Washington, western Oregon, and northern and eastern California (Fig. 40b). This period was followed by a rapid increase in temperature and a return to excessive precipitation during the next 10 days (24 December 1996-2 January 1997), with $450-825 \mathrm{~mm}$ of precipitation falling on orographically-favored areas and more than $150 \mathrm{~mm}$ falling elsewhere throughout the affected region (Fig. 40c). Due to the ex- tremely warm weather during the period, much of this precipitation fell as rain. This wet and warm weather produced significant snow melt at lower and middle elevations, resulting in severe flooding throughout the Northwest and the higher elevations in California. During this period, the liquid water runoff (rainfall plus snowmelt) exceeded $300 \mathrm{~mm}$ in many areas (Fig. 41) and reached a maximum of 580 $\mathrm{mm}$ in Squaw Valley, California.

The circulation features during the three periods are shown in Fig. 42. The first heavy precipitation period was characterized by below-normal heights at upper levels of the troposphere over southwestern Canada (Fig. 42a) and jet stream winds (not shown) averaging $10-15 \mathrm{~m} \mathrm{~s}^{-1}$ stronger than normal across Oregon, northern California, and southern Idaho. At low levels, abnormally strong southwesterly flow covered the western United States during the period, bringing a series of major storms with abundant moisture into the western United States.

The subsequent transition to cooler and drier conditions during the 10day period ending 23 December resulted from the development of strong northwesterly flow at upper levels throughout the northwestern United States (Fig. 42b) and a concurrent drop to below-normal moisture levels throughout the region. This evolution occurred in association with the onset of strong ridging across the high latitudes of the North Pacific and North Atlantic Ocean basins and with the formation of an abnormally deep trough of low pressure across central North America (Fig. 42b).

During the 10-day period ending 2 January 1997, a well-defined blocking pattern became established over the central and eastern North Pacific (Fig. 42c). This pattern featured a very strong lowlatitude jet stream flow (20-30 $\mathrm{m} \mathrm{s}^{-1}$ above normal) south of the mean ridge in the vicinity of Hawaii (Fig. 43a) and enhanced southwesterly flow extending from the subtropical North Pacific to the northwestern United States. This flow directed a se- 


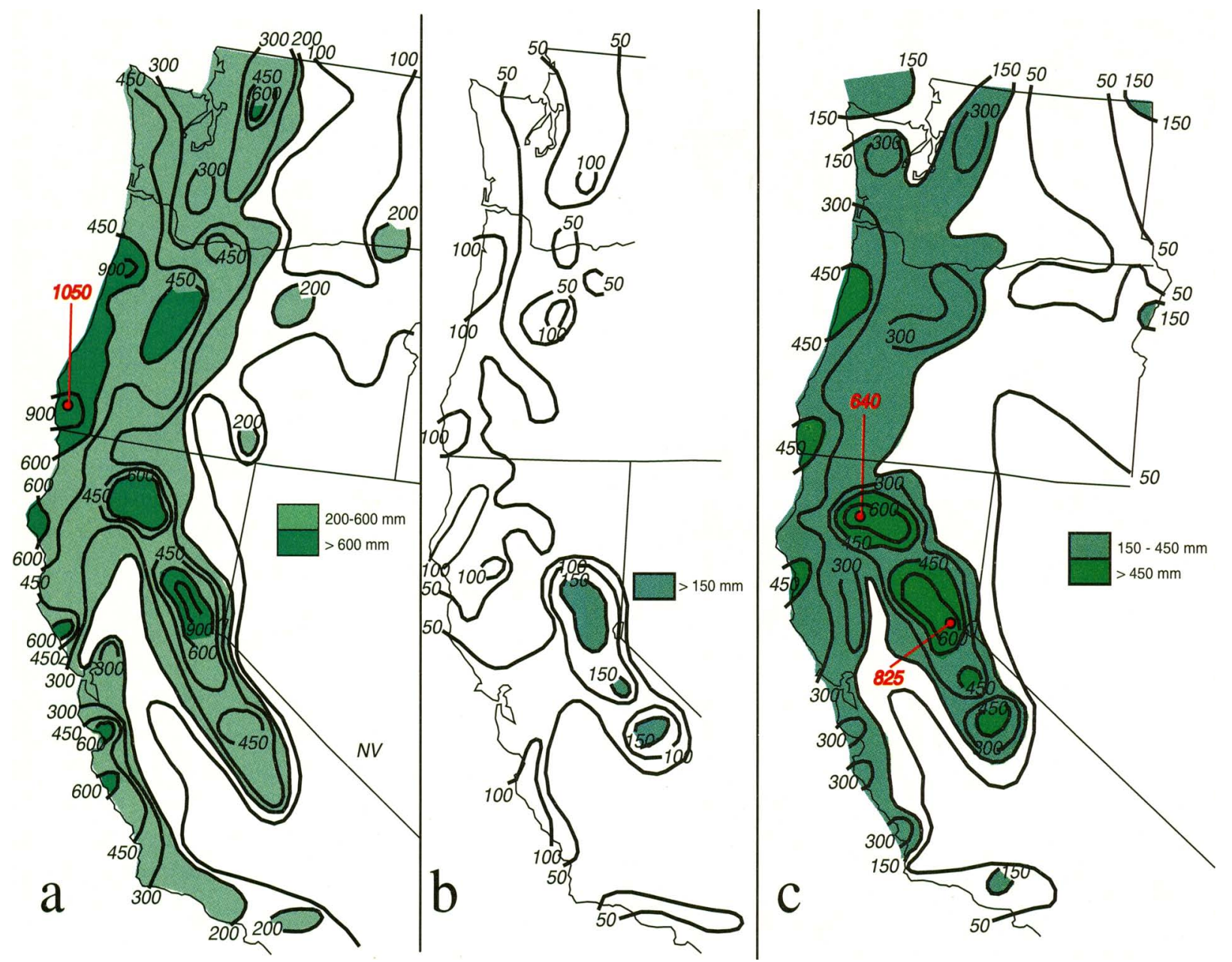

FIG. 40. Total precipitation (mm) for (a) 16 November-13 December 1996, (b) 14-23 December 1996, and (c) 24 December 19962 January 1997. Contours in (a) are drawn at 100, 200, 450, 600, and $900 \mathrm{~mm}$, in (b) at 50, 100, and 150 mm, and in (c) 50, 150, 300, 450 , and $600 \mathrm{~mm}$.
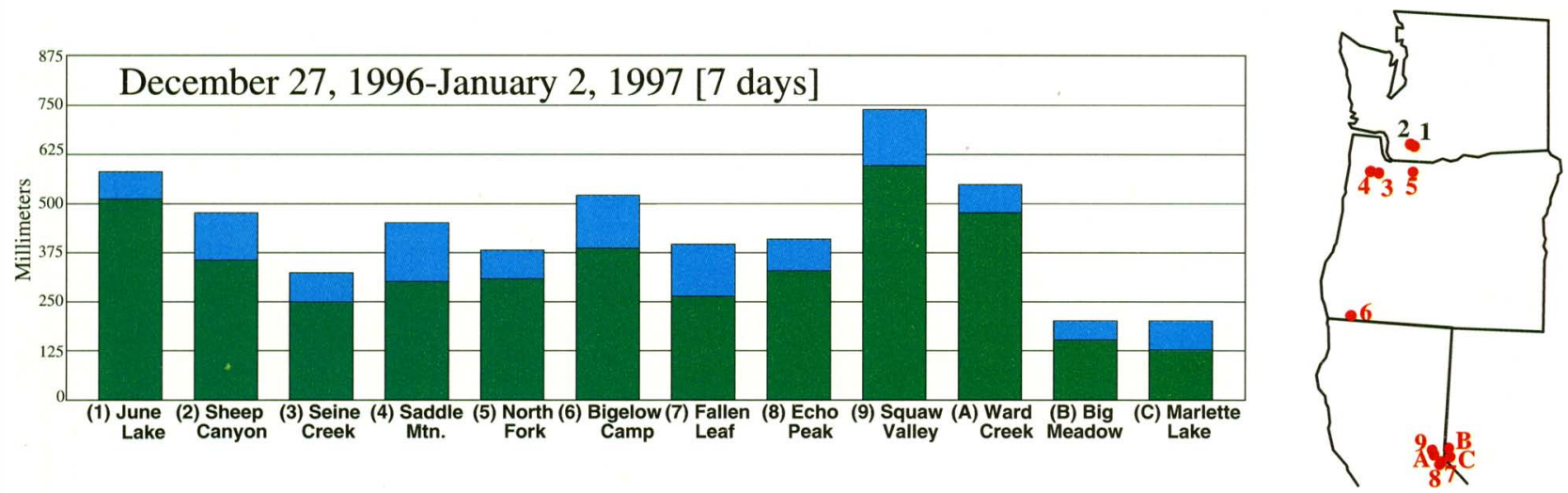

FIG. 41. Total precipitation (mm, green bars) + snow water equivalent melt (mm, blue bars) for 27 December 1996-2 January 1997 for selected SNOTEL sites. (SNOTEL data were obtained from the Western Regional Climate Center, Reno, NV, and the Water and Climate Center of the Natural Resources Conservations Service, Portland, Oregon.)

ries of major storms, with very warm air and significant moisture from the deep subtropics, well into the western United States (Fig. 43b). The pattern also featured a strong trough over western Canada (Fig. 42c), which contributed to abnormally strong northerly flow over the eastern Gulf of Alaska. This 
16 November-13 December 1996

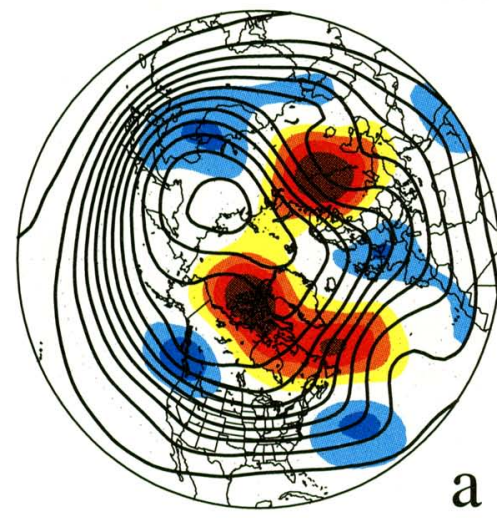

14-23 December 1996

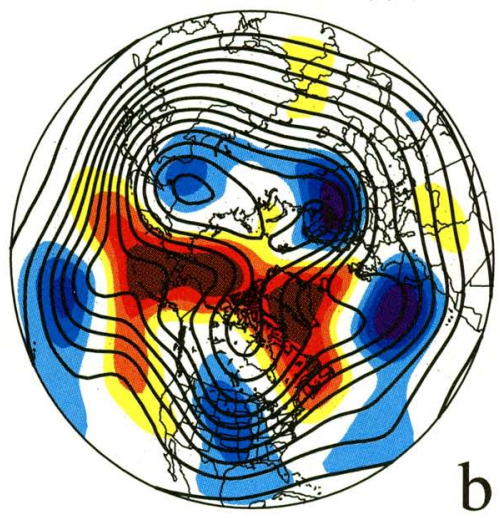

24 December 1996-2 January 1997

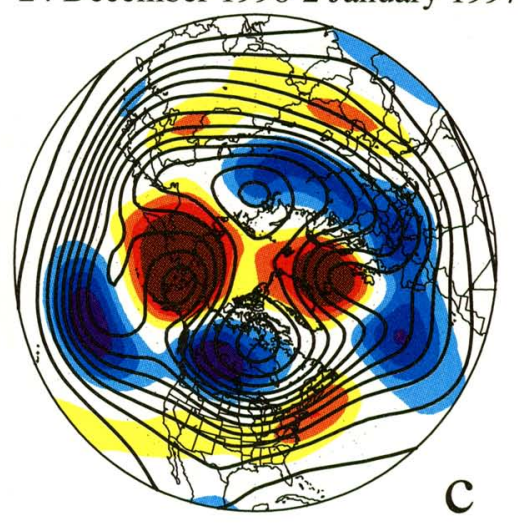

$\mathrm{c}$

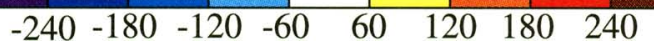

FIG. 42. 250-hPa heights (solid contours, interval is $120 \mathrm{~m}$ ) and anomalies (shading) for (a) 16 November-13 December 1996, (b) 1423 December 1996, and (c) 24 December 1996-2 January 1997. Anomalies are departures from the 1979-95 base period means.
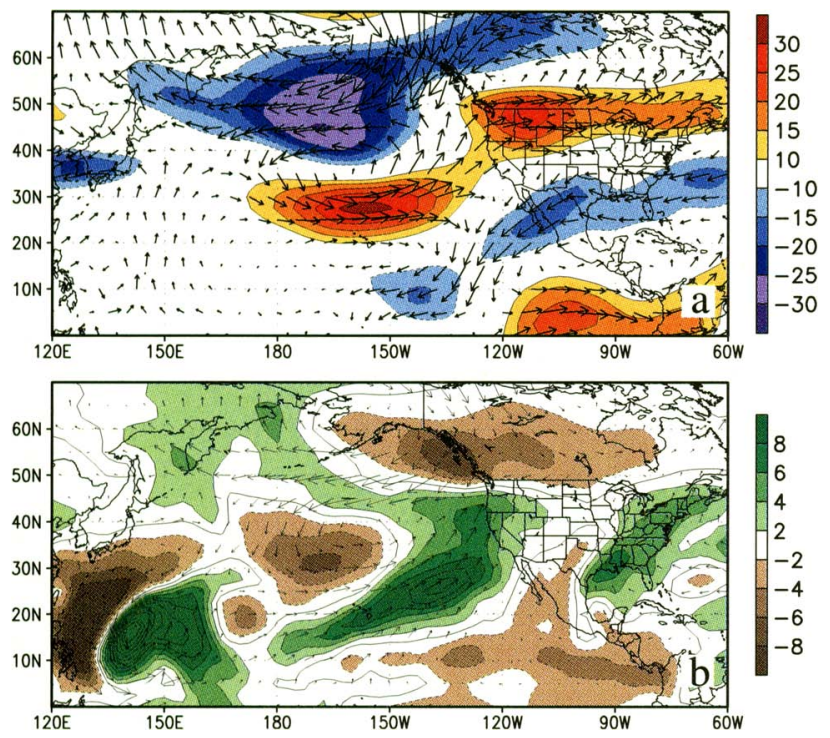

FIG. 43. Analyses for 24 December 1996-2 January 1997: (a) 250-hPa zonal wind anomalies (shading, $\mathrm{m} \mathrm{s}^{-1}$ ) and vector wind anomalies, and (b) precipitable water anomalies (shading, $\mathrm{mm}$ ) and 925-hPa vector wind anomalies. Anomalies are departures from the $1979-95$ base period means.

feature combined with the enhanced subtropical flow to produce very strong frontal systems and enhanced frontal-type precipitation, further increasing precipitation totals throughout the Northwest.

The above analysis indicates that heavy precipitation observed in the Northwest during November and December resulted from two essentially distinct flow patterns, each of which brought major storms and moisture from the subtropics into the region. The first was a more east-to-west-oriented pattern of abnormally strong jet stream winds across the Northwest, which directed a series of major storms through the region. The second pattern featured a strongly blocked flow at high latitudes of the North Pacific Ocean and an amplified lowlatitude flow throughout the depth of the troposphere, which emanated from the subtropical North Pacific and extended directly into the northwestern United States.

The variability in the atmospheric circulation over the eastern North Pacific Ocean and the northwestern United States during November and December was likely related in part to intense MJOs across the western tropical Pacific (see section $3 b$ ). For example, satellite imagery confirmed that the strong southwesterly flow of warm, moist air into the Northwest in late December actually extended westward to the western tropical Pacific and emanated from the region of enhanced tropical convection associated with the MJO.

\section{2) October 1995-MAy 1996 dRought:}

SOUTHWESTERN AND SOUTHERN PLAINS STATES AND NORTHERN MEXICO

Climatologically, precipitation is rather low over the southwestern United States during OctoberMay, with totals averaging only $80-160 \mathrm{~mm}$ in most areas (Fig. 44a). Mean totals increase farther east to more than $400 \mathrm{~mm}$ across the eastern half of Texas, the eastern half of Oklahoma, and southeastern Kansas. Nonetheless, drought began to develop across the southwestern United States, the southern plains states, and northern Mexico dur- 

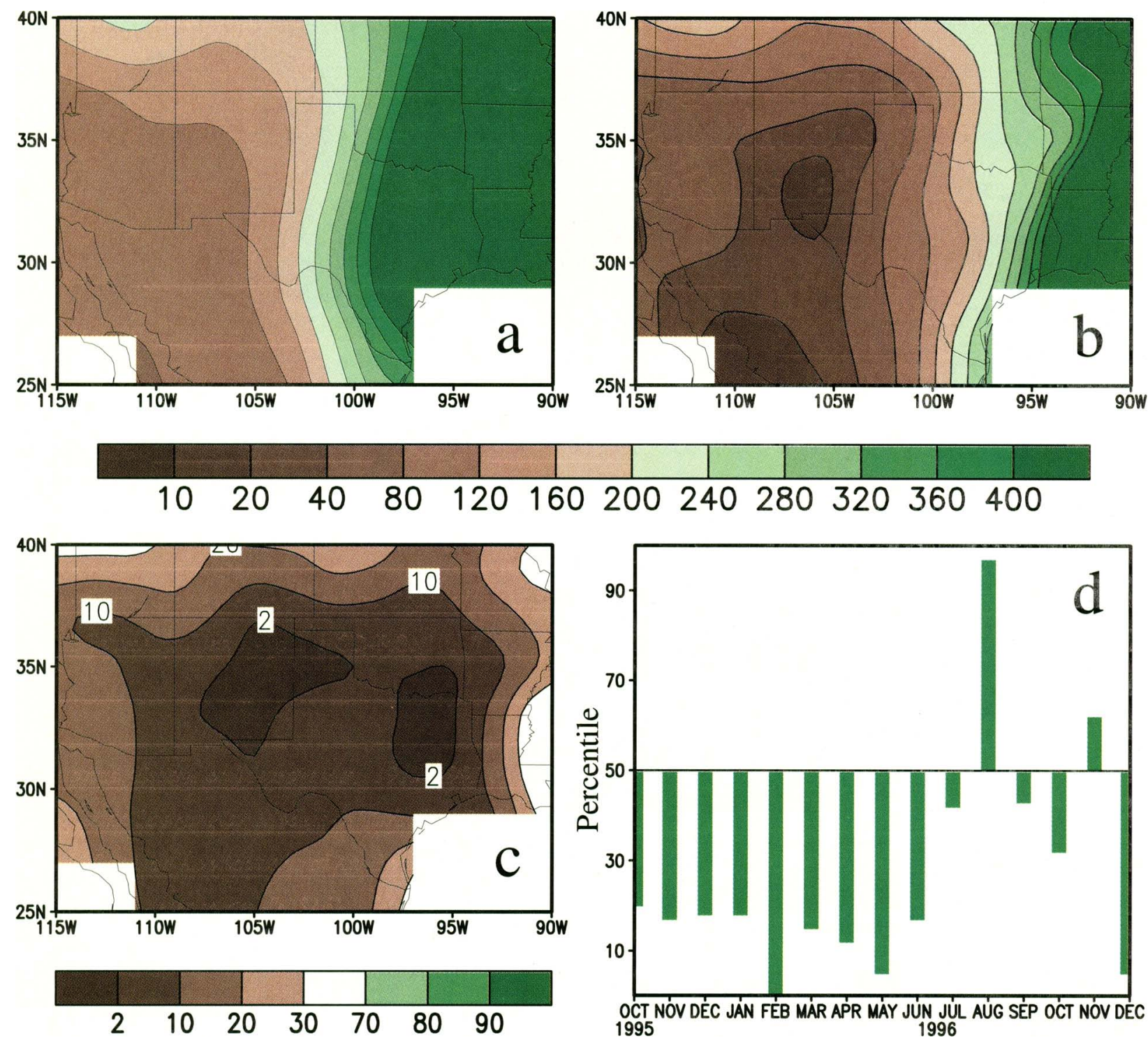

FIG. 44. October-May precipitation totals for the (a) 1961-90 base period and (b) 1995-96. (c) October 1995-May 1996 precipitation percentiles based on a gamma distribution fit to the 1961-90 base period October-May means and (d) a monthly time series of precipitation percentiles, based on precipitation totals averaged over the entire region shown in (a)-(c).

ing October 1995 and by May 1996 had severely affected Arizona, Kansas, New Mexico, Oklahoma, and Texas. Overall, the drought resulted in a substantial deterioration of many of the region's crops and pastures, destroying nearly the entire unirrigated winter wheat crop in New Mexico and rendering 90\% of the state's sorghum crop in poor or very poor condition. Fortunately, the impact of the drought on reservoirs, lakes, and rivers was relatively minor. However, notable exceptions were the Rio Grande River and its reservoirs, and water supplies and stream flows across northern Mexico, all of which reached record or near-record low levels during the period.
For the region as a whole, precipitation averaged below the 30th percentile in each of the 9 months from October 1995 through June 1996 (Fig. 44d). Exceptionally scant totals of less than $25 \mathrm{~mm}$ were observed across southwestern Texas, the southern half of New Mexico, and western Mexico, with portions of south-central New Mexico and northern Mexico receiving less than $10 \mathrm{~mm}$ total precipitation during the period (Fig. 44b). Farther east, October-May totals were less than the 10th percentile over most of the region (Figs. 44c). Oklahoma recorded its driest October-May period on record dating to 1895, while Texas and Arizona reported 
TABLE 1. Rankings of statewide-average precipitation for the October 1995-May 1996 period based on data beginning in January 1895. Rankings are calculated from hundreds of first-order stations and thousands of River Forecast Center station reports. Rankings are from driest to wettest, such that " 1 " means the driest such period on record for the state, and " 102 " represents the wettest such period on record. Bold values indicate a ranking in the lowest one-third of the record. (Data provided by the National Climate Data Center.)

\begin{tabular}{lrrrrrrrrr}
\hline \hline State & OCT & NOV & DEC & JAN & FEB & MAR & APR & MAY & OCT-MAY \\
\hline Arizona & $\mathbf{8}$ & 45 & 21 & 7 & 66 & 21 & 9 & 37 & 2 \\
Kansas & $\mathbf{3}$ & $\mathbf{2 2}$ & 49 & 44 & 7 & 35 & 15 & 83 & 7 \\
New Mexico & $\mathbf{3}$ & $\mathbf{3 2}$ & 37 & 29 & 41 & 16 & 51 & 24 & 5 \\
Oklahoma & $\mathbf{1 5}$ & $\mathbf{1 5}$ & $\mathbf{7}$ & $\mathbf{3 3}$ & $\mathbf{1}$ & 36 & 19 & $\mathbf{1 9}$ & $\mathbf{1}$ \\
Texas & $\mathbf{1 8}$ & 45 & 45 & $\mathbf{9}$ & $\mathbf{2}$ & $\mathbf{1 5}$ & $\mathbf{2 8}$ & $\mathbf{7}$ & $\mathbf{2}$ \\
\hline
\end{tabular}

their second driest such period (Table 1). In fact, there were only two monthly, statewide precipitation rankings in the drought region that were above median during this period: Arizona during February and Kansas during May.

The drought in the Southwest was aggravated by above-normal temperatures, very low humidity, and frequently windy conditions. Temperatures averaged more than $2.0^{\circ} \mathrm{C}$ above normal throughout New Mexico and western Arizona during the period (Fig. 45) and $1.0^{\circ}-2.0^{\circ} \mathrm{C}$ above normal elsewhere in the Southwest.

Drought conditions evolved somewhat differently in various parts of the affected region. For example, exceptionally little precipitation was recorded during the entire October 1995-May 1996 period from the southwestern high plains westward across the Southwest and northern Mexico. In the northwestern quarter of Texas and much of Oklahoma, well below normal October through midMarch precipitation was measured, but amounts increased thereafter. In late April, the first significant precipitation in months fell in west-central Texas, and during the latter half of May widespread light to moderate rains fell on most of central and northeastern Texas and much of Oklahoma. However, this rainfall was only near or slightly below normal for the period and failed to alleviate drought conditions in these regions.

Farther south across southern and eastern Texas, moderate to heavy precipitation $(200-350 \mathrm{~mm})$ fell during October-December 1995, but exceptionally low totals were subsequently reported during January-May 1996. In fact, the state of Texas as a whole reported its driest such January-May period on record, with Brownsville, Texas, measuring only $20 \mathrm{~mm}$ of precipitation during the period.

The drought finally began to abate in New Mexico and portions of northwestern Mexico during June, as precipitation totals reached the 60th and 70th percentiles across the region (Fig. 46a). The heaviest and most widespread rains since September 1995 fell across New Mexico and adjacent areas during 11-16 June, with between 12.5 and $30 \mathrm{~mm}$ falling on most of the eastern half of the state and $50-90 \mathrm{~mm}$ falling on portions of east-central New Mexico.

Subsequently, above-normal rainfall developed across the Texas panhandle and the Baja peninsula

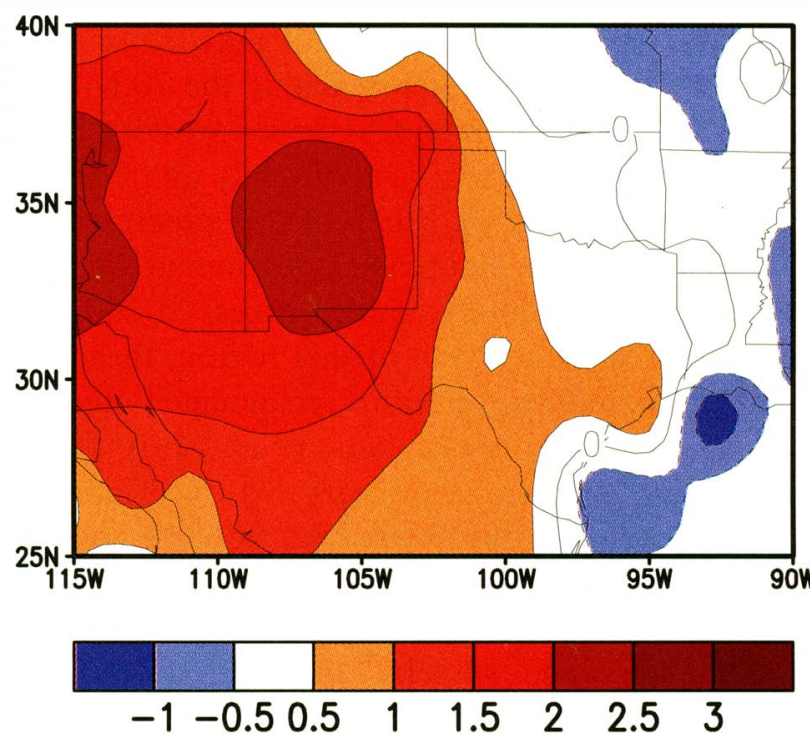

FIG. 45. Temperature anomalies $\left({ }^{\circ} \mathrm{C}\right)$ during October 1995-May 1996. Anomalies are departures from the 1961-90 base period means. 

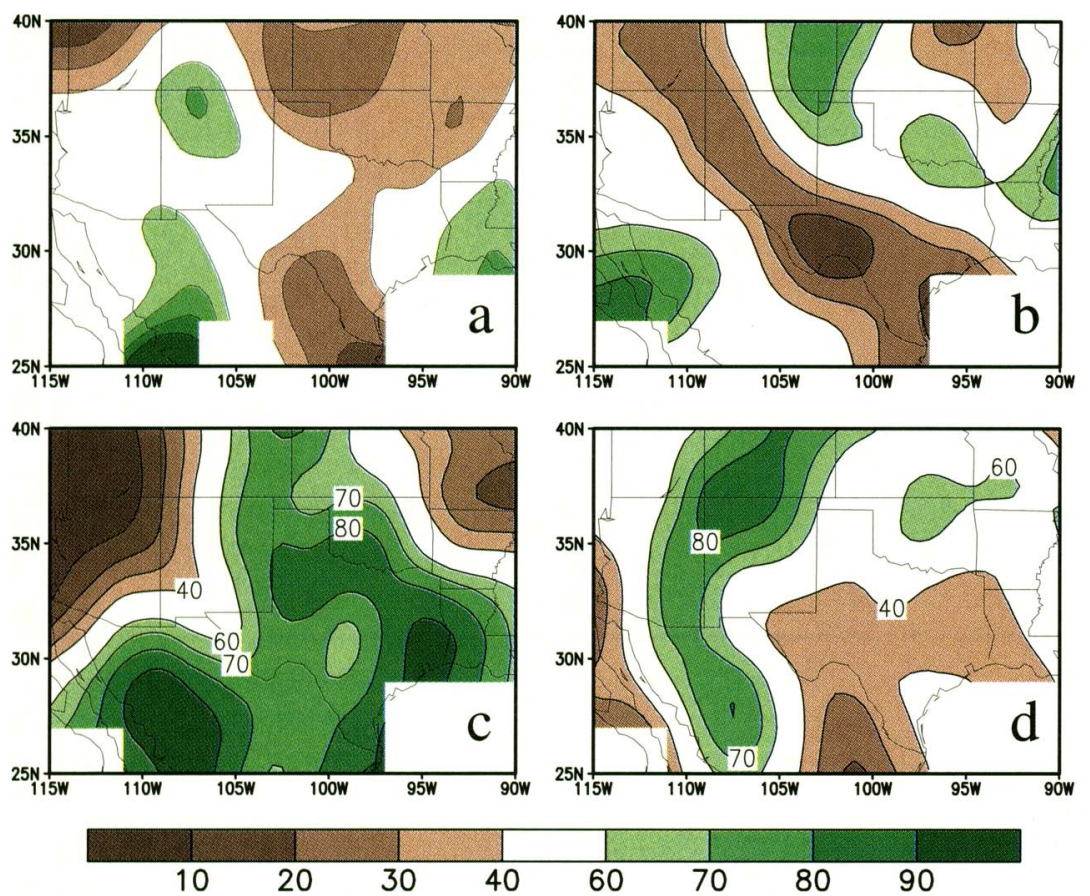

FIG. 46. Monthly precipitation percentiles for (a) June, (b) July, (c) August, and (d) September 1996. Percentiles are based on a gamma distribution fit to the 1961-90 base period means.

during July (Fig. 46b), with near-normal rainfall persisting across New Mexico. By mid-July, the accumulated October 1995-May 1996 precipitation deficit had been completely eliminated in parts of New Mexico and was halved in northern Texas and portions of western Oklahoma. Elsewhere, widespread relief from the drought came in August and September (Fig. 46c,d), with August precipitation totals exceeding the 90th percentile over much of eastern Texas and reaching the 70th-80th percentiles across western Oklahoma, western Kansas, eastern New Mexico, and virtually all of northern Mexico (Fig. 46c). Much of this precipitation was associated with Hurricane Dolly in mid-August, which produced rainfall totals in excess of $200 \mathrm{~mm}$ in many areas. For much of this region, these totals were more than the entire accumulated precipitation observed between January and July 1996. During September, the primary region of abovenormal rainfall shifted westward to northwestern Mexico, western New Mexico, and eastern Arizona, and continued over large portions of western Oklahoma and western Kansas (Fig. 46d).

The drought was but one manifestation of an extremely persistent planetary-scale circulation pattern that extended from the North Pacific across North America to eastern Europe during October
1995-May 1996 (Fig. 47). This pattern featured above-normal heights over the high latitudes of the North Pacific and throughout the southwestern United States, and below-normal heights across the central latitudes of the North Pacific, throughout Canada, and across the eastern United States (Fig. 47).

Over the North Pacific, these anomalies reflected significant blocking activity at high latitudes, along with enhanced westerlies across the central latitudes. The enhanced Pacific jet stream extended into the northwestern United States, where mean southwesterly and westerly wind speeds at upper levels averaged more than $6 \mathrm{~m} \mathrm{~s}^{-1}$ above normal (Fig. 47). This flow pattern directed the mean storm track into the Pacific Northwest, resulting in reduced storm activity, frontal activ-
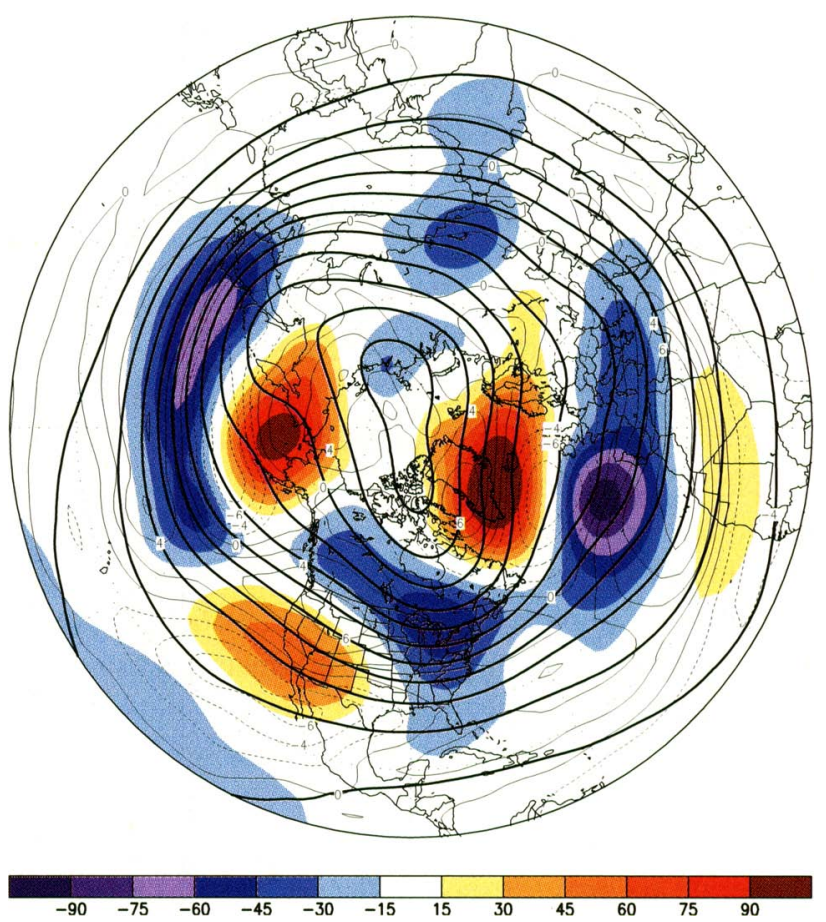

FIG. 47. 250-hPa mean heights (thick solid contours, interval is $120 \mathrm{~m}$ ), height anomalies (shading), and wind speed anomalies (thin contours, interval is $2.0 \mathrm{~m} \mathrm{~s}^{-1}$ ) for October 1995-May 1996. Anomalies are departures from the 1979-95 base period means. 
ity, and precipitation across the Southwest throughout the 8-month period. Also, one expects descending motion between the ridge and downstream trough axes in a typical midlatitude wave and ascending motion between the trough and downstream ridge axes. During October-May 1995/96, the entire drought region was centered between the large-scale mean ridge and trough axes, in a region of enhanced, descending motion and reduced precipitation.

An apparent phase-locking of two prominent climate factors provides a partial explanation for the extreme duration of the planetary-scale circulation pattern observed during the drought. These factors are 1) cold-episode conditions in the tropical $\mathrm{Pa}$ cific and 2) an extremely persistent negative phase of the North Atlantic oscillation. Mature-phase cold-episode conditions favor an enhanced upperlevel ridge over the high latitudes of the North $\mathrm{Pa}$ cific and over the eastern North Pacific/southwestern United States and, thus, a northward displacement of the jet stream and storm track over the western United States (Livezey et al. 1997). These conditions favor below- (above-) normal precipitation across the Southwest (Pacific Northwest), consistent with that observed during October-May 1995/96. Farther east, below-normal heights are favored across Canada and the northern tier of the United States during cold-episode conditions (Livezey et al. 1997), reflecting an overall amplification of the climatological-mean Hudson Bay trough.

A strong and persistent negative phase of the NAO also reflects an amplification of the mean Hudson Bay trough, as well as a southward extension of the trough into the east-central United States (Figs. 32a, 47). Thus, it appears that the circulation features associated with both the Pacific cold episode and the negative phase of the NAO tended to reinforce each other over eastern North America during the October-May period, resulting in the extremely persistent and coherent planetary-scale circulation pattern that extended from the central North Pacific eastward to southern Europe. In addition to the drought in the Southwest and southern plains states, other manifestations of this persistent pattern included 1) above-normal precipitation in the northwestern United States during November 1995-February 1996 [see section 4b(1)], 2) an abnormally cold and snowy winter across the Great Lakes region and the northeastern United
States [see section 4b(3)], and 3) anomalous temperature and precipitation patterns throughout $\mathrm{Eu}-$ rope (see section $4 \mathrm{a})$.

\section{3) WINTER $1995 / 96$}

The 1995/96 winter (DJF) season featured abnormally cold and snowy conditions in the northern plains, the eastern half of the Midwest, the Northeast, the mid-Atlantic states, and much of Canada. For the season as whole, temperatures averaged $3^{\circ}-5^{\circ} \mathrm{C}$ below normal across western and central Canada, and $1^{\circ}-2^{\circ} \mathrm{C}$ below normal across the northern tier of the United States and throughout the eastern seaboard from Florida to New England (see section 5, Fig. 59a). In the East, these conditions contrasted with the abnormally warm temperatures and low snowfall totals (less than $25 \%$ of normal) observed during the 1994/95 winter.

One prominent aspect of the 1995/96 winter season was a recurring pattern of enhanced northwesterly flow, which extended from northern Alaska and the Bering Sea to southeastern Canada and the north-central United States. This flow brought a series of major winter storms and severe winter outbreaks to the northern and eastern United States, resulting in record-breaking cold and snowfall totals in many regions. The season also featured considerable variability over large portions of the United States and Canada, with periods of extreme cold and snow followed by brief periods of warmth and rain.

The most notable cold-air outbreak occurred during 29 January-6 February 1996, when temperatures averaged $11^{\circ}-17^{\circ} \mathrm{C}$ below normal from the southern Canadian prairies southeastward through the northern and central plains and western Great Lakes and more than $6^{\circ} \mathrm{C}$ below normal throughout the rest of the United States with the exception of the Southwest. Temperatures dropped below $-40^{\circ} \mathrm{C}$ throughout interior Canada during the period and below $-46^{\circ} \mathrm{C}$ in some portions of central Canada. In the United States, all-time record low temperatures were set in four states (Minnesota, Iowa, Illinois, and Rhode Island), and nearly 400 daily record lows were either tied or broken. Additionally, the cold temperatures were accompanied by strong winds that produced extreme wind chill temperatures below $-50^{\circ} \mathrm{C}$ over much of Canada and large portions of the northern United States. The upper-level height and anomaly fields (Fig. 48a) reveal that the Arctic outbreak was associated with 

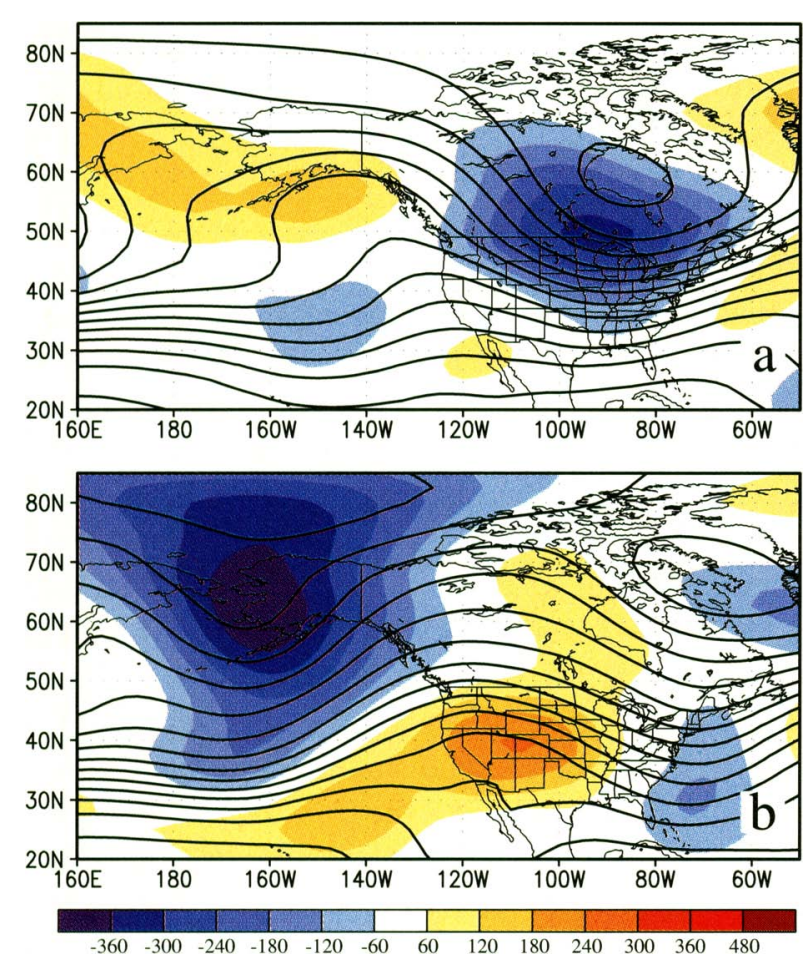

FIG. 48. 250-hPa heights (contours, interval is $120 \mathrm{~m}$ ) and anomalies for (a) 29 January-6 February 1996 and (b) 6-10 February 1996. Anomalies are departures from the 1979-95 base period means.

a highly amplified flow, featuring above normal heights across the high latitudes of the central North Pacific and well below normal heights throughout central North America. Within this flow pattern, height contours originating in Alaska, eastern Siberia, and the Arctic Circle covered central and southern Canada and extended southeastward across the upper one-third of the United States east of the Rocky Mountains. This pattern resulted in a sustained flow of pure Arctic air into central and eastern North America.

This Arctic outbreak was immediately followed during 6-10 February by much milder air across central North America. During this 5-day period, temperatures reached $21^{\circ} \mathrm{C}$ in the plains states, more than a $50^{\circ} \mathrm{C}$ increase from the record-low readings observed the prior week. At Tulsa, Oklahoma, new February extreme minimum $\left(-24^{\circ} \mathrm{C}\right)$ and maximum $\left(32.2^{\circ} \mathrm{C}\right)$ records were set within 18 days of each other in association with the Arctic out- break and subsequent warm-up. This warm-up was associated with a large-scale transition in the upper-level flow to below-normal heights and a deep trough over western Alaska and an amplified ridge over the intermountain region of North America (Fig. 48b). This pattern resulted in a strong and extensive flow of marine air from the central North Pacific into virtually all of North America.

Overall, snowfall totals by the end of February averaged more than $150 \%$ of normal over the Dakotas and the upper Midwest and over the central and eastern United States from Indiana northeastward to southeastern Maine and southeastward to the Virginia coast (Fig. 49). Totals exceeded 200\% of normal from southern Virginia northward to northern Massachusetts, and more than $300 \%$ of normal snowfall was recorded from central Maryland northward to southern New York and throughout the southern Appalachian Mountains region. Totals also averaged $200 \%-300 \%$ of normal over eastern North Dakota, northwestern Minnesota, and western South Dakota.

Many locations established new all-time record seasonal snowfall totals during the 1995/96 cold season (Table 2). The largest total snowfall $(573 \mathrm{~cm})$ was observed at Sault Saint Marie, Michigan, which broke its previous highest total snowfall accumulation record of $454 \mathrm{~cm}$. Most of the other records were established in the East, extending from Virginia in the south to Massachusetts in the Northeast. For many of these cities, the previous snowfall records were broken by mid-February. In some locations the previous record snowfall totals were exceeded by more than $60 \mathrm{~cm}$ during the winter of 1995/96.

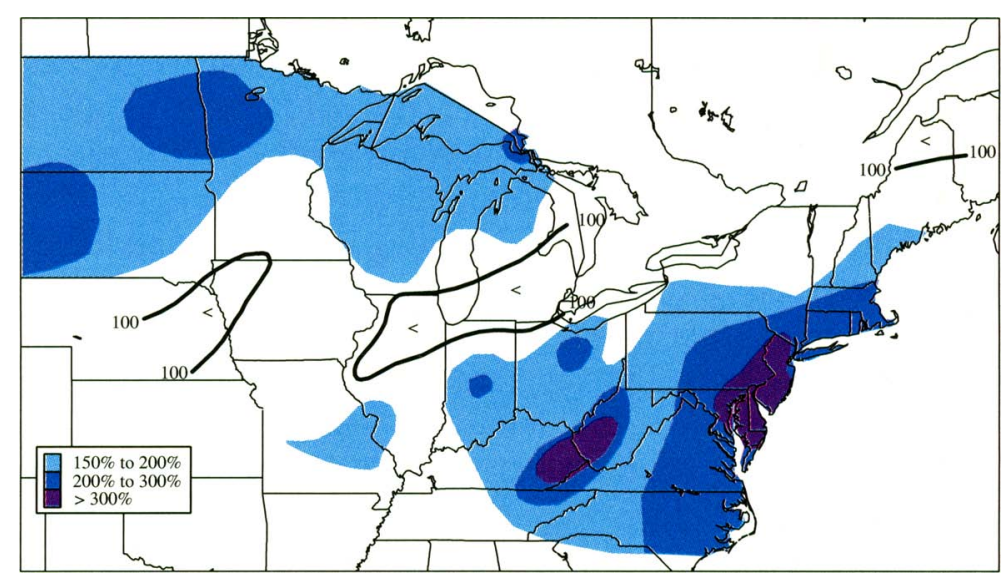

FIG. 49. Percent of normal total snowfall for the period 1 September 1995-29 February 1996. Values are based on first-order stations only. Normals are calculated with respect to the full record for each station. 
TABLE 2. Seasonal snowfall records (cm) during $1995 / 96$ in the United States and previous record snowfall total and year of occurrence.

\begin{tabular}{lccc}
\hline Station & $\begin{array}{c}\text { Total } \\
(\mathbf{m})\end{array}$ & \multicolumn{2}{c}{$\begin{array}{c}\text { Previons record } \\
\text { and year }\end{array}$} \\
\hline Sault Ste. Marie, MI & 573 & 454 & $(1976 / 77)$ \\
Blue Hill Observatory, MA & 365 & 330 & $(1947 / 48)$ \\
Elkins, WV & 345 & 322 & $(1993 / 94)$ \\
Duluth, MN & 339 & 334 & $(1949 / 50)$ \\
Worcester, MA & 338 & 305 & $(1992 / 93)$ \\
Binghamton, NY & 335 & 334 & $(1993 / 94)$ \\
Hartford/Bradley, CT & 293 & 216 & $(1993 / 94)$ \\
Boston, MA & 273 & 245 & $(1993 / 94)$ \\
Providence, PI & 269 & 192 & $(1947 / 48)$ \\
Charleston, WV & 209 & 195 & $(1977 / 78)$ \\
Mansfield, OH & 224 & 197 & $(1977 / 78)$ \\
Williamsport, PA & 223 & 212 & $(1977 / 78)$ \\
Newark, NJ & 199 & 191 & $(1867 / 68)$ \\
Bridgeport, CT & 195 & 131 & $(1933 / 34)$ \\
New York/Central Park, NY & 192 & 161 & $(1947 / 48)$ \\
New York/Kennedy, NY & 175 & 148 & $(1960 / 61)$ \\
Philadelphia, PA & 160 & 141 & $(1898 / 99)$ \\
Jackson, KY & 159 & 122 & $(1993 / 94)$ \\
Baltimore, MD & 158 & 132 & $(1963 / 64)$ \\
Washington/Dulles, VA & 151 & 113 & $(1966 / 67)$ \\
Washington/National, DC & 117 & 103 & $(1957 / 58)$ \\
& & &
\end{tabular}

Perhaps the most notable snow event during the winter was the blizzard of 6-9 January 1996 , which affected the entire eastern Uwited States. During this event, $50-120 \mathrm{~cm}$ of snow covered the eastern seaboard from the mid-Ohio valley eastward to eastern Virginia and northward to southern Massachusetts (Fig. 50). Totals exceeded $76 \mathrm{~cm}$ at Philadelphia, Pennsylvania, establishing a new single-storm record, and reached $87.5 \mathrm{~cm}$ in west-central New Jersey and $120 \mathrm{~cm}$ in Pocahantas County, West Virginia. Additionally, most areas from Washington, D.C., northeastward to Providence, Rhode Island, reported one of the five biggest single-storm snowfall totals on record during the storm, which resulted in a shutdown of most aipon is on the East Coast from Virginia northward and made other modes of transportation virtually impossible.

In contrast, during the following week the eastern United States experienced a dramatic warm-up and heavy rains $(50-150 \mathrm{~mm})$, resulting in a rapid snow melt and extensive runoff. These conditions produced flooding throughout the mid-Allantic states and the Northeast during 19-24 January. During this period, all major rivers in Pennsylvania, Ohio, West Virginia, Virgina, Maryland, New York, and Vermont crested 1.2-3.6 $\mathrm{m}$ above flood stage. In many areas, this was the highest recorded crest since the flooding associated with Hurricane Agnes in June 1972.

4) The 1996 Atlantic hurricane SEAson

The Atlantic hurricane season is normally most active from August to October and peaks during the second week of September. On average, 9-10 tropical storms are observed over the North Atlantic between June and November, with 5-6 of these systems becoming hurricanes. Typically, two to three systems reach intense hurricane status in a given year, as measured by a category 3,4 , or 5 on the Safir-Simpson scale (Simpson 1974). The 1996 Atlantic hurricane season featured 13 tropical storms (Fig. 51), with 9 of these systems reaching hurricane status. Six of these storms became intense hurricanes, with all but one intense hurricane (Bertha in July) forming during August-October. In total, there were 78.75 named storm days during the season, 45.0 hurricane days, and 13.0 intense hurricane days. The longest lived of these systems was Hurricane Eduoard (21 August-2 September), which lasted for 10.25 days as a hurricane and 7.75 days at intense hurricane status.

Nine tropical storms formed during August-October, two formed in June (Arthur and Bertha), one formed in July (Cesar), and one formed extremely late in the season on 19 November (Gustov). Interestingly, every tropical depression over the subtropical North Atlantic during the season strength-

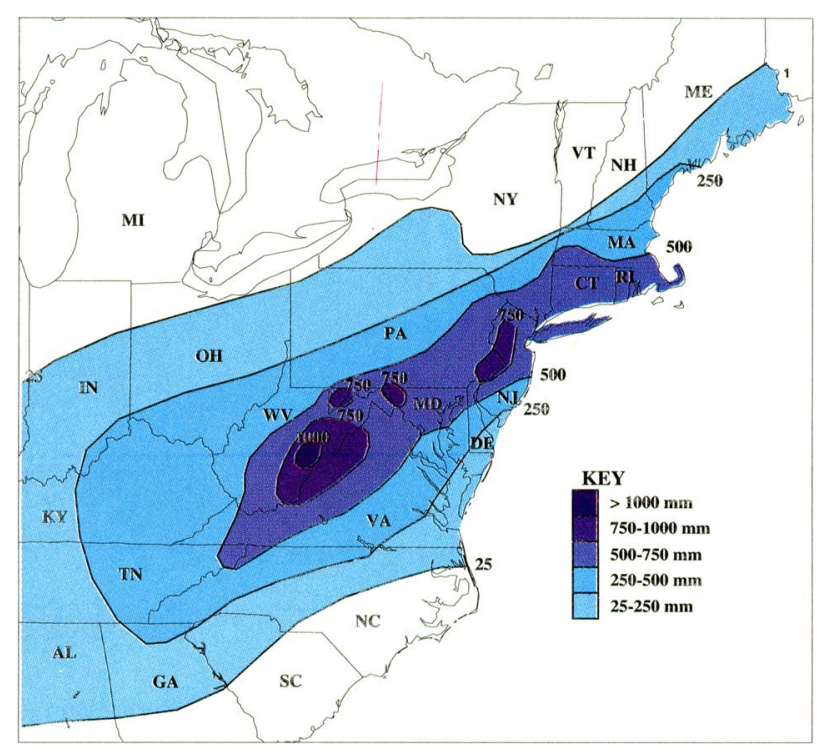

FIG. 50. Total snowfall (mm) from 6 to 9 January 1996 during the "Blizzard of 1996." 


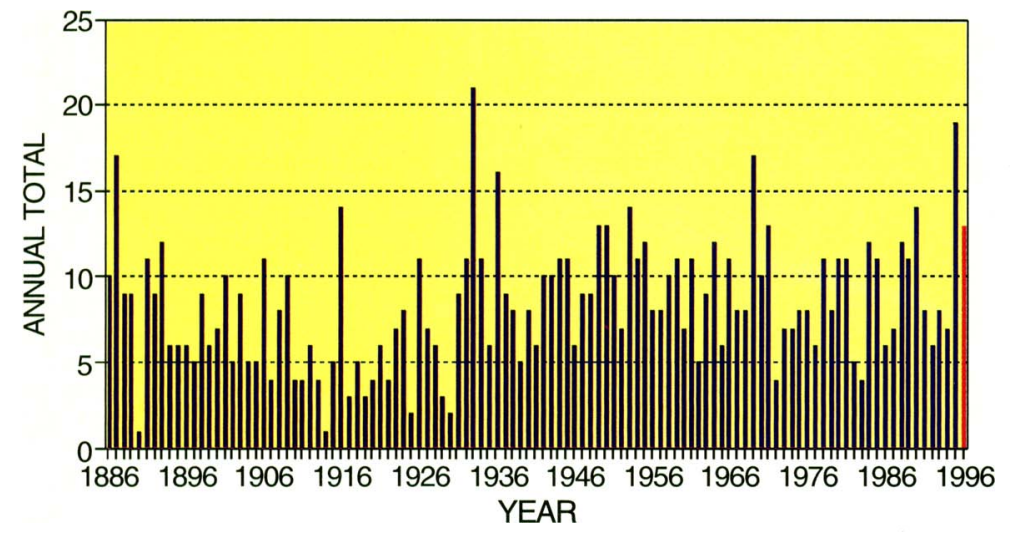

FIG. 51. Number of hurricanes and tropical storms for the North Atlantic basin: 1996 is shown in red. (Source: National Climatic Data Center.) varies widely throughout the region, with the northern regions typically recording $100-300 \mathrm{~mm}$ during the season and the southern areas receiving well in excess of $500 \mathrm{~mm}$. For the region as a whole, the 1996 rainy season brought near-normal rainfall to all but the southwestern and extreme southeastern sections of the Sahel, as compared to the 1961-90 base period means.

Total rainfall during the 1996 wet season averaged between 200 and $1000 \mathrm{~mm}$ across the region (Fig. 52a), with the largest amounts in the southwestern Sahel and western Guinea and the smallest amounts in the North. ened into a tropical storm. This ratio of tropical storms to depressions appears to be unprecedented in the historical record.

The 1996 season was the second consecutive year for above-normal North Atlantic tropical storm and hurricane activity. These two active years follow the extremely inactive period of 1991-94, during which six to eight tropical storms and three to four hurricanes were observed each year. In total, 32 tropical storms have been observed in the last 2 yr, compared to 29 during the entire 1991-94 period. This ties 1995-96 with 1933-34 as the most active 2 -yr period for tropical storm activity dating back to 1871 . Also, 20 hurricanes were observed during the 1995 and 1996 seasons, with 10 of these systems reaching intense hurricane status, compared to 17 hurricanes and 4 intense hurricanes during 1991-94.

\section{c. Africa}

\section{1) JunE-SEPTEMBER 1996: Western Africa (SaHel) RAINY SEASON}

The Sahel region $\left(8^{\circ}-18^{\circ} \mathrm{N}\right.$, $\left.17^{\circ} \mathrm{W}-20^{\circ} \mathrm{E}\right)$ receives about $90 \%$ of its mean annual precipitation during the June-September period. This rainfall is closely related to the north-south movement of the ITCZ, which begins its northward movement in March and reaches its northernmost position $\left(15^{\circ} \mathrm{N}\right)$ in August. Precipitation

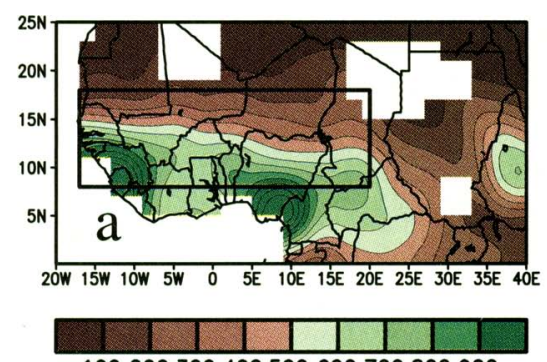

100200300400500600700800900

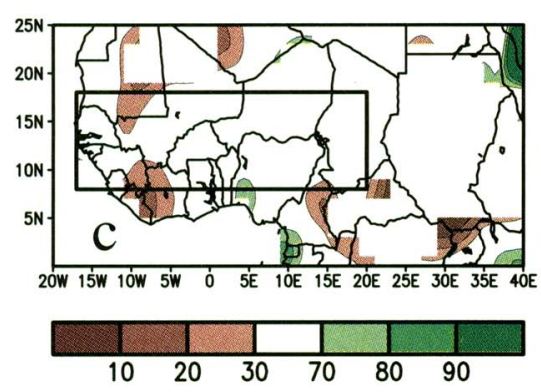
There were only isolated areas of substantially above-normal (50-150 mm) rainfall during 1996 (Fig. 52b), which included parts of central Mali, Burkina Faso, and Ghana. Elsewhere, much of the northern and central Sahel received near-normal rainfall during the season (Figs. 52b,c), while large portions of the southwestern and southeastern Sahel received below-normal rainfall (Fig. 52b).

In the southwestern Sahel region, the most substantial dryness (50\%-80\% of normal rainfall) covered western Mali, all of Guinea, Sierra Leona, and Liberia, with totals averaging more than 150-200 $\mathrm{mm}$ below normal (Fig. 52b) and precipitation per-

FIG. 52. June-September 1996 (a) total precipitation (mm), (b) precipitation anomalies (mm), (c) precipitation percentiles based on a gamma distribution fit to the 1961-90 base period and (d) a monthly time series of precipitation percentiles based on precipitation totals averaged over the boxed region depicted in (a)-(c). 
centiles averaging between the 10th and 20th percentiles (Fig. 52c). In the southeastern Sahel, eastern Chad, southeastern Nigeria, and northwestern Cameroon also experienced significant rainfall deficits during 1996, with negative anomalies exceeding $200 \mathrm{~mm}$ in the latter two regions.

The time series of percentiles of area-averaged monthly mean precipitation for the boxed region $\left(17^{\circ} \mathrm{W}-20^{\circ} \mathrm{E}, 8^{\circ}-18^{\circ} \mathrm{N}\right)$ shown in Figs. $52 \mathrm{a}-\mathrm{c}$ reveals a near-normal onset and finish to the 1995/ 96 rainy season (Fig. 52d), with the most significant dryness occurring during July and August, when area-averaged precipitation totals dropped below the 30th and 40th percentiles, respectively. In contrast, the wettest month as a whole was September, when area-averaged precipitation totals slightly exceeded the 50th percentile.

\section{2) October 1995-April 1996: Southern Africa RAINY SEASON}

In southern Africa, the rainy season typically lasts from October to April and reaches maximum strength between November and March. Most locations receive more than $75 \%$ of their annual precipitation during this 7 -month period, with some parts in the northwest receiving more than $90 \%$ of their total annual rainfall. The yearto-year variability in rainfall over southern Africa shows a strong relationship to the ENSO cycle (Ropelewski and Halpert 1987, 1989), with below-normal rainfall generally observed during Pacific warm episodes (e.g., the 1994/95 rainy season) and above-normal rainfall generally observed during Pacific cold episodes (e.g., the 1995/96 rainy season).

Overall, very strong gradients in rainfall totals were observed across southern Africa during the 1995/96 rainy season, with the largest totals exceeding $1000 \mathrm{~mm}$ in the north and east, and the lowest totals of less than $100 \mathrm{~mm}$ in the southwest (Fig. 53a). Above-normal rainfall during the period covered the climatologically high precipitation areas such as northeastern South Africa, southern Mozambique, and much of central Madagascar (Fig. 53b). For example, much of the northeastern sector re- corded totals exceeding $200 \mathrm{~mm}$ above normal during the season, with isolated areas recording more than $400 \mathrm{~mm}$ above normal. Seasonal totals in these regions exceeded the 70 th and 90th percentiles, respectively (Fig. 53c). This above-normal rainfall contrasts with the abnormally dry 1994/95 rainy season (Fig. 53d). Elsewhere during the 1995/96 wet season, below-normal totals were confined to climatologically low precipitation areas such as northern Namibia, eastern Angola, and western Zambia. These areas also received below-normal rainfall during 1994/95. Elsewhere, central South Africa, northern Botswana, southern Namibia, and northern Zimbabwe all received near-normal rainfall during the 1995/96 season.

The time series of percentiles of area-averaged monthly mean precipitation for the boxed region $\left(15^{\circ}-35^{\circ} \mathrm{E}, 18^{\circ}-35^{\circ} \mathrm{S}\right)$ shown in Figs. $53 \mathrm{a}-\mathrm{c}$ reveals a slow onset and an early end to the 1995/96 rainy season (Fig. 53d), with heavy rainfall recorded from late-November through February. In fact, the period December-February brought significantly above-normal rainfall to the region, with mean totals during December and January approaching the 90th percentile and totals during February approaching the 70th percentile.
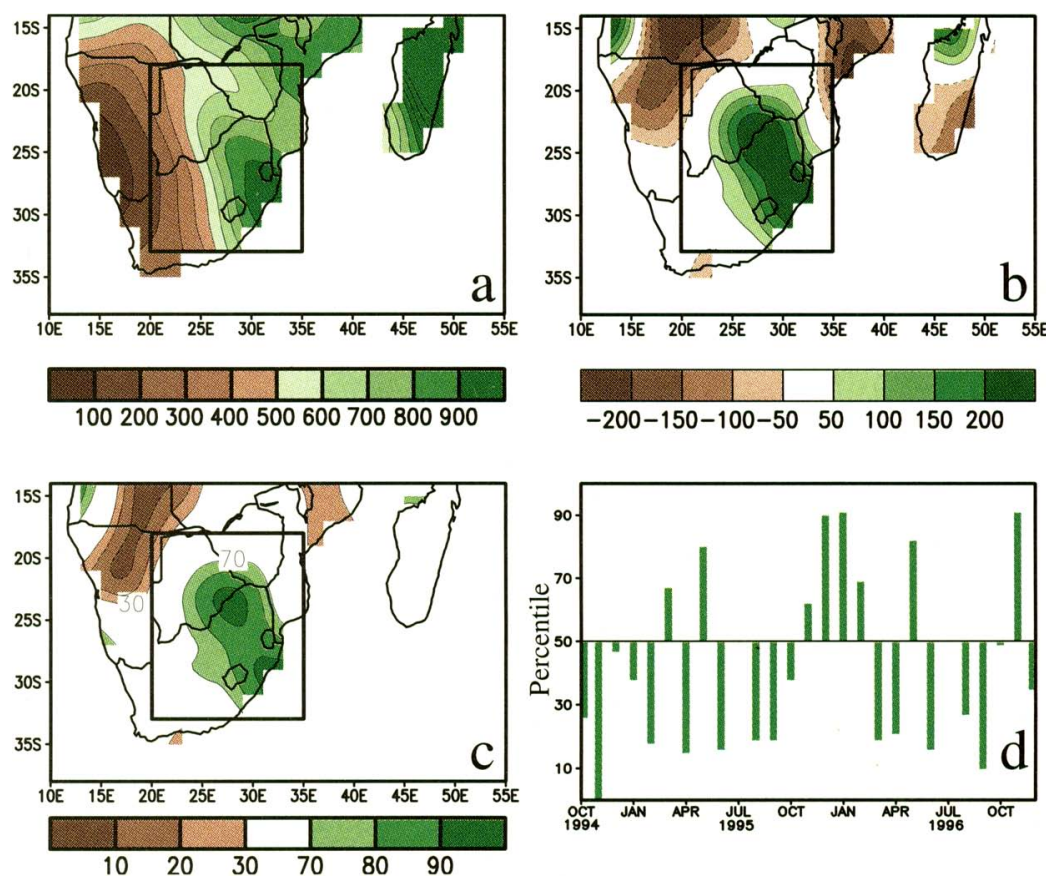

FIG. 53. October 1995-April 1996 (a) total precipitation (mm), (b) precipitation anomalies ( $\mathrm{mm})$, (c) precipitation percentiles based on a gamma distribution fit to the 1961-90 base period, and (d) a monthly time series of precipitation percentiles based on precipitation totals averaged over the boxed region depicted in (a)-(c). 


\section{d. Australia and New Zealand}

\section{1) Precipitation}

(i) Northern and northeastern Australia

Northern and northeastern Australia (indicated by the boxed area in Fig. 54a) experience a welldefined rainy season that typically begins in October and ends in April. Much of the area receives more than $75 \%$ of its mean annual precipitation (with portions of extreme northern Australia recording more than 90\%) during this 7-month period (Fig. 54b). This annual cycle is strongly modulated by the Southern Oscillation, with below(above-) normal rainfall typically observed during Pacific warm (cold) episodes (Ropelewski and Halpert 1987, 1989). Overall, precipitation during the 1995/96 wet season averaged below normal throughout the region, with large deficits observed in all months except October and April (Fig. 54b). The largest deficits were recorded in extreme northeastern Arnhem Land, where totals were more than $700 \mathrm{~mm}$ below normal for the entire season (Fig. $54 \mathrm{a})$. Elsewhere, totals averaged $100-300 \mathrm{~mm}$ below normal, with the exception of the southeast portion of the region where they averaged 50-100 $\mathrm{mm}$. Last year, rainfall totals averaged $200-500 \mathrm{~mm}$ above normal across north-central Australia, including a record amount of $2384 \mathrm{~mm}$ at Darwin, and 200-400 $\mathrm{mm}$ below-normal in the northeast (not shown).

The reduced precipitation during the 1995/96 wet season reflected a weaker than normal Australian monsoon system, and contrasts with the enhanced rainfall typically expected during Pacific cold episodes. There appears to be two primary reasons for this reduced rainfall: 1) a pronounced shift in the area of maximum convection to north of the equator during this cold episode, particularly during December-February (Fig. 24a); and 2) a persistent and amplified upper-level trough over extratropical eastern Australia (Figs. 60 and 62). This feature affected the large-scale atmospheric circulation well into the subtropics, and contributed to anomalous upperlevel convergence and descending motion across central and north-central Australia.

\section{(ii) Eastern Australia}

Rainfall totals in eastern Australia (indicated by the boxed area in Fig. 55a) are largest during the warm season between November and May, with the annual peak observed during January-March (Fig. 55b). This region also exhibits a strong ENSO
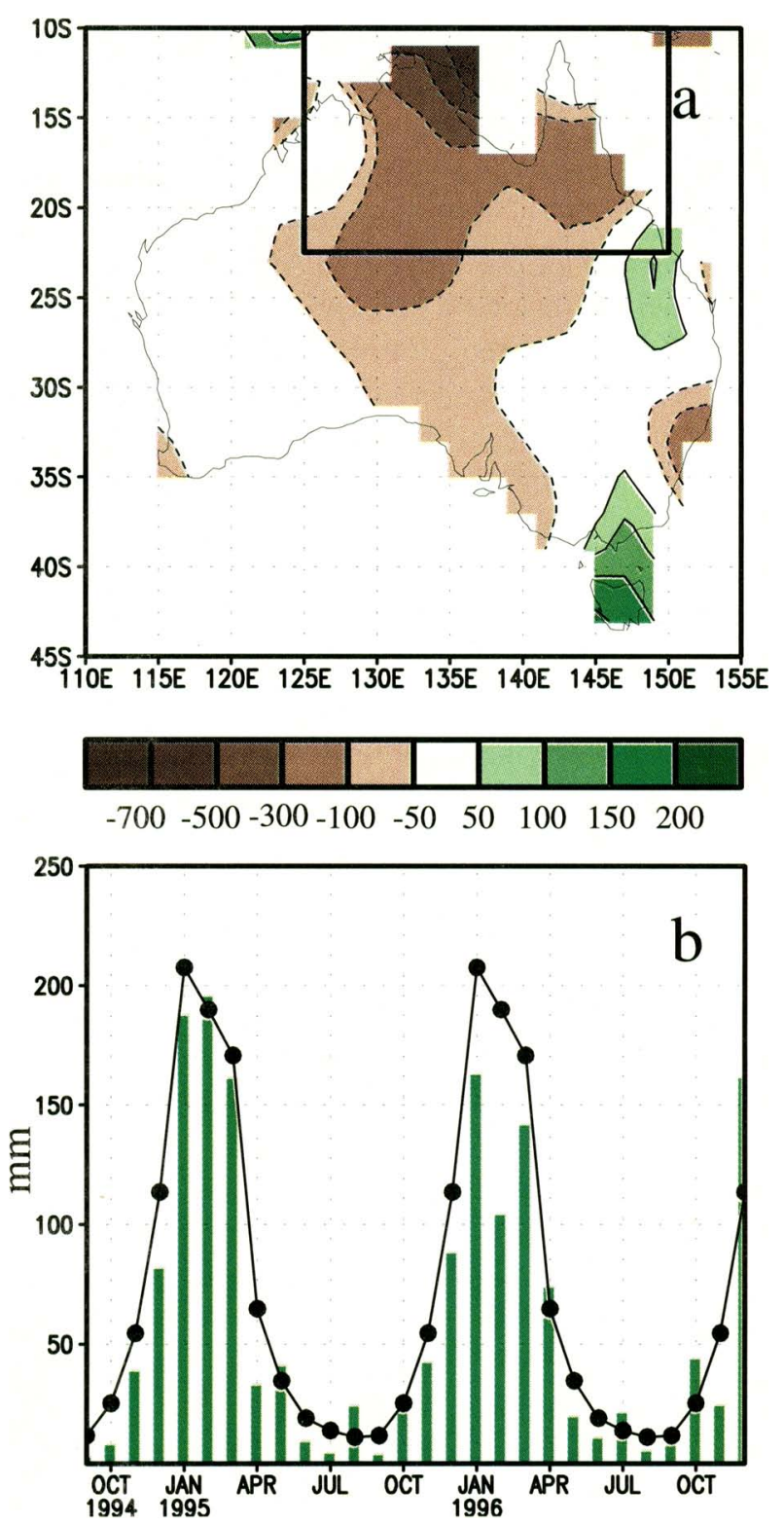

FIG. 54. (a) Precipitation anomalies (mm) for October 1995April 1996 and (b) monthly total precipitation (mm, bars) and the 1961-90 mean (mm, line) averaged over the boxed region shown in (a).

signal, with suppressed (enhanced) rainfall often occurring during Pacific warm (cold) episodes (Ropelewski and Halpert 1987, 1989). During the November 1995-May 1996 season, area-averaged rainfall totals were largest in the 3-month period November 1995-January 1996, with much of the eastern and northeastern parts of the region recording anomalies greater than $150 \mathrm{~mm}$, and the western and southwestern areas recording surpluses of 50-100 mm (Fig. 55a). The heaviest precipitation fell in January, when area-averaged totals (197 

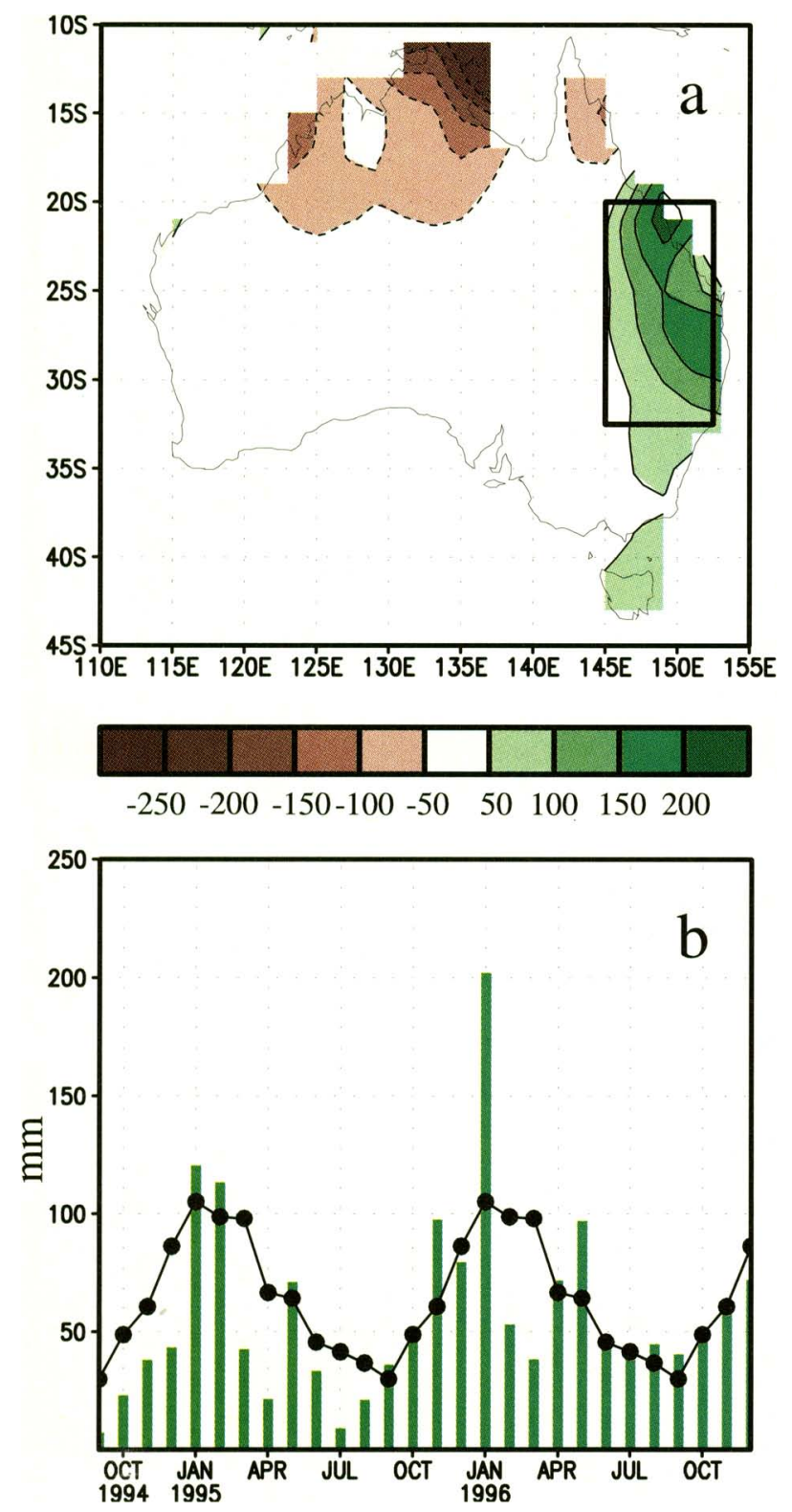

FIG. 55. (a) Precipitation anomalies (mm) for November 1995May 1996 and (b) monthly total precipitation (mm, bars) and the 1961-90 mean (mm, line) averaged over the boxed region shown in (a).

$\mathrm{mm})$ nearly doubled the climatological mean (105 $\mathrm{mm})$. This heavy precipitation was associated with Tropical Cyclone Barry during 1-9 January and with several storm systems later in the month. The rainfall contributed significantly to a further easing of drought conditions that developed across the region during much of 1994 and 1995. Below-normal rainfall totals returned to the region during February and March 1996, followed by normal to above-normal rainfall during the remainder of the year (Fig. 55b).

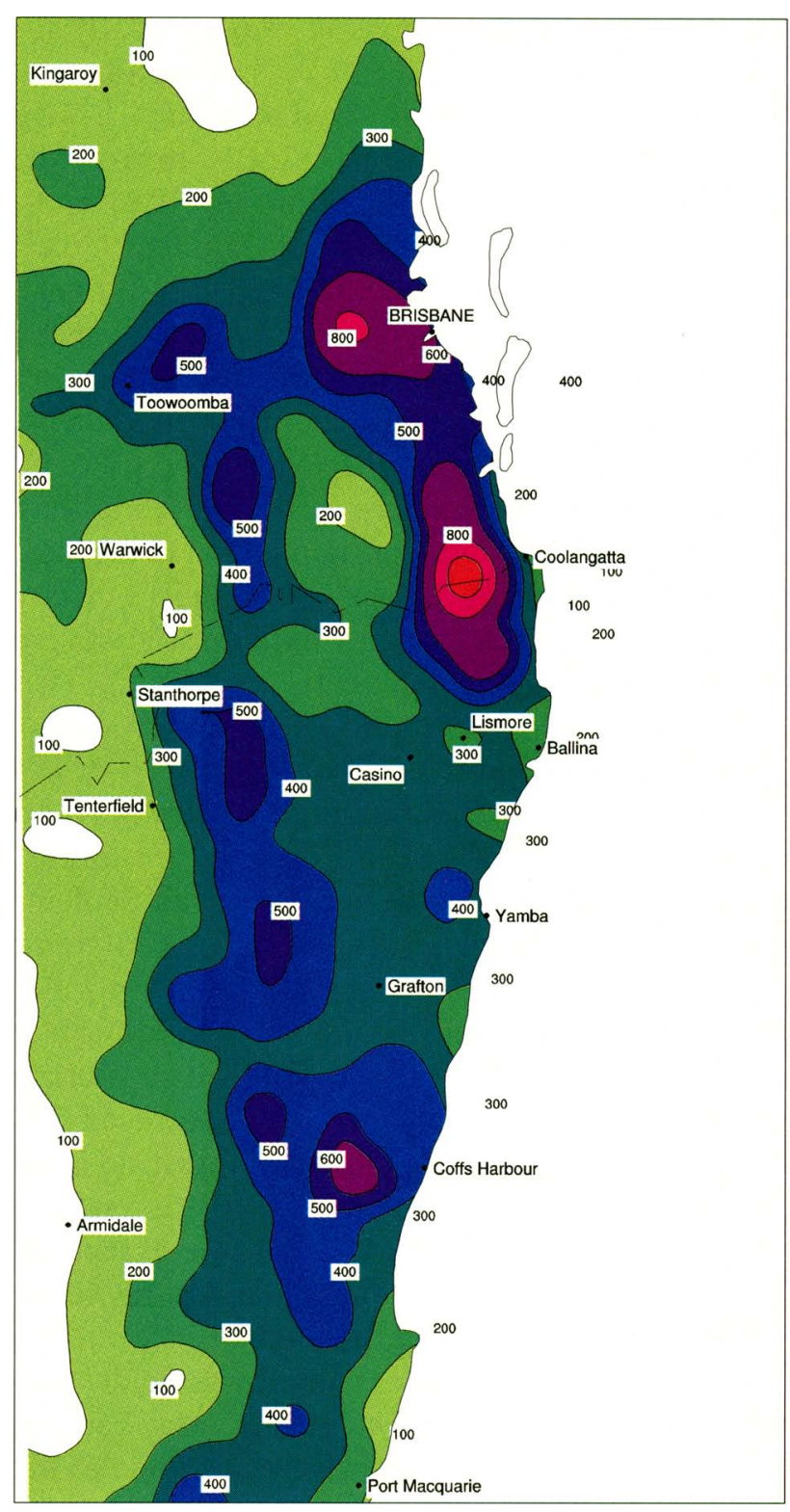

FIG. 56. Total precipitation (mm) for 1-7 May 1996. (Source: Australian Bureau of Meteorology.)

According to the Australian Climate Analysis Center Annual Climate Summary for 1996 (Australian Bureau of Meteorology 1997), "the most dramatic event of the year occurred over southeast Queensland and northern New South Wales during the first week of May" (Fig. 56), "in association with a moist onshore airstream and a sharp, slow-moving upper level trough." These features brought "torrential rains to the region, with many monthly and daily records broken during the first week." Numerous stations in the area received 
250-500 mm, while stations in orographically-favored locations received in excess of $1000 \mathrm{~mm}$. The largest totals were observed at Natural Bridge (1808 mm), Springbrook (1600 mm), Mt. Tamborine (1161 mm), Mt. Glorious (1053 mm), Doon Doon $(1030 \mathrm{~mm})$, Commissioners Creek $(980 \mathrm{~mm})$, and Mt. Nebo $(931 \mathrm{~mm})$. These totals, which in some cases were more than double the previous record rainfall for the entire month, resulted in severe flooding in southeastern Queensland. Brisbane, the capital city, recorded $606 \mathrm{~mm}$ during this period, surpassing the previous May record by over $200 \mathrm{~mm}$. This rainfall led to the most severe flooding since January 1974 and ironically occurred in an area that had experienced severe drought during the past 5 years.

\section{(iii) Southeast and Tasmania}

Rainfall totals in southeastern Australia (indicated by the boxed area in Fig. 57a) are largest during the cool season between May and September, with the annual peak observed in July and August (Fig. 57b). During 1996, below-normal rainfall was observed in May and above-normal precipitation fell during June-September. During this latter period, accumulated totals averaged 50$200 \mathrm{~mm}$ above normal, with the largest positive anomalies observed in extreme southern Victoria and western Tasmania (Fig. 57a). These exceptionally heavy rains led to flooding of the Murray River during late September/early October.

For the year as a whole, rainfall was below normal in this region in only two months: May and December. In fact, January-September was one of the wettest periods on record for the region, with Melbourne recording its highest period totals since 1911. Many local rainfall records were also set in southern and western Tasmania during JanuaryApril.

\section{(iv) New Zealand}

Overall, 1996 was abnormally wet and stormy over the North Island and drier than normal on the South Island. There were two primary episodes of very heavy rainfall during the year, which led to "flash flooding." The first occurred during the last week of January in Gisborne, which received 80 $\mathrm{mm}$ of rain during the week, but with much larger totals at higher elevations. The same storm produced $362 \mathrm{~mm}$ of rain in $48 \mathrm{~h}$ at Raoul Island, the highest 2-day total there since records began in
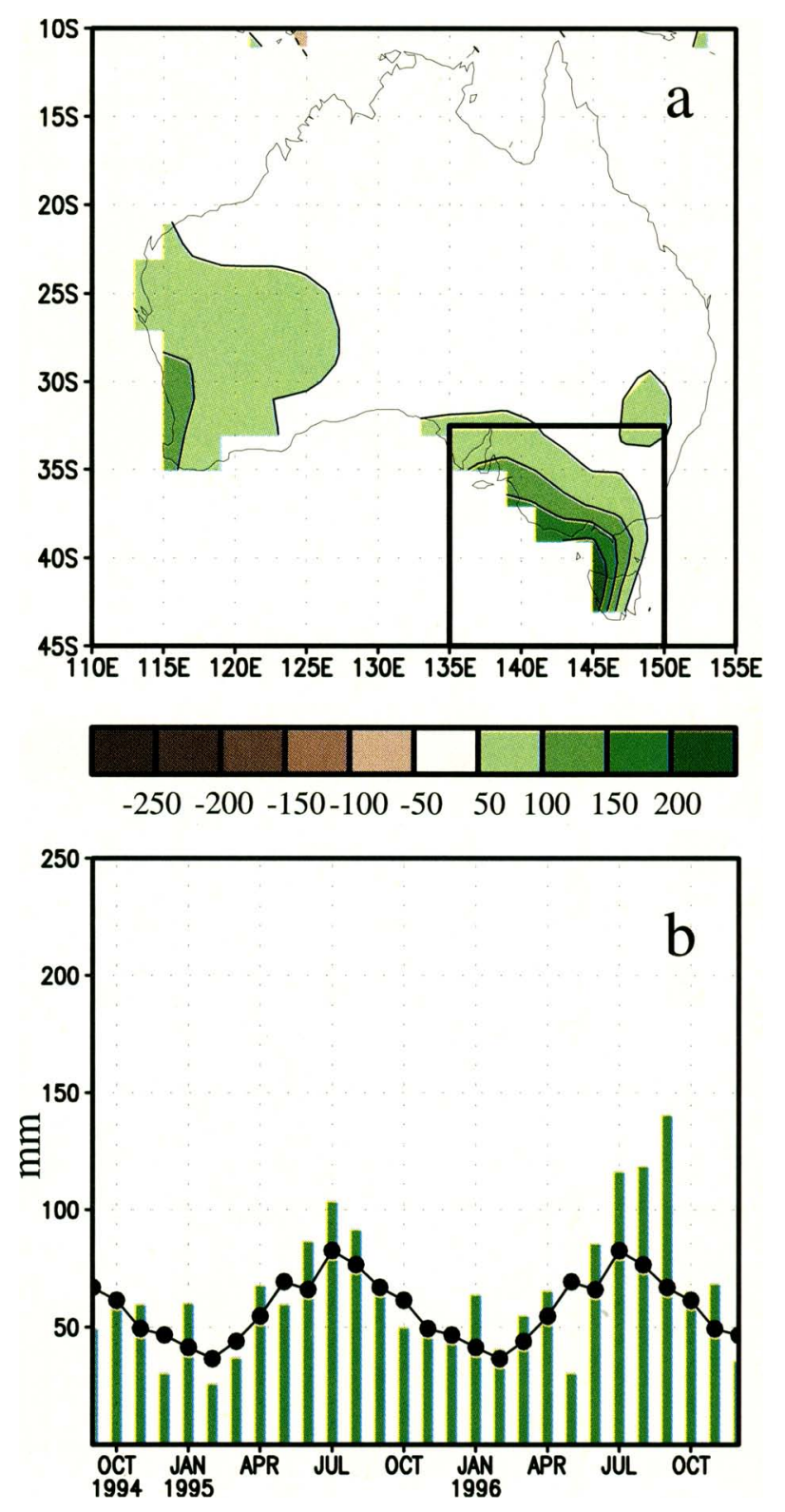

FIG. 57. (a) Precipitation anomalies (mm) for May-September 1996 and (b) monthly total precipitation (mm, bars) and the 196190 mean ( $\mathrm{mm}$, line) averaged over the boxed region shown in (a).

1937. Gisborne then received another severe rainfall and flooding event on 30-31 March from Extratropical Cyclone Beti, with $164 \mathrm{~mm}$ of rain measured in Gisborne and over $300 \mathrm{~mm}$ measured at higher elevations during the 2-day period. Another flooding episode occurred during 7-8 February in both South Canterbury and Wellington, with the former region receiving more than $300 \mathrm{~mm}$ of rain during the 2-day period.

2) Temperatures

Overall, mean annual temperatures in Australia 
during 1996 were the fifth warmest on record dating back to 1910 , averaging $0.65^{\circ} \mathrm{C}$ above the $1961-90$ mean. This warmth was not uniform across the continent, with the largest positive temperature anomalies occurring across the subtropics during June-August and the largest negative anomalies occurring in the southeast throughout most of the year.

There were at least two notable warm periods during the year over Australia. The first was a major heat wave in the Southwest during 1-20 February 1996. During this event, Perth recorded a record 16 consecutive days with temperatures exceeding $32^{\circ} \mathrm{C}$. The second was an abnormally warm June over inland Australia, particularly in the center of the continent where many locations recorded their highest mean temperatures on record for the month. During this period, extensive areas recorded temperatures $3^{\circ}-6^{\circ} \mathrm{C}$ above normal.

\section{e. Indian summer monsoon}

The Indian summer monsoon typically lasts from June to September (Fig. 58d), with large areas of western and central India receiving more than $90 \%$ of their total annual precipitation during the period, and southern and northwestern India receiving 50\%$75 \%$ of their total annual rainfall. Overall, monthly totals average $200-300 \mathrm{~mm}$ over the country as a whole, with the largest values observed during the heart of the monsoon season in July and August.

There was an early start to monsoon conditions during 1996, with monsoonal rains completely covering India by 30 June, 2 weeks earlier than normal. There was also a late finish to the monsoon season, with a complete withdrawal of monsoonal rains from India not seen until 11 October. For the area as a whole, rainfall was above normal during June and July, near normal during August, slightly below normal during September, and then substantially above normal during October (Fig. 58d). In fact, average October totals nearly equalled those observed during September.

Regionally, the 1996 monsoon season brought near-normal rains to large portions of central India (Fig. 58b). Above-normal rains were observed over the southern, coastal western, and north-central regions, while significantly below-normal rainfall (deficits exceeding $1500 \mathrm{~mm}$ and totals falling below the 10th percentile) was confined to the eastcentral region, including much of Burma and Bangladesh (Fig. 58c). Normally, the heaviest monsoonal rains are observed in these regions.

In contrast, the largest rainfall totals of the season were observed in southwestern coastal India, where more than $1200 \mathrm{~mm}$ was reported at most locations (Fig. 58a) and a seasonal high of 2760 $\mathrm{mm}$ was reported in Mangalore (located in coastal Karnataka). These totals averaged 200-300 mm above normal (Fig. 58b) but were below the 70th percentile based on the 1961-90 base period means (Fig. 58c). In southeastern India, large totals of 600-800 $\mathrm{mm}$ (200-300 $\mathrm{mm}$ above normal) during the season primarily resulted from a rare tropical cyclone on 14-17 June, which moved westward into the region from the Bay of Bengal. This storm brought $350 \mathrm{~mm}$ of rain in $24 \mathrm{~h}$ to Chennai on 14 June, which is a record single-day total for the month of June. Kioda, in Telangana, reported $670 \mathrm{~mm}$ of rain on 17 June, which is also an all-time record. A second tropical storm to affect India formed over the Arabian Sea and crossed northwestern India on 19 June. This system contributed substantially to the abnormally large seasonal totals (800-1000 $\mathrm{mm}$ ) observed across the region (Fig. 58a). 


\section{Seasonal summaries}
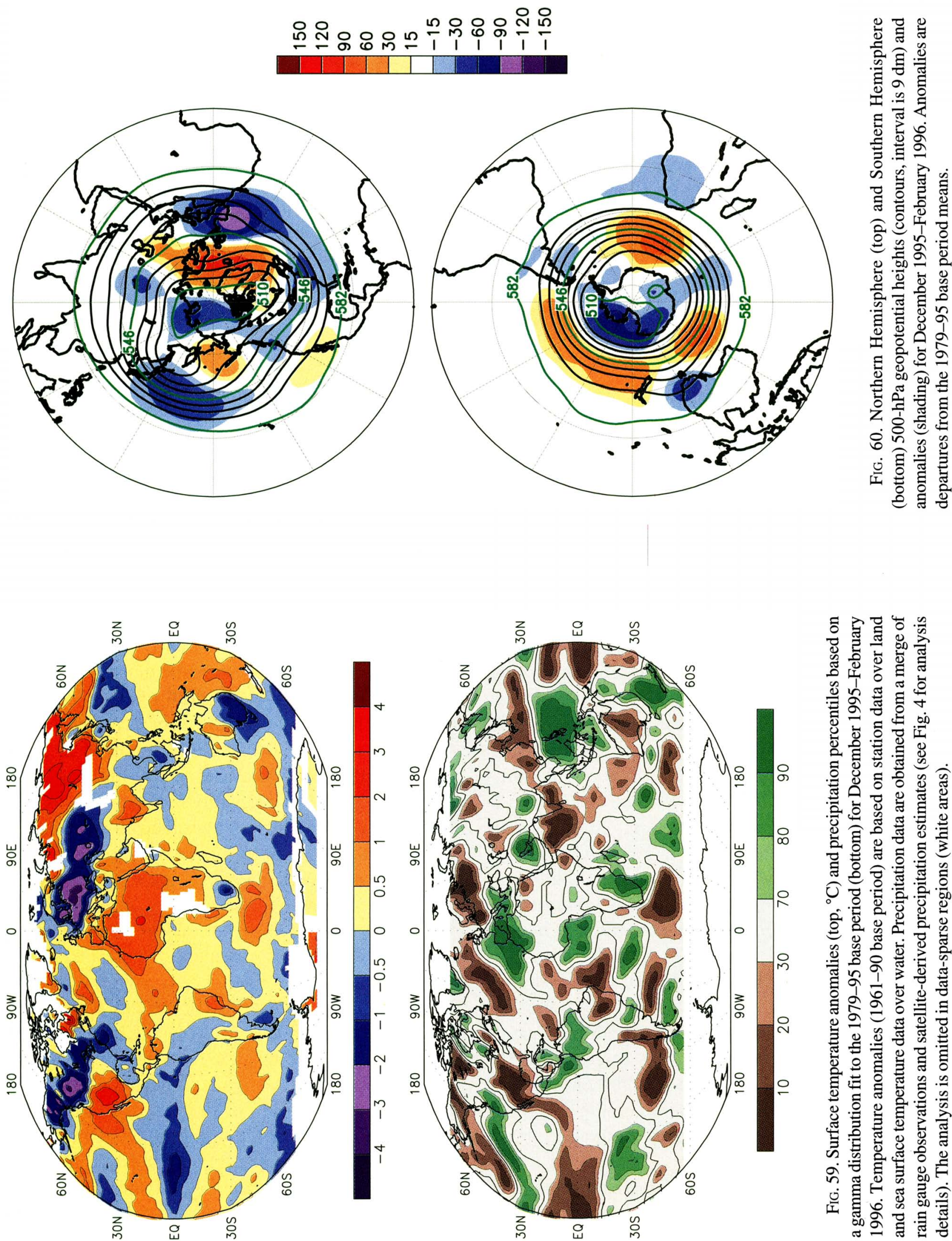


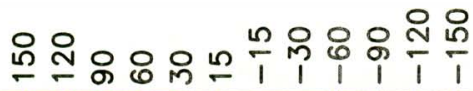
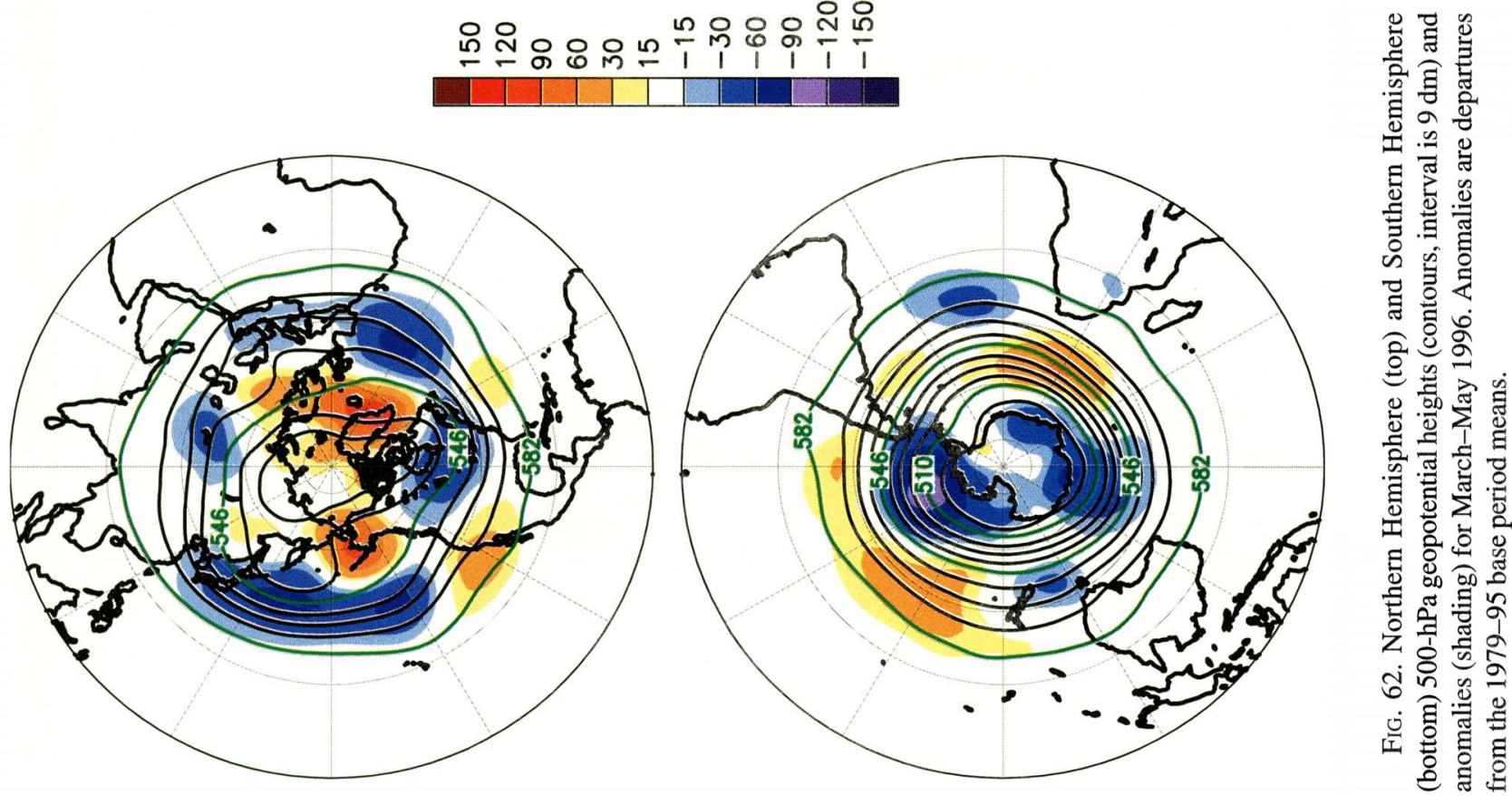

䨔

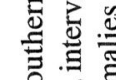

战

สี

응

需空

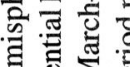

工

हี क्षे

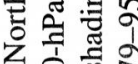

ํํㅇ

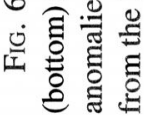
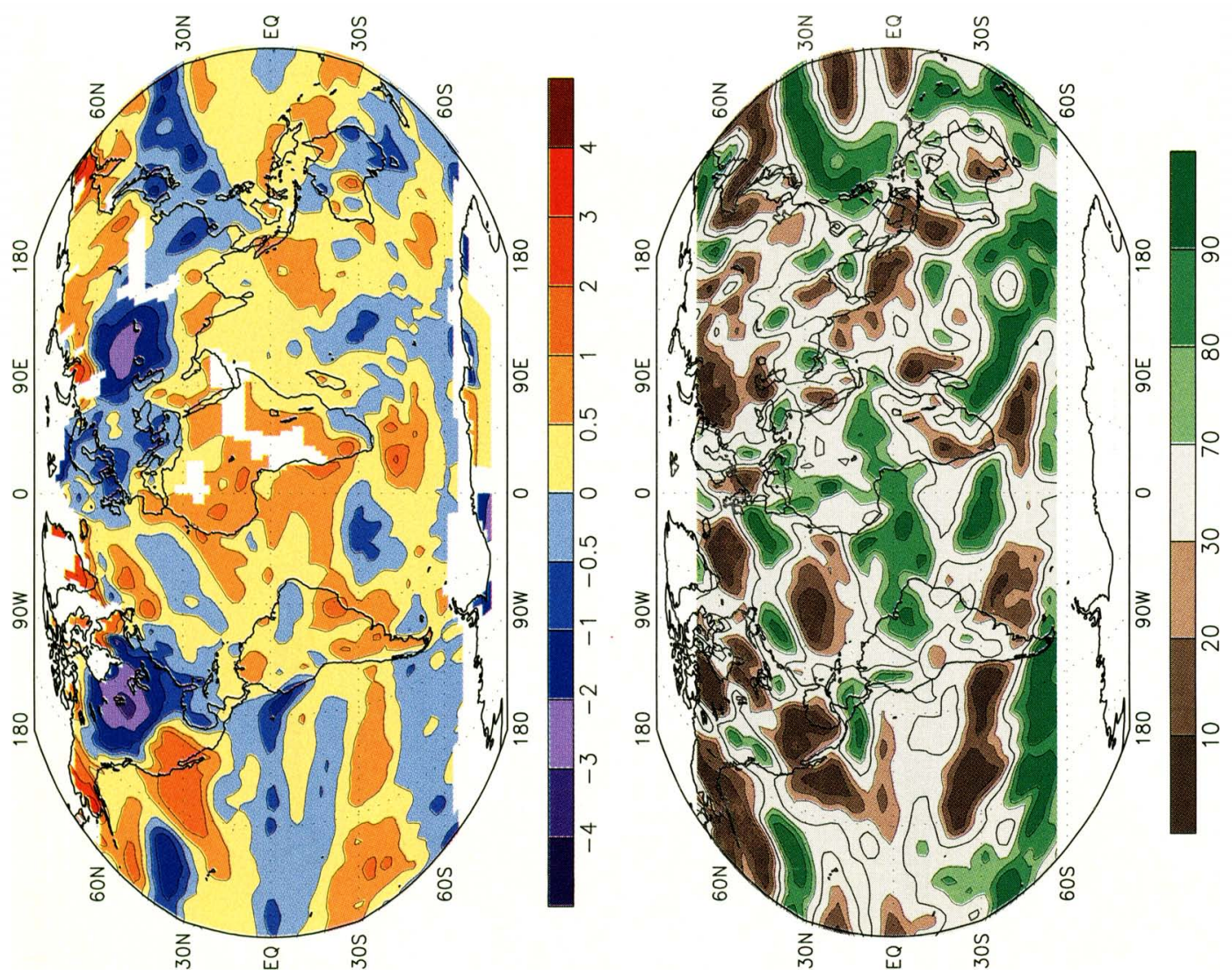

ठี ڤँ

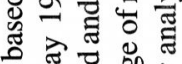

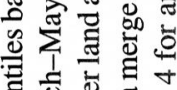

可

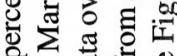

实 㐘

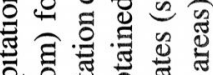

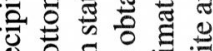

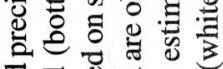

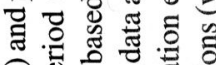

○े क्ष

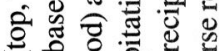

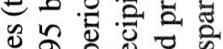

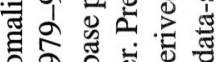

हิ

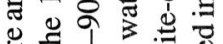

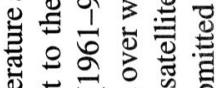

远记

窇

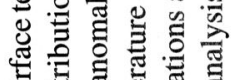

号

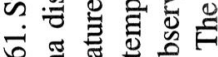

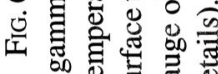




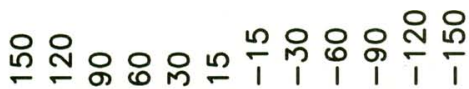
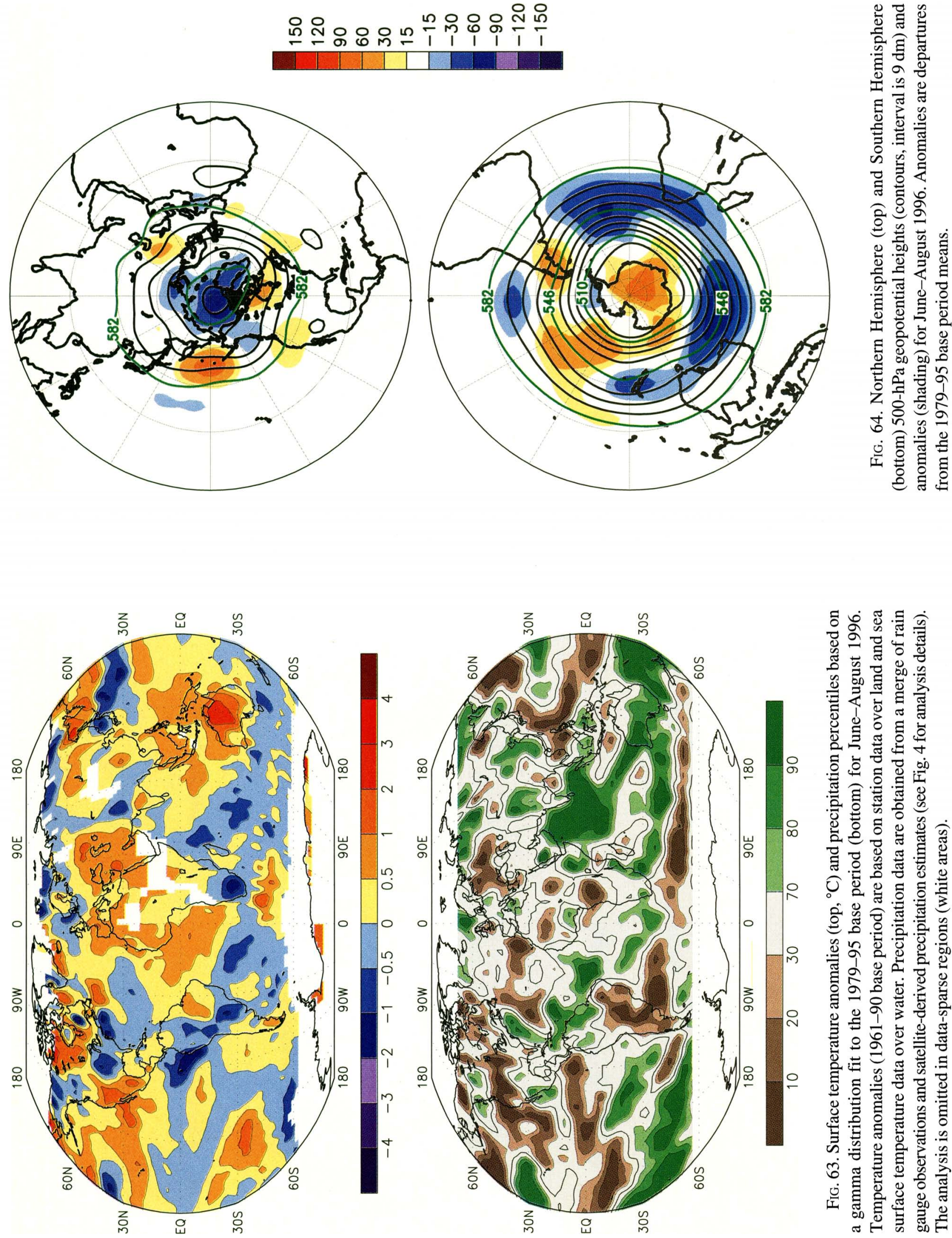

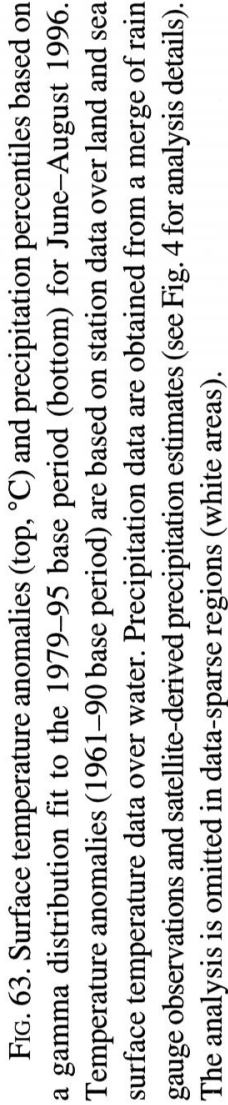




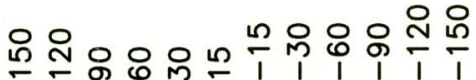
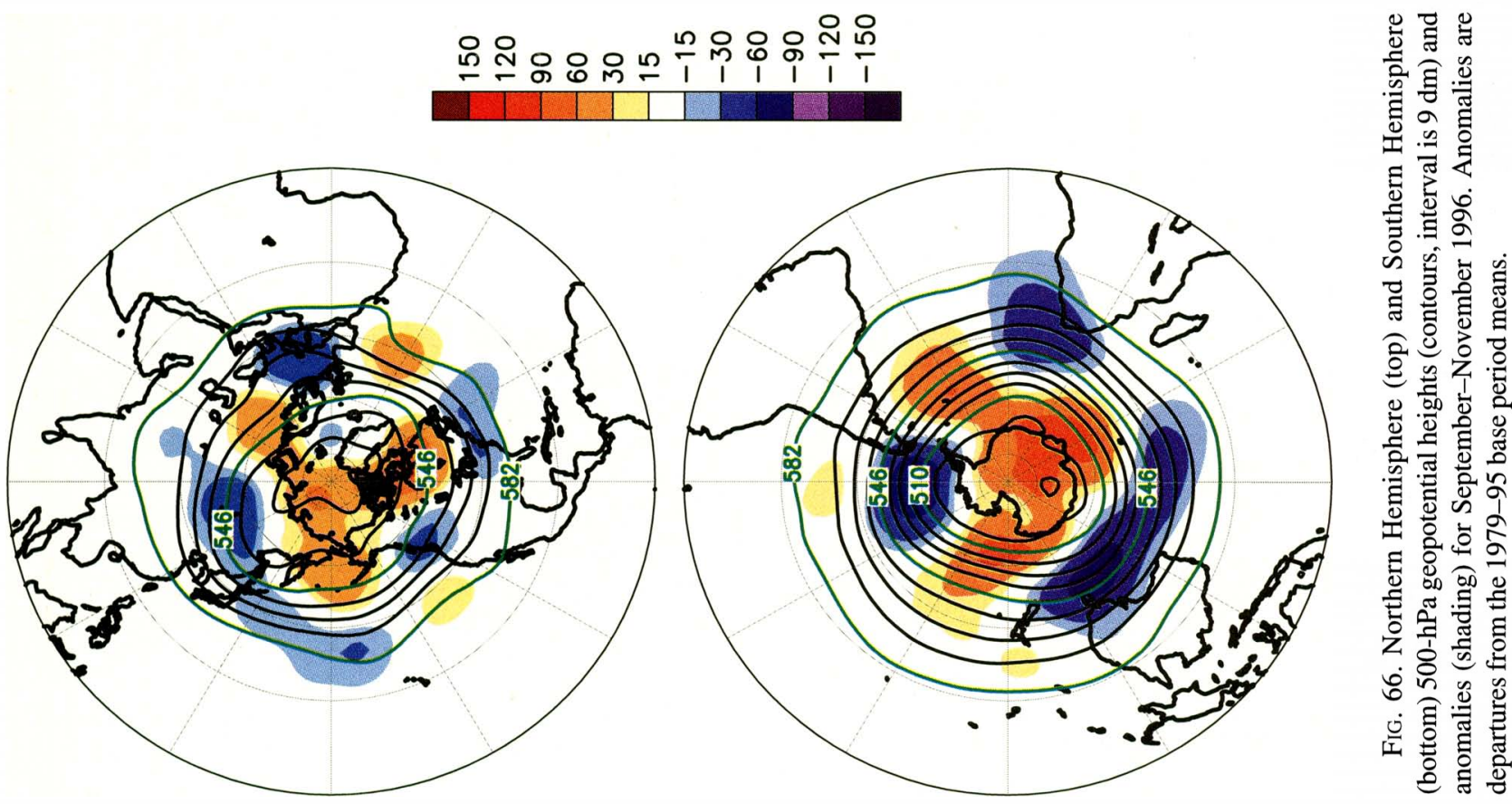

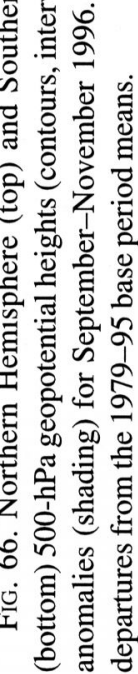
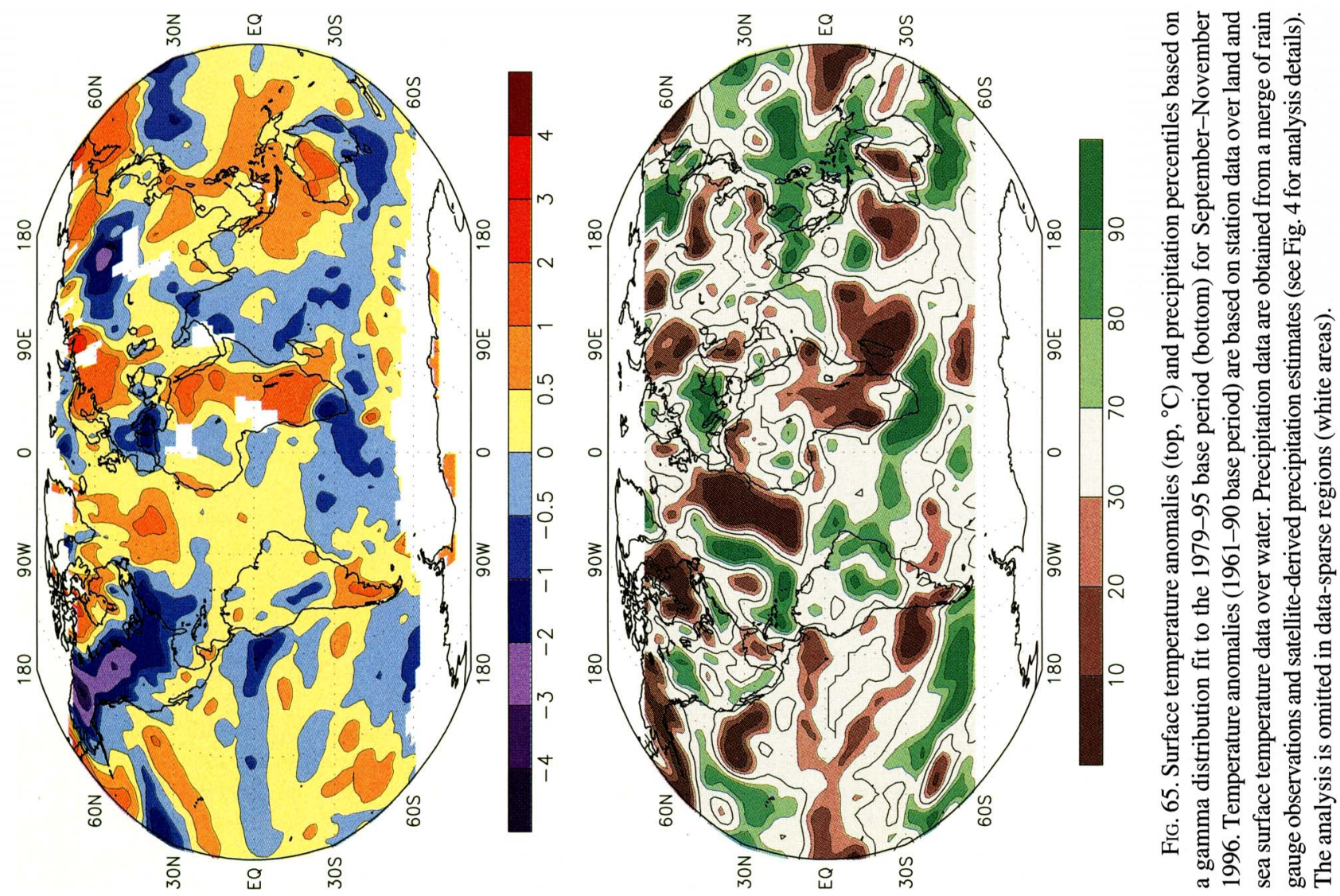


\section{Appendix: Contribuĩors}

Air Resources Laboratory/ERL/NOAA

- J. Angell

Australian Bureau of Meteorology, National Climate Centre, Climate Analysis Section

- W. Wright

Climate Prediction Center/NCEP/NWS/NOAA

- D. Garrett

- M. Gelman

- J. Kopman

- V. Kousky

- C. Long

- D. Miskus

- C. Ropelewski

- W. Thiao

- R. Tinker

Climate Monitoring and Diagnostics Laboratory/ERL/ NOAA

- E. Dlugokencky

- J. Peterson

- P. Tans

Climatic Research Unit, University of East Anglia (UK)

- P. Jones

Department of Geography, Rutgers University

- D. Robinson

Hadley Centre for Climate Prediction and Research (UK)

- B. Horton

- M. O’Donnell

- D. Parker

Indian Meteorological Department

- K. C. Sinha Ray

National Climatic Data Center/NESDIS/NOAA

- W. Brown

- M. Crowe

- R. Heim Jr.

Acknowledgments. This assessment would not have been possible without the cooperation and contributions from various scientists representing a cross section of the NOAA climate community. We also wish to acknowledge the contributions from the scientists outside of NOAA in other federal laboratories, at universities, and at several sites around the world. All of these scientists are in the contributors list (appendix) and we thank them for their timely and useful input. We are especially grateful to those international scientists who contributed their time and effort. In addition, we would like to thank C. Ropelewski, W. Higgins, J. Janowiak, V. Kousky, T. Karl and an anonymous reviewer for their comments that helped to strengthen the article. This assessment is supported by a grant frorr the NOAA Office of Global Program's Climate Change Data and Detection Program.

\section{References}

Australian Bureau of Meteorology, 1997: Annual Climate Summary 1996. 12 pp. [Available from the Climate Analysis Section, National Climate Centre, Melbourne, Australia.]

Bell, C.D., and M. S. Falpet, 1995: Interseasonal and interannual variability: 1986-1993. NOAA Atlas 12. [Available from Climate Prediction Center, 5200 Auíh Rd., Rm. 605, Camp Springs, MD 20746.]

Berlage, H.P., 1957: Fluctuations of the general atmospheric circulation of more than one year, their nature and prognostic value. Mededelingen on Verhandelingen, No. 69, Koninkijk Nedceriands Metcorologisch Instituut, $152 \mathrm{pp}$.

Bjerknes, I., 1969: Atmospheric teleconnections from the equatorial Pacific. Mon. Wea. Rev., 97, 163-172.

Diugokencky, E. I., K. A. Masarie, P. M. Lang, P. P. Tans, L. P. Steele, and E. G. Niscet, 1994: A dramatic decrease in the growth rate of atmospherio methane in the Northern Hemisphere during 1992. Ceophys. Res. Lett., 21, 45-48.

Gray, W. M., C. W. Landsea, P. W. Mielke Jr., and K. J. Berry, 1992: Predicting Allantic seasonal hurricane activity 6-11 month in advance. Wea, Forecasting, 7, 440-455.

Halpert, M. S., G. D. Bell, V. E. Kousky, and C. F. Ropelewski, 1996: Climate assessment for 1995. Bull. Amer. Meteor. Soc., $77(5), 51-544$.

Higgins, R. W., and K. C. Mo, 1997: Persistent North Pacific circulation anomalies and the tropical intraseasonal oscillation. $J$. Climate, 10, 223-244.

Holton, J. R., 1979: An introduction to Dynamic Meteorology. Second ed, Academic Press, 319 pp.

Hoskins, B. Jo, I. Draghici, and H. C. Davies, 1978: A new look at the w-equation. Owart. J. Roy. Meteor. Soc., 104, 31-38.

Hsu, H.-H., 1996: Global view of the intraseasonal oscillation during northern winter. I. Climate, 9, 2386-2406.

Hurrell, J. W., 1995: Decadal trends in the North Atlantic oscillation: Regional temperature and precipitation. Science, 269, 676697.

Hurrell, J. W., and K. E. Trenberth, 1997: Spurious trends in satellite temperatures from merging different satellite records. $\mathrm{Na}$ ture, 386, 164-167.

IPCC, 1995: Climate Change 1995, The Science of Climate Change, J. T. Houghton, L, G. Meira Filho, B. A. Callander, N. Harris, A. Kartenberg and K. Maskell, Eds., Cambridge University Press, 572 p.

Janowiak. J. E., and P. A. Arkin, 1991: Rainfall variations in the tropics during 1986-1989, as estimated from observations of cloud-top temperatures. J. Geophys. Res., 96, 3359-3373.

Ji, M., A. Leetmaa, and J. Derber, 1995: An ocean analysis system for seasonal to interannual climate studies. Mon. Wea. Rev., 123, 460-481. 
Kalnay, E., and Coauthors, 1996: The NCEP/NCAR 40-year Reanalysis Project. Bull. Amer. Meteor. Soc., 77, 437-471.

Keeling, C. D., R. B. Bacastow, and T. P. Whorf, 1982: Measurements of the concentration of carbon dioxide at Mauna Loa Observatory, Hawaii. Carbon Dioxide Review: 1982, W. C. Clark, Ed., Oxford University Press, 377-385.

Keyser, D., and M. A. Shapiro, 1986: A review of the structure and dynamics of upper-level frontal zones. Mon. Wea. Rev., 114, 452-499.

Knutson, T. R., and K. M. Weickmann, 1987: 30-60 day atmospheric oscillations: Composite life cycles of convection and circulation anomalies. Mon. Wea. Rev., 115, 1407-1436.

Lau, K.-M., and P. H. Chan, 1985: Aspects of the 40-50 day oscillation during the northern winter as inferred from outgoing longwave radiation. Mon. Wea. Rev., 113, 1889-1909.

Livezey, R. E., M. Masutani, A. Leetmaa, H. Rui, M. Ji, and A. Kumar, 1997: Teleconnective response of the Pacific-North American region atmosphere to large central equatorial Pacific SST anomalies. J. Climate, in press.

Madden, R. A., and P. R. Julian, 1971: Detection of a 40-50-day oscillation in the zonal wind in the tropical Pacific. J. Atmos. Sci., 28, 702-708.

$\longrightarrow$, and - 1972: Description of global-scale circulation cells in the tropics with a 40-50 day period. J. Atmos. Sci., 29, 11091123.

$\longrightarrow$, and - 1994: Observations of the 40-50 day tropical oscillation: A review. Mon. Wea. Rev., 122, 814-837.

Mo, K. C., and V. E. Kousky, 1993: Further analysis of the relationship between circulation anomaly patterns and tropical convection. J. Geophys. Res., 98, 5103-5113.

Palmén, E., and C. W. Newton, 1969: Atmospheric Circulation Systems. Academic Press, 603 pp.

Rasmusson, E. M., and T. H. Carpenter, 1982: Variations in tropical sea surface temperature and surface wind fields associated with the Southern Oscillation/El Niño. Mon. Wea. Rev., 110, 354-384.

— ciated with the El Niño/Southern Oscillation. Coupled OceanAtmosphere Models, J. C. Nihoul, Ed., Elsevier, 289-302.

Reynolds, R. W., and T. Smith, 1995: A high-resolution global sea surface temperature climatology. J. Climate, 8, 1571-1583.

Rogers, J. C., and H. van Loon, 1979: The seesaw in winter temperatures between Greenland and northern Europe. Part II: Some oceanic and atmospheric effects in middle and high latitudes. Mon. Wea. Rev., 107, 509-519.

Ropelewski, C. F., and M. S. Halpert, 1987: Global and regional scale precipitation patterns associated with the El Niño/Southern Oscillation. Mon. Wea. Rev., 115, 1606-1626.

$\longrightarrow$, and _ 1989: Precipitation patterns associated with the high index phase of the Southern Oscillation. J. Climate, 2, 268284.

Simpson, R. H., 1974: The hurricane disaster potential scale. Weatherwise, 27, 169-186.

Spencer, R. W., J. R. Christy, and N. C. Grody, 1990: Global atmospheric temperature monitoring with satellite microwave measurements: Method and results 1979-84. J. Climate, 3, 1111-1128.

Stolarski, R., R. Bojkov, L. Bishop, C. Zerefos, J. Staehelin, and J. Zawodny, 1992: Measured trends in stratospheric ozone, Science, 256, 205-208.

Thoning, K. W., P. P. Tans, and W. D. Komhyr, 1989: Atmospheric carbon dioxide at Mauna Loa Observatory 2. Analysis of the NOAA/GMCC data, 1979-85. J. Geophys. Res., 94, 85498565.

van Loon, H., and J. C. Rogers, 1978: The seesaw in winter temperatures between Greenland and northern Europe. Part I: General description. Mon. Wea. Rev., 106, 296-310.

Walker, G. T., and E. W. Bliss, 1932: World weather V. Mem. Roy. Meteor. Soc., 4, 53-84.

Wallace, J. M., and D. S. Gutzler, 1981: Teleconnections in the geopotential height field during the Northern Hemisphere winter. Mon. Wea. Rev., 109, 785-812.

Weickmann, K. M., 1983: Intraseasonal circulation and outgoing longwave radiation modes during the Northern Hemisphere winter. Mon. Wea. Rev., 111, 1838-1858.

WMO/UNEP, 1994: Scientific assessment of ozone depletion: 1994. WMO, Rep. No. 37. [Available from the World Meteorological Organization, Case Postale No. 2300, 1211 Geneva, Switzerland.]

Xie, P., and P. A. Arkin, 1996: Analyses of global monthly precipitation using gauge observations, satellite summaries, and numerical model predictions. J. Climate, 9, 840-858.

$\longrightarrow$, and — 1997: Global monthly precipitation estimates from satellite-observed outgoing longwave radiaiton. J. Climate, in press.

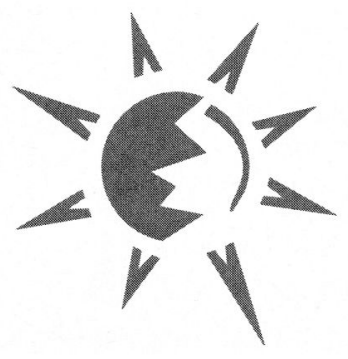




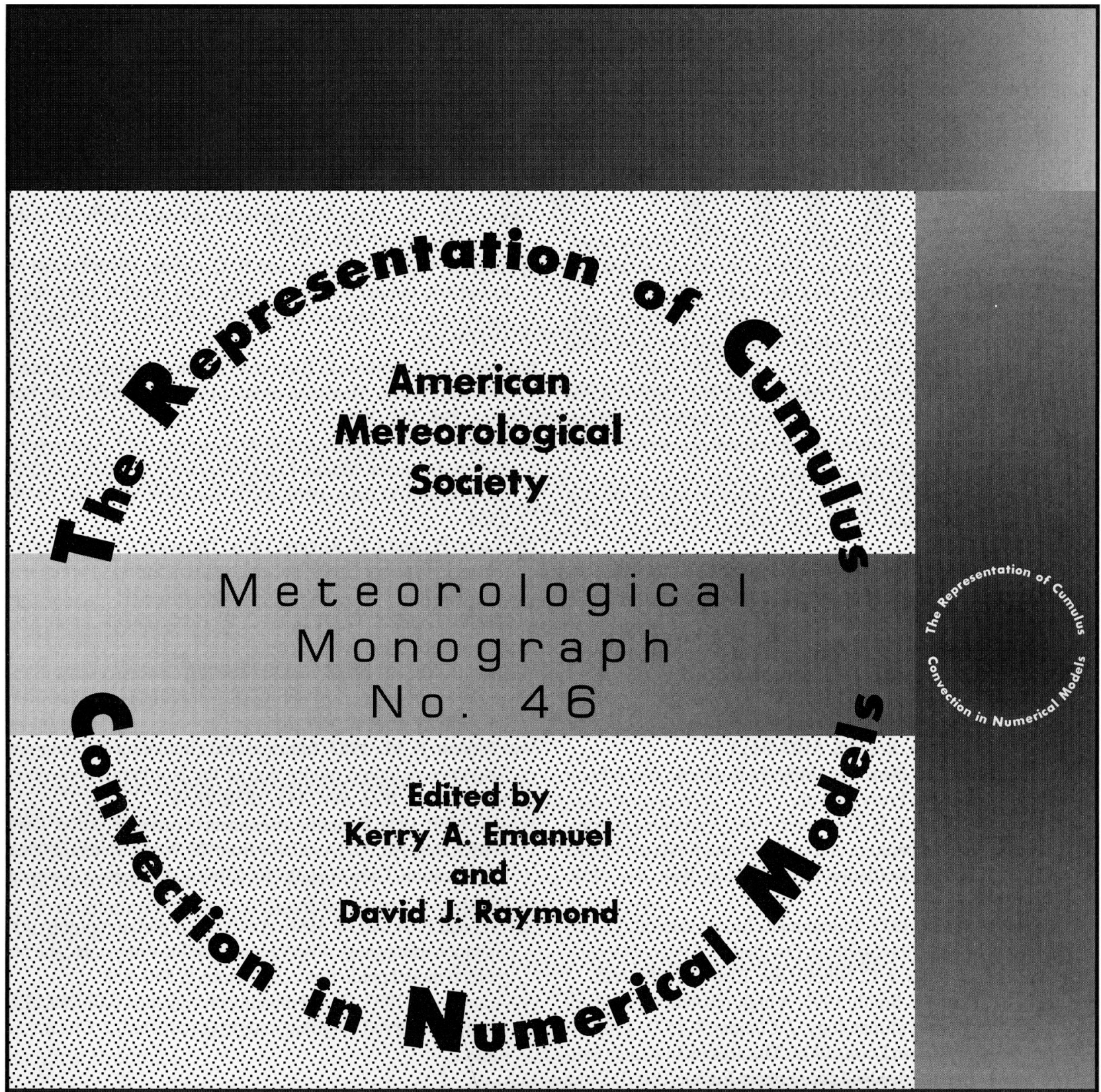

Cumulus convection is perhaps the most complex and perplexing subgrid-scale process that must be represented in numerical models of the atmosphere. It has been recognized that the water vapor content of large parts of the atmosphere is strongly controlled by cloud microphysical processes, yet scant attention has been paid to this problem in formulating most existing convection schemes. This monograph is the fruit of the labors of many of the leading specialists in convection and convective parameterization to discuss this and other issues. Its topics include: an overview of the problem; a review of "classical" convection schemes in widespread use; the special problems associated with the representation of convection in mesoscale and climate models; the parameterization of slantwise convection; and some recent efforts to use explicit numerical simulations of ensembles of convective clouds to test cumulus representations.

1994 American Meteorological Society. Hardbound, B\&W, 246 pp. \$65 list \$45 members (includes shipping and handling). Please send prepaid orders to: Order Department, American Meteorological Society, 45 Beacon St., Boston, MA 02108-3693. 